\title{
Identification of School Physical Activity Leader Competencies Using Concept Mapping
}

Kiel M. Illg

West Virginia University

Follow this and additional works at: https://researchrepository.wvu.edu/etd

\section{Recommended Citation}

Illg, Kiel M., "Identification of School Physical Activity Leader Competencies Using Concept Mapping" (2014). Graduate Theses, Dissertations, and Problem Reports. 267.

https://researchrepository.wvu.edu/etd/267

This Dissertation is protected by copyright and/or related rights. It has been brought to you by the The Research Repository @ WVU with permission from the rights-holder(s). You are free to use this Dissertation in any way that is permitted by the copyright and related rights legislation that applies to your use. For other uses you must obtain permission from the rights-holder(s) directly, unless additional rights are indicated by a Creative Commons license in the record and/ or on the work itself. This Dissertation has been accepted for inclusion in WVU Graduate Theses, Dissertations, and Problem Reports collection by an authorized administrator of The Research Repository @ WVU.

For more information, please contact researchrepository@mail.wvu.edu. 
Identification of School Physical Activity Leader Competencies Using Concept Mapping

\author{
Kiel M. Illg \\ Dissertation submitted to the \\ College of Physical Activity and Sport Sciences \\ at West Virginia University \\ in partial fulfillment of the requirements \\ for the degree of \\ Doctor of Philosophy \\ in \\ Kinesiology \\ Major in Physical Education Teacher Education \\ Sean Bulger, Ed.D., Chair \\ Paul Chapman, Ph.D. \\ Emily Jones, Ph.D. \\ Robert Wiegand, Ph.D. \\ Richard Walls, Ph.D. \\ Department of Coaching and Teaching Studies \\ Morgantown, WV \\ 2014
}

Keywords: comprehensive school physical activity programs, educational leadership, professional preparation, concept mapping 


\section{ABSTRACT \\ Identification of School Physical Activity Leader Competencies Using Concept Mapping}

Kiel M. Illg

Background/Purpose: Various public health and educational organizations have called for the implementation of comprehensive approaches at the state, district, and school levels to promote physical education and physical activity among children and adolescents. Proponents have argued that physical education teachers are positioned to assume the role of director of physical activity in the school setting; however many physical educators do not see directing comprehensive school physical activity programs (CSPAP) as their responsibility, nor have they been formally trained to provide this measure of leadership. Furthermore, there is limited research on CSPAPs and the associated leadership roles integral to planning, implementing, managing, and evaluating change in this area. The purpose of this exploratory study was to identify the knowledge, skills, and behavioral competencies that a school leader would need to develop in order to implement and sustain a CSPAP.

Method: Researchers used an integrated approach to concept mapping that involved brainstorming, statement analysis and synthesis, sorting and rating of ideas, multidimensional scaling and cluster analysis, and development and interpretation of multiple graphic organizers. These steps were delivered in sequential phases using a web-based communication platform: anonymous brainstorming $(n=51)$, sorting and rating of ideas by key stakeholders $(n=18)$, and interpretation of maps through semi-structured interviews $(n=3)$. The participants across all phases included K-12 physical educators, school administrators, and higher education researchers identified through systematic review of the literature and snowball sampling.

Analysis/Results: Data aggregation and analysis were completed using multi-dimensional scaling and cluster analysis to determine relationships among brainstormed statements. A variety of maps were developed to graphically display these relationships. Five primary clusters of ideas were identified: (1) Teambuilding and Facilitating, (2) Capacity Building, (3) Knowledge of Instructional Practices, (4) Content Knowledge, and (5) Program Development and Management. Data from the semi-structured interviews were analyzed inductively and used to verify results, determine final cluster names, and identify possible implications for teacher preparation.

Conclusions: The findings support the need for the development of transformational leaders in schools who are capable of empowering others through modification of the work environment, facilitating intrinsic motivation among colleagues, and supplying necessary resources. Teacher education and educational leadership programs have an opportunity to help develop transformational leaders in the area of school physical activity by modifying curricula to provide opportunities for pre-service and in-service teachers to develop the knowledge, skills and behaviors pre-requisite to the implementation and maintenance of CSPAPs within school environments. 


\section{ACKNOWLEDGMENTS}

It is fitting to find in my results that teamwork and facilitating is essential in developing transformational leaders for the future in education. I myself truly understand what it takes to have a team to support you in this process and it is only fitting that I thank my teammates.

I want to begin by acknowledging my committee first. I recently read a quote by Ben Stein expressing, "Personal relationships are the fertile soil from which all advancement, all success, all achievement in real life grows." Without the relationships that I built with the individuals on my committee I would not be in the position where I am today and I am truly thankful for each our relationships.

Dr. Bulger: My dissertation chair, mentor, colleague and friend you truly have taken the time to help mold me into a better scholar, teacher, professional and person. You not only took me under your wing but you also gave me an opportunity to grow; without you none of this was possible, words can't express how grateful I am to you. "Go Bills"

Dr. Jones: My second in command; wow has this been a journey. Thank you for being there to listen in your office, give advice and help mentor me into a better learner, scholar, and professional. I truly am grateful to have you through this journey as a motivator and mentor.

Dr. Wiegand: My reliever from the bullpen, thank you for joining the committee after a fellow colleague retired; I truly appreciate you taking the time to help me in this endeavor. I'll never forget supervision and curriculum in the summer as well as our golf outings. Thank You for being there as a release to get away from course work and to enjoy the greens of West Virginia. You are the man!

Dr. Chapman: While at West Virginia you helped mentor me into the leader I have become.

Since the first day you helped guide me through the educational leadership process and encouraged me to become a better leader each day. I am grateful for you not only in the dissertation process but also in the process of obtaining my administrative certification in a state that I was unfamiliar with. You eased the transition and put me in contact with school leaders in West Virginia that provided a great learning 
experience for me. I am a better man and leader because of it and I truly thank you for all that you have done for me.

Dr. Walls: First, congratulations on your retirement you have been a great leader for West Virginia University and have helped many doctoral students including myself through this process. I am thankful that you remained on my committee to see this through You are a great inspiration to me of a man selfless and who cares for others and for that I am thankful that I had a chance to learn from you.

To all of my fellow doctoral students and colleagues at West Virginia University in PETE, SEP and Ed Psych thank you for all of the memories, long hours in the swamp, intramural championship and motivating each other to finish, I am truly blessed to build relationships with people from all over the world and look forward to growing those relationships in the future.

My final teammates to thank are my family and friends in Buffalo. Jason and Amber thank you for being my brother and sister and helping me through these last four years. Ilio my P.I.C. finally you will be done hearing me say I have to work on my dissertation. Last, Brandy thank you for being there every morning and every night through the past two years; you have encouraged me, loved me, and never given up on me; I am truly a blessed man to have all of you in my life. 


\section{DEDICATION}

This dissertation is dedicated to my family for all of their continued support and guidance through this process; especially to my mother Lynn Illg and father Brian Illg. We did it! 


\section{Table of Contents}

Section Title $\quad$ pg\#

$\begin{array}{lr}\text { Introduction } & 8\end{array}$

$\begin{array}{ll}\text { Purpose Statement } & 13\end{array}$

$\begin{array}{ll}\text { Methods } & 14\end{array}$

Recruitment of Participants-Generating the Ideas $\quad 15$

Phase I: Generating the Ideas 16

Recruitment of Participants-Structuring of Ideas $\quad 17$

Phase II: Structuring of Ideas $\quad 18$

Phase III: Data Analysis and Map Generation 20

$\begin{array}{ll}\text { Phase IV: Interpretation } & 21\end{array}$

Results $\quad 22$

$\begin{array}{ll}\text { Participant Demographics } & 22\end{array}$

Brainstorming 22

$\begin{array}{ll}\text { Structuring } & 22\end{array}$

Brainstorming and Structuring of Statements 23

$\begin{array}{ll}\text { Interpretation } & 25\end{array}$

$\begin{array}{ll}\text { Discussion } & 26\end{array}$

$\begin{array}{ll}\text { References } & 38\end{array}$

Table 1: Brainstorming Demographics $\quad 44$

Table 2: Structuring Demographics 45

Table 3: List of Statements 46

Table 4: Cluster 1 Teambuilding/Facilitation-Statements 48

Table 5: Cluster 2 Capacity Building-Statements 49

Table 6: Cluster 3 Knowledge of Instructional Practices-Statements 50

Table 7: Cluster 4 Content Knowledge-Statements 51

Table 8: Cluster 5 Program Development and Management-Statements 52

Figure 1: Point Map $\quad 53$

Figure 2: Five Cluster Map Solution $\quad 54$

Figure 3: Four Cluster Map Solution $\quad 55$

Figure 4: Six Cluster Map Solution $\quad 56$

Figure 5: Seven Cluster Map Solution $\quad 57$

Figure 6: Pattern-match Display 58

Figure 7: Cluster Rating Map-Importance $\quad 59$

$\begin{array}{ll}\text { Figure 8: Go-Zone Display Map } & 60\end{array}$

Appendix A: Extended Literature Review 61

$\begin{array}{lr}\text { Children's Physical Activity and Health } & 61\end{array}$

Health Benefits of a Physically Active Lifestyle $\quad 61$

National Health Objectives in the United States 63

Professional Guidelines and Recommendations for 
$\begin{array}{ll}\text { Youth Physical Activity } & 65\end{array}$

American Heart Association 65

Centers for Disease Control and Prevention 65

National Association for Sport and Physical Education $\quad 66$

U.S. Dept. of Agriculture and U.S. Dept. of Health and Human Services $\quad 68$

Achieving Recommendations for Youth Physical Activity 69

Roles of Schools from a Public Health Perspective 70

Social Ecological Model: Framework for

Physical Activity Intervention in Schools $\quad 77$

Comprehensive School Physical Activity Programs 82

The Role of Leadership in Comprehensive School Physical Activity

$\begin{array}{lr}\text { Programs } & 88\end{array}$

$\begin{array}{ll}\text { References } & 96\end{array}$

$\begin{array}{ll}\text { Appendix B: Brainstorming Protocol } & 110\end{array}$

Appendix C: Structuring Ideas Protocol 116

$\begin{array}{ll}\text { Appendix D: Interpretation Protocol } & 120\end{array}$

Appendix E: Curriculum Vitae 154 


\section{Identification of School Physical Activity Leader Competencies Using Concept Mapping}

The childhood obesity epidemic in the United States is a national health crisis that some have argued has reached epidemic proportion. Nearly one in every three children ages 2-19 is overweight or obese and therefore pre-disposed to greater risk for developing a variety of co-morbidities such as coronary artery disease, hypertension, high cholesterol, and/or diabetes mellitus (Ogden, Carroll, Curtin, Lamb \& Flegal, 2010; U.S. Department of Health and Human Services 2008). Physical inactivity is an integral factor that has significantly contributed to this problematic increase in childhood obesity within the United States (Wang, Gortmaker, Sobol, \& Kuntz, 2006). Regrettably, physical activity levels among American youth remain low and continue to trend downward as age and year in school increases (U.S. Department of Health and Human Services, 2012). This pattern of behavior is particularly disconcerting when one considers the well documented interaction involving time spent being physically active, consumption of proper nutrition, and limited sedentary time and its possible contribution to the maintenance of overall health and wellness (McKenzie, 2007; National Association for Sport and Physical Education, 2004a, 2004b; U.S. Department of Health and Human Services, 2008). Accordingly, physical activity is one of the most important steps that people of all ages can take to improve their health and quality of life. It is recommended that children and adolescents participate in 60 minutes or more of daily moderate-to-vigorous physical activity (MVPA) that is developmentally appropriate, enjoyable, and inclusive of a variety of activity types including aerobic, muscle-strengthening, and bone-strengthening (Strong et al., 2005; U.S. Department of Health and Human Services, 2008).

While this set of recommendations seems relatively straightforward and achievable, there are many different factors that influence the physical activity levels of children and adolescents including individual (i.e., gender, age, ethnicity, self-efficacy), social (i.e., parental, sibling, peer support), and environmental determinants (i.e., facility and equipment access, opportunities to be active). Given the multi-dimensional and complex nature of physical activity and other health-related behaviors, ecological 
models have frequently been employed as the conceptual basis for related research and behavioral intervention. Sallis et al. (2006) developed a social ecological model that conceptualizes the determinants of physical activity behavior from a public health perspective. This social ecological model incorporates five levels of influence that reflect the processes available for targeting within health promotion interventions including: intrapersonal factors, interpersonal factors, institutional factors, community factors, and public policy. This social ecological perspective directs attention to the broader range of political and environmental factors that shape individual characteristics and interpersonal interactions within a community and organizational setting such as a school (Sallis et al., 2006). Because there are multiple levels of influence on youth physical activity, multilevel interventions or programs, which target these influences from a comprehensive perspective are considered to be more effective in facilitating behavior change than those that focus on a single level (Bergh et al., 2012; Sallis \& Glanz, 2006; Zhang, Solomon, Gao, \& Kosma, 2012).

Comprehensive school physical activity programs (CSPAP) have been promoted as a model for districts and schools to provide expanded physical activity opportunities before, during, and after the regular school day. The National Association for Sport and Physical Education (NASPE) $(2008,2013)$ recommends that a CSPAP include the following components: (a) quality physical education, (b) schoolbased physical activity opportunities, (c) school employee wellness and involvement, and (d) family and community involvement. Quality physical education represents the foundation for a CSPAP; due to its role in helping students to learn the knowledge, skills, and dispositions to become proficient movers and participants in a lifetime of health-enhancing physical activity (NASPE, 2004a). The key strategies for improving the quality of physical education include the implementation of a well-designed, standardsbased curriculum and the provision of appropriate training for teachers and related accountability (U.S. Department of Health and Human Services, 2010a). In a review of the literature, Bulger and Housner (2009) identified a number of additional strategies for improving the quality of school-based physical education and physical activity programs such as increased expectations for pre-service teachers and 
involvement of teacher educators in schools, collaboration with other physical activity providers in the community, integration of "cool" physical activity alternatives that are personally meaningful for students, teacher engagement in professional organizations, and use of innovative instructional technologies to extend programming options.

As a complement to quality physical education, alternative physical activity programs occurring before, during, and after regular school hours (i.e., intramurals, recess, classroom activity breaks, active transport, and interscholastic sport) also have considerable potential to increase overall daily physical activity levels of children and adolescents (Dywer et al., 2007; Young et al., 2007). Along with quality physical education and alternative physical activity opportunities during non-traditional times, staff and faculty involvement can influence health-related behaviors in school settings. Employee wellness programs have been shown to improve school staff health and increase physical activity levels (Eaton, Marx, \& Bowie, 2007). Indirectly, these types of programs also enable school staff and faculty to serve as positive role models for students by demonstrating a healthy lifestyle that includes regular physical activity. The final component of a CSPAP relates to family and community involvement in school physical activity programming. To effectively influence children and increase physical activity, schools must reach out to families and community stakeholders to increase access to developmentally appropriate physical activity opportunities. According to Jago and Baranowski (2004), additional physical activity opportunities can be made available through school partnerships and collaboration with a range of community-based providers of after-school programs (i.e., Boys and Girls Clubs and YMCA's), summer day camps, and active transportation to and from school.

While comprehensive approaches to school physical activity intervention are well-grounded in the social ecological model and there is evidence to support the effectiveness of these approaches (Wang, Castelli, Liu, Bian, \& Tan, 2010), they have not been widely implemented. The American Alliance for Health, Physical Education, Recreation, and Dance (2011) completed a survey to better understand the extent to which schools across the United States have been implementing the components of a CSPAP. 
Key findings from the survey indicate that less than one sixth of the responding schools were providing all components of a CSPAP. One of recommended strategies for increasing the percentage of schools meeting this benchmark was for districts to provide coordination and support by employing a district physical education coordinator, while within individual schools, the principal can set the tone that physical education and physical activity are valued by requesting that teachers incorporate physical activity into their daily routines (American Alliance for Health, Physical Education, Recreation and Dance, 2011). Continued decreases in state and federal assistance may make this type of specialized position cost-prohibitive as schools struggle to prioritize discretionary spending and balance their budgets with cuts to faculty, staff, and programs (National Education Association, 2013).

Faced with these budgetary constraints and numerous competing priorities, schools looking to develop CSPAPs will continue to be reliant on current staff and faculty, many of who are already overburdened with various competing professional responsibilities. Beighle, Castelli, Erwin, and Ernst (2009) recommend that the physical education teacher may be best positioned to facilitate the development of a CSPAP, which requires a diverse set of expectations including forming and leading committees, creating long term goals and objectives, serving as the school liaison, and conducting physical activity events in a range of settings (Beighle et al., 2009). While this recommendation is a logical one given the physical educator's unique set of qualifications related to the instruction of a wide range of movement forms, others have questioned their readiness (and perhaps willingness) to transform school climate from a health-oriented perspective (Bulger \& Housner, 2009; Sallis, McKenzie, Beets, Beighle, Erwin, \& Lee, 2012; Siedentop, 2009).

The future readiness of physical educators and other personnel to provide comprehensive physical activity interventions in schools is likely to be dependent on a number of factors including the revision of "undergraduate and graduate courses of study to reflect contemporary health needs, and prepare teachers to implement evidence-based HOPE [health-optimizing physical education]" (Sallis et al., 2012, p. 132). For example, McKenzie (2007) argued that the preparation of physical educators to address societal 
expectations regarding this new public health role would require the (a) modification of content preparation in teacher education programs to include behavioral theories and strategies, determinants of childhood physical activity, and environmental factors and modifications impacting health-related behavior; (b) increased diversity of field placements to include community-based and family-based physical activity programs; and (c) development of the promotion, advocacy, and politicking skills needed to influence decision-makers at various levels. Many of these recommendations are supported by Bulger and Housner (2007) who employed a modified Delphi method "to determine the critical exercise science competencies and associated instructional methods recommended for inclusion in the physical education teacher education curriculum" (p. 57).

In the interest of facilitating teacher professional development in this area, NASPE initially developed a program to certify physical educators or other school personnel as Directors of Physical Activity (DPA) and to provide the competencies needed to implement a CSPAP effectively (Carson, 2012). Based on ecological systems theory, the DPA certification program was developed as an integral part of AAHPERD's Let's Move in Schools Initiative. The certification process included the following: (1) attendance at a one-day interactive workshop; (2) follow-up participation in 12-months of web-based support containing learning modules, implementation resources, and a certification exam; (3) development of a teacher-generated action plan to implement at least one component of the CSPAP; and (4) submission of artifacts documenting the effectiveness of implementation (Carson, 2012, p. 17). More specifically, the one-day training consisted of a six hour interactive workshop where attendees participated in skill-based training pertaining to the implementation of various physical activity strategies. Second, the web based support provide professional development and online-learning modules through the support web site to train teachers in marketing, planning, developing collaborations, and many other skills not typically taught in physical education teacher education (PETE) programs. Participants completed a certification exam to test their knowledge and comprehension of the related concepts followed by the development of an action plan that identified a target group, a specific CSPAP 
component, and potential artifacts demonstrating successful implementation. As the participants begin implementing and working toward sustainability of their CSPAP, artifacts such as testimonials or pictures were provided to demonstrate completion of tasks (Carson, 2012).

More recently, a physical activity leader program has been established in conjunction with First Lady Michelle Obama's Let's Move Active Schools initiative. The Physical Activity Leader (PAL) program is a collaborative effort designed to develop and support individuals who will champion an effort in their local school/school district to ensure 60 minutes a day of physical activity for all school-aged youth. The 12-18 month PAL learning system is purported to be a dynamic, action-focused initiative resulting in skilled individuals with the capabilities to initiate tailored plans of action in their respective school settings. The PAL learning system begins with a 7-hour face-to-face training session. The PAL learning system is provided free of charge to those who are willing to serve as school champions.

While these initial efforts to develop school personnel to bring about transformational changes regarding physical activity intervention in schools represents an important starting point, there is very little information available regarding their effectiveness and there is a clear need for additional exploratory research related to the leadership of these types of comprehensive approaches. In its report titled Educating the Student Body: Taking Physical Activity and Physical Education to School, the Institute of Medicine (IOM) (2013) highlighted the need to identify exemplary training programs and highlight best practice. Furthermore, the IOM indicated the importance of determining the related competencies that pre-service teachers and in-service teachers must develop through teacher education and continuing professional development programs respectively.

\section{Purpose Statement}

With childhood obesity and overweight remain on the rise in our society it is imperative for schools to play a more central role from a public health perspective, including the promotion of regular physical activity and its associated physical, mental, and social benefits (NASPE, 2008a). Various public 
health and educational agencies have called for the implementation of more comprehensive approaches at the state, district, and school levels to enhance physical education and physical activity in schools (Lee et al., 2007). Advocates of these approaches have argued that physical education teachers are best prepared to assume the role of director of physical activity in the school setting; however many physical educators do not see directing a CSPAP as their responsibility, nor have they been formally trained to provide this measure of leadership (Beighle et al., 2009; Rink, 2012). Furthermore, there is limited research on the CSPAP model and the related leadership roles that are integral to planning, implementing, managing, and assessing meaningful school and community change in this area. The purpose of this exploratory study is to identify the knowledge, skills, and behavioral competencies that a school leader would need to develop in order to implement and sustain a CSPAP.

\section{Methods}

Concept mapping has been described in the literature as an integrative approach that allows groups to collaboratively engage in a problem-solving process by generating ideas on a particular issue, organizing those ideas and making value judgments, and graphically representing the ideas in maps or diagrams that illustrate the decision-making process (Trochim \& Linton, 1986; Trochim, 1989). Concept mapping can be considered a structured method for organizing the ideas of a group or organization, bringing together diverse groups of stakeholders, and helping them rapidly form a common framework that can be used for planning and/or evaluation (Kane \& Trochim, 2007). Concept mapping involves a mixed methods approach that integrates qualitative group processes (brainstorming and pile sorting) with quantitative statistics (multidimensional scaling and cluster analysis) to help a group describe ideas or statements and represent those ideas visually through mapping techniques (Trochim, 1989; Trochim \& Linton, 1986).

This study employed a multi-phase integrated concept mapping process involving brainstorming of ideas, structuring of ideas through expert sorting and rating, data analysis and map generation, and 
interpretation of results by key stakeholders (Kane \& Trochim, 2007). Across those phases, the researcher completed a six step process to facilitate group decision-making: (a) preparation and selection of participants, (b) group brainstorming to generate statements, (c) structuring statements through a sorting and rating process to create clusters, (d) representation of the statements/clusters through map generation, (e) interpretation of the maps, and (f) use of the maps by key stakeholders (Trochim, 1989).

\section{Phase I Generating the Ideas - Recruitment of Participants}

A variety of sample sizes has been employed in concept mapping research. Previous concept mapping studies within the related field of health promotion have used roughly equivalent numbers of participants (e.g., Kelly, Baker, Brownson \& Schootman, 2007, n=42; Lebel et al., 2011, n=45; Ries, Voorhees, Gittelsohn, Roche \& Astone, 2008, $n=50)$. In accordance with these recommendations, the researcher attempted to recruit 50 participants, 25 higher education professionals/researchers and 25 practitioners (school teachers and/or administrators) to complete the first (Generating the Ideas) phase of the study. The researcher used purposive sampling, as well as snowball sampling, to recruit participants with specific knowledge and background regarding the topic. According to Patton (2002), "the underlying principle that is common to all purposeful strategies is to select information-rich-cases from which one can learn a great deal about matters of importance and therefore worthy of in depth study" (p. 230).

The first selection criteria concentrated on compiling a list of researchers who have published peer reviewed articles related to CSPAP. Since CSPAP is a relatively new concept, the five programming requirements of CSPAP were considered as relevant topics including (a) quality physical education, (b) physical activity before and after school, (c) physical activity during school, (d) school employee involvement, and (e) family and community involvement (NASPE, 2008). To be eligible to participate, an individual must have authored or co-authored a peer-reviewed paper regarding a component of CSPAP within the past five years. Within the electronic database SPORTDiscus with Full text, a search using key terms (e.g., "comprehensive school physical activity program" or "quality physical education" or "school 
physical activity programs" or "school employee wellness and involvement" or "family and community involvement") produced a list of higher education professionals/researchers with relevant knowledge and experience related to the issue. After the list of higher education professionals/researchers was compiled a search of publically available contact information was completed to obtain email addresses and telephone numbers. Using the publically available contact information, recruitment e-mails were sent following IRB approval as an invitation to participate in this research study.

A snowball sampling method was used to gain access to other physical education professionals and/or school administrators with expertise in the area of CSPAP. The researchers asked those individuals identified through the literature search to provide the names of physical educators and/or school administrators who are qualified to contribute to the concept mapping process or forward the email onto the practitioner. When provided with contact information, the research team followed-up with each identified prospective participant using the previously described invitation email. In order to retain participants in this study, active tracking was used to recruit participants and to maintain contact. A follow-up email was sent to each participant as a reminder of the closing date for each phase of the study. In total, three emails were sent to prospective participants for Phase I. Fifty-one ( $n=51)$ participants were successfully recruited to participate in the anonymous brainstorming phase by means of the recruitment process described above. See Table 1 for a breakdown of recruitment and participation for Phase I.

\section{Phase I Generating the Ideas - Data Collection}

Brainstorming sessions are used to generate statements, or in this case a list of competencies, in response to the focus statement or prompt. Participants in brainstorming were directed to use the WebBased Input Concept System computer software (Concept Systems, Inc. Ithaca, NY). The primary intent of the brainstorming process was to produce as many ideas or statements as possible in response to the following prompt: "One competency needed for a school leader to implement and sustain a comprehensive school physical activity program is..." The goal of the brainstorming session was to 
develop a set of items that represent the diversity of the individual participants in context to the conceptual focus of the study. In order for the study to produce a diverse group of statements from various stakeholders anonymous brainstorming was used to provide various subgroups an opportunity to express their ideas. Participants during the course of the brainstorming session were able to see previously provided statements in order to make the web based data collection similar to that of an inperson concept mapping collection of data.

In addition to providing ideas during the brainstorming session, participants were asked to provide demographic information. Individuals were e-mailed a cover letter with a link that led to the online data collection tool. Before beginning their brainstorming session, participants were asked to provide information on the following demographic questions: (a) What is your gender (male or female)? (b) What is your job description (Higher Education Professional/Researcher or K-12 Educator/ Administrator)? (c) What is your geographical location (Northeast, Southeast, Midwest, Northwest, Southwest, Mid-Atlantic)? (d) How many years have you been involved in education? (1-5, 6-10, 11-15, 16-20, 20+)? (e) What is the highest level of education you have completed (some high school, high school graduate, some college, trade/technical/vocational training, college graduate, some postgraduate work, post graduate degree)? Once participants finished the demographic questions, they were able to begin the brainstorming. The facilitator prepared for brainstorming by sending an email with an attachment of a cover letter for participants. The cover letter informed the participant of the procedure and instructions as previously stated. Through the course of the brainstorming process, the facilitator monitored the process and answered any questions participants had via an e-mail address which was provided in the cover letter. See Appendix B for all supporting materials.

\section{Phase II Structuring of Ideas - Recruitment of Participants}

At the conclusion of the brainstorming phase participants were provided with a thank you statement and encouraged to complete Phase II of the study. Participants were directed to a hyperlinked 
electronic form to sign up for the next phase in which they were asked the following questions: (a) What is your first name? (b)What is your last name? (c) Are you a researcher or practitioner (Higher Education Professional/Researcher, K-12 Educator/Administrator, or other)? (d) What is your email address? (e) What is your phone number? Participants then received a cover letter with information regarding the procedures of Phase II as well as the hyperlink to the online concept mapping tool. Participants when directed to the online software needed to setup a username and register their individual account. All of the higher education professionals/researchers from the brainstorming phase were contacted to participate in Phase II. A small incentive was used to help recruit participants; a \$10 gift card was mailed to each participant at the end of the structuring of ideas to help improve the rate of participation in Phase II of the study. Overall, a total of twenty-five $(n=25)$ individuals agreed to participate. However, seven of these individuals did not begin any of the three participant steps of this phase even after multiple email reminders and extension of the associated deadline. A total of 18 (12 practitioners and 6 higher education professionals/researchers) individuals successfully completed the sorting and rating tasks (see Table 2).

\section{Phase II Structuring of Ideas - Data Collection}

At the end of the brainstorming session, the facilitator (KI) and other research team member (SB) created a concise and edited set of ideas or statements for the second phase or structuring of ideas. It is essential that the number and clarity of statements be refined or reduced following brainstorming in order to give participants a statement set that is workable. The research team used a form of qualitative content analysis to accomplish this task. According to Patton (2002): "content analysis is used to refer to any qualitative data reduction and sense-making effort that takes a volume of qualitative material (i.e., statements) and attempts to identify core consistencies and meanings" (p. 453). Members of the research committee team (KI \& SB) worked independently to reduce the statement set. Researchers used the following content analysis guidelines when reducing the set: statements were organized into three groups of competencies (knowledge, behavioral, and skills), common statements were combined, irrelevant statements were deleted, statements that had multiple ideas were separated and statements were edited to 
provide greater clarity. Research team members worked independently to complete the content analysis, and then met to compare results and collaborate to produce a final statement list for structuring of ideas.

The participants were provided the final statement list within the concept mapping software under the sorting and rating surveys. Once participants logged into the system, a brief overview was provided with an explanation of the necessary tasks that the participants were asked to complete in this phase. The first task required participants to record their demographic characteristics using the same questions as Phase I. After completion of the demographic questions, the participants were asked to sort the statements based on the following prompt: "Combine statements into groups in a way that makes sense to you." The grouping or sorting of statements or ideas into piles helps identify participant views of the relationships of the statements to one another (Kane \& Trochim, 2007). Each participant was notified that there were four restrictions when grouping the statements: (1) "statements cannot be placed into a single pile," (2) "all the statements cannot be put into their own separate group (although there can be groups of just one statement)," (3) "Each statement can only be placed into one group," and (4) "there should not be a miscellaneous group."

Kane and Trochim (2007) explained that when individual statements are put into only one pile, they do not show interrelationships consequently not providing connections among the ideas generated by the panel of participants. Therefore, participants need to be cognizant of not sorting any statements in individual piles instead trying to correlate statements as closely as they can during this phase. The third task involved rating of each statement based on one variable: importance. Participants were asked to rate each competency as it relates to the development, implementation, management, and/or assessment of a CSPAP. The importance variable was measured using a five-point Likert scales: (5) critical, (4) very important, (3) important, (2) slightly important and (1) not important. The rating step followed the sorting of statements so that participants were not unduly influenced on how they created the groups based upon their ratings of importance (Kane \& Trochim, 2007). See Appendix C for all supporting materials. 


\section{Phase III Data Analysis and Map Generation}

Concept mapping software was used to construct the various maps and to analyze the quantitative statistical data. Specifically, a similarity matrix representing the likeness of participant sorting data was created. The final similarity matrix demonstrated how the participants grouped the statements. Second, a multidimensional scaling analysis was used to produce a two-dimensional solution which positioned each statement on an $\mathrm{x}, \mathrm{y}$ graph. Multidimensional scaling is a multivariate analysis that takes a table of similarities as input and places points on a map so that the original data are accurately represented (Kane $\&$ Trochim, 2007). Statements that are closer to each other on this map are generally sorted together more frequently, whereas distant statements on the map are grouped together less frequently. During this step, the key diagnostic statistic related to reliability is the stress index. The stress value is a diagnostic statistic used in multidimensional scaling that measures the degree which the distances on the map are different from the values of the sorting data provided by the participants (similarity matrix). In a metaanalysis of 38 concept mapping projects an estimated average stress value of .285 was found; approximately $95 \%$ of concept mapping projects are likely to yield stress values that range between about .205 and .365 (Trochim, 1993). According to the analysis of these results, the concept mapping process can be considered reliable and stress values should be reported.

Third, a hierarchical cluster analysis partitions the statements on this map into clusters; these clusters are more general conceptual groupings of the original set of statements. Graphically speaking, the individual statements are grouped on the point map using $\mathrm{x}, \mathrm{y}$ coordinates and the analysis clusters statements that reflect similar concepts into polygonal shapes. The cluster analysis required the researchers to select the final number of clusters that makes the most sense based on their subjective interpretation of the data. The research team $(\mathrm{KI} \& \mathrm{SB})$ analyzed the data and selected the final number of clusters based upon prior knowledge of the concept mapping process, knowledge of the issue, and discretion in examining the different cluster solutions. 
In preparation for the interpretation of the results, a collection of maps was produced as a result of the data analysis. The following maps were generated: point rating maps, cluster rating maps, pattern matching displays, and go zone map displays. The point rating map displays the average rating for each statement across participants. The cluster rating map incorporates the participant rating data and displays the average rating for all statements in each cluster. Pattern matching maps compare the equivalent data from two cluster rating maps. Pattern matching was used to show how two sets of ratings compare with each other. Finally, the go zone map displays are bivariate graphs, like pattern matching, also compare ratings. Although similar, go zone maps analyze the data into a four quadrant map by the mean rating values of each variable (Kane \& Trochim, 2007).

\section{Phase IV: Interpretation}

After the analysis of the quantitative data, the researcher provided an executive summary of the results to the participants who completed the rating and sorting process. The executive summary included an explanation of what the maps represented as well as the results of the statistical analyses. In addition to receiving the summary data, participants $(n=3)$ from Phase II were selected to complete a 30-minute semi-structured telephone interview to verify the clustering of results and discuss approaches for preparing professionals to implement a CSPAP. The interview protocol consisted of the following procedures: (1) recording of date, place, interviewer, and interviewee names; (2) instructions for the interviewer to follow so that standard procedures are used from one interview to another; (3) the interview questions; (4) space between the questions to record responses; and (5) a final thank you to acknowledge the time the interviewee invested.

Research team members used qualitative data inductive content analysis to analyze the semistructured interview data. The lead researcher first organized and prepared the data for analysis with the interviews being audio recorded, and transcribed; researcher handwritten notes were also used to capture participant responses. Second, the researcher read through all of the data gaining a general sense of the 
information and reflecting on its meanings and themes. The interviews were then analyzed using a coding process; the coding process was used to generate a small number of themes or categories which were verified by another member of the research team and used to inform the naming of clusters and interpretation of results. See Appendix D for all supporting materials.

\section{Results}

\section{Participant Demographics}

Phase I Brainstorming. A total of 51 participants participated in the anonymous brainstorming phase of this study (8 participants did not indicate any demographic information). There were 21 males and 22 females (see Table 1). The geographical location of the United States was represented with participants residing in the following areas: 21 participants in the Northeast, 8 from the Southeast, 5 MidAtlantic, 4 from the Midwest, 4 from the Southwest and 1 from the Northwest. With respect to their years of service within their profession 24 participants indicated 20 or more years of service, 6 participants 16-20 years of service, 8 participants $11-15$ years, 1 participant $6-10$ years and 4 participants indicated 1-5 years of service. In terms of education 41 responded as receiving a post graduate degree, 1 participant responded as graduating college and 1 participant indicated some post graduate work completed. Lastly, in terms of job description 19 participants indicated they were a higher education professional or researcher and 23 participants responded as working in K-12 education either as an educator or administrator (1 participant did not respond to job description).

Phase II Structuring. A total of 18 individuals participated and completed the sorting and rating phase of the concept mapping process (see Table 2). There were 13 female and 5 male participants. Among this group, 9 were geographically represented by the Northeast, 3 from the Southwest, 3 from the Midwest, 2 from the Southeast and 1 from the Mid-Atlantic region. In terms of years of service, 13 participants had 20 or more years of service in their profession, 2 indicated 16-20 years of service, 2 other participants indicated 11-15 years and 1 participant indicated having 1-5 years of service. All 18 
participants indicated earning a post graduate degree. Lastly, in terms of job description 9 participants indicated they were a higher education professional or researcher and 12 described as working in K-12 education either as an educator or administrator.

\section{Brainstorming and Structuring of Statements}

The 51 participants who participated in the brainstorming phase of the study provided 83 total statements. Reduction of these statements produced 56 statements in total (see Table 3). These 56 statements were then used by participants for the sorting and rating tasks during the structuring phase. The results of the sorting task are represented in the Tables 4-8 which includes the individual statements arranged by cluster and Figure 2 which graphically displays the selected five cluster map solution; this map can be considered representative of the data provided by participants as its stress value is 0.2189 . The five clusters were (1) "Teambuilding/Facilitating" (sample statements: "Communicating effectively with colleagues and other stakeholders" and "Establishing positive relationships with colleagues and administrators that foster school-wide participation in physical activity promotion and implementation"), (2) "Capacity Building" (sample statements: "Advocating for the physical activity needs of children both at school and in the broader community" and "Raising funds needed to support programming in physical activity promotion"), (3) "Knowledge of Instructional Practices" (sample statements: "Modeling effective physical activity programming for others to emulate" and "Knowing the processes by which students learn and the instructional environments that are most effective"), (4) "Content Knowledge" (sample statements: "Maintaining knowledge of a broad range of traditional and non-traditional physical activity alternatives" (i.e., competitive/cooperative, individual/group, adventure) and "Remaining current with the literature in the field including recommendations for best practice and related resources"), and (5) "Program Development and Management"(sample statements: "Finding physical activity opportunities that can be made available to students, faculty/staff, and community members" and "Organizing, managing, and leading the various components of a program"). 
The five cluster solution was selected by research team members for numerous reasons. At six clusters there were two conceptually related clusters that dealt with the concept of teambuilding skills (these two clusters combined to form Cluster 1 "Teambuilding/Facilitating Skills" in the five cluster solution). At four clusters, two very different clusters collapsed (Clusters 3 "Knowledge of Instructional Practices" and 4 "Content Knowledge" in the five cluster model) to form a wide-range of statements into a category that lacked coherence. See Figures 3, 4, and 5 for graphic representation of the various cluster solutions.

The cluster rating map (see Figure 6) represents the average ratings of statements within each cluster and provides a visual representation with respect to how important participants rated statements within each cluster. Cluster 1 "Teambuilding/Facilitating" was rated as the most important cluster (4.194.28) whereas Cluster 4 "Content Knowledge" was rated at the least important cluster in comparison to the others (3.85-3.94). Individually represented, statements from Cluster 1 "Teambuilding/Facilitating" were among the highest rated statements based upon importance. The go-zone displays provide a visual representation of statement ratings and can be used to identify statements that are considered to be "actionable" as they were rated highly on importance by K-12 practitioners and higher education professionals/researchers (see Figure 7). Statement 1 "Communicating effectively with colleagues and other stakeholders" and statement 22 "Establishing positive relationship with colleagues and administrators that foster school-wide participation in physical activity promotion and implementation" were among the most important items as rated by participants.

Various maps can be used to identify differences in the way the statements were conceptualized between the two groups of participants, practitioners and higher education professionals/researchers. At the cluster level using the pattern-match display (see Figure 8), both groups viewed some of the clusters similarly as well as different regarding importance. Cluster 1 "Teambuilding/Facilitating" was rated by both groups to be the most important Cluster at 4.21 (practitioner) and 4.42 (higher education professional/researcher) respectively. Each group however had a difference of opinion on the ranking of 
the clusters in comparison to importance; the practitioner group rated on average that cluster 5 "Program Development and Management” was second followed by Cluster 3“Knowledge of Instructional Practices," Cluster 4 "Content Knowledge and the last Cluster 2 "Capacity Building." On the other hand higher education professionals/researchers found Cluster 2 "Capacity Building" to be the next important cluster followed by Cluster 5 "Program Development and Management," Cluster 3 "Knowledge of Instructional Practices," and Cluster 4 "Content Knowledge.”

The individual statements can also be compared amongst the two groups, using the go-zone displays (see Figure 8). For importance, group comparison go-zone graphs show that there are a number of statements that both groups rated highly; however, there are differences between both groups as well on importance. For example in terms of importance the practitioners viewed statements 11 and 30 "Understanding how the goals of a program contribute to the overall wellness and education of students from a school-wide perspective" and "Appreciating the benefit and impact that a physical activity program will have on all members of the school community" as more important than average whereas the higher education professionals/researchers did not. Conversely, the higher education professionals/researchers rated the following statements as more important than average whereas the practitioners did not: statement 32 "Understanding the capabilities of the school faculty and staff" and statement 45 "Identifying already available programs and related resources in physical activity promotion." The correlation value between the two groups ratings equaled $\mathrm{r}=0.59$.

\section{Interpretation}

The interpretation of results phase of the study involved recruitment of three individuals from the study who participated in each of the phases; these individuals participated in a semi-structured interview to verify the five cluster solution, cluster names, and go-zone statements that were produced using the concept mapping software. The three individuals represented each participant group in the study including a K-12 physical education teacher, K-12 director of physical education and health and higher 
education professional/researcher. The semi-structured interview consisted of asking each participant if they agreed that the title of the cluster adequately represented the competencies that were sorted together in the group; if participants felt they did not they were prompted for recommendations of a more appropriate title for the cluster.

As a result all three participants verified that Cluster 1 "Teambuilding/Facilitating," Cluster 4 “Content Knowledge” and Cluster 5 "Program Development and Management” were a direct representation of the statements clustered within each group. Cluster 2 originally titled "Funding" was not agreed upon as an appropriate representation of statements by the higher education professional/researcher and K-12 administrator; with recommendations taken from each "Capacity Building" was considered a more appropriate representation of the statements clustered in this group. Finally, Cluster 3 originally entitled "Knowledge of Pedagogy" was not agreed upon by the higher education professional/researcher; following consultation with other research team members (SB \& EJ) "Knowledge of Instructional Practices" was determined to be a more appropriate title.

\section{Discussion}

The primary objective of this study was to employ a concept map design to gain insight from various stakeholders (K-12 practitioners and higher education professionals/researchers) regarding the competencies needed to lead a CSPAP. This study extends the related literature base by identifying specific competencies that a director of physical activity should develop and maintain using a systematic method (Beighle, Erwin, Castelli, \& Ernst, 2009). The resultant recommendations can be used to guide curriculum design and modification in undergraduate/graduate PETE and educational leadership programs.

\section{CSPAP Leadership and Empowerment}

The problem of childhood inactivity is multidimensional with various contributing factors and because there is no single direct cause of sedentary lifestyles, there are no convenient solutions. Despite 
these complexities, with sedentary lifestyles representing a prevalent concern among children and adolescents, the need to develop physical and social environments that support increased physical activity is readily apparent. Toward that end, schools represent the most important setting for promoting physical activity because time spent in school accounts for a majority of the weekday hours that children are awake and susceptible to influence (Pate et al., 2006). Schools can be viewed as an investment in public health, and have been identified as the institution with primary responsibility for promoting physical activity in this segment of the population (Sallis \& McKenzie, 1991; McKenzie, 2007; U.S. Department of Health and Human Services, 2012). While schools do not represent the only mechanism to change the physical activity patterns of youth, they have the potential to play a significant role. For this reason, NASPE recommends use of comprehensive approaches to school-based physical activity programming that contribute to the achievement of the recommended amounts of daily physical activity for children and adolescents (Lee, Burgeson, Fulton, \& Spain, 2007; National Association for Sport and Physical Education, 2008).

If this type of systemic change is going to occur on a large scale in schools, transformational leaders need to be at the forefront creating a shared vision and implementing supportive policies. Researchers have determined that a transformational leader is one who can influence major changes in the attitudes and assumptions of an organization through empowerment, inspiration, and elevation of individuals to higher levels of motivation and morality (Anderson, 2008; Bryant, 2003; Hackman \& Johnson, 2004). This designated leader, through the use of the empowerment process, can work to coordinate efforts to implement a CSPAP within their individual local school or district. The empowerment process emphasizes three major components in which the leader influentially energizes followers to ultimately achieve the stated organizational vision and goals. The first component is modifying the environment, the second is supplying necessary resources for followers to be successful, and the third is helping the followers or workers in building a sense of personal power (Conger, 1989; Conger \& Kanungo, 1988). Researchers have found that through the empowerment process, shared 
power can help elevate the organization, increase job satisfaction of followers, and create a sense of shared decision making (Bass \& Avolio, 1993; Conger, 1989; Hackman \& Johnson, 2004, Ostroff, 1992).

The empowerment model is one educational leadership model recommended to develop transformational leaders as well as provide a framework for organizational change. As described earlier the components of the empowerment process include modifying the environment, building intrinsic motivation, and supplying resources. The clusters and competencies identified in this study serve as an example of how a school leader can engage in the empowerment process to implement and sustain a CSPAP. Modifying the environment consists of important elements such as elimination of situational factors that produce a sense of powerlessness, organizational structure, workflow and physical layout; within the empowerment model the environment is redesigned to shift decision making authority to followers as well. Specific to Cluster 5 "Program Development and Management" school leaders can use the statements found within this cluster to modify the environment to effectively shift the decision making authority to others. As mentioned in the verification of results by an interviewee, the leader of a CSPAP needs to be very cognizant that during the course of program development and management "It is going to take a small team of people who are able to get the rest of the participants at least on board and part of the process, and engaged in activities and part of the actual outcomes; because otherwise it will remain fully dependent on the individual and that certainly above all will not create sustainability and culture change." Therefore the CSPAP leader needs to believe it is his or her responsibility to direct program efforts and recruit others who buy into this principle. As the leader continues to organize, manage and lead the various components of the CSPAP the organizational structure will be created and in return help eliminate any confusion of individual roles and responsibilities within the program. Additionally, it is essential that the program meet the needs of the particular individual school and district. Statement 33 "Designing effective exercise and physical activity programs across varying developmental levels" and statement 35 "Modifying program features based on the characteristics of the students it is designed to impact," are important factors pertaining to the determination of the best program structure. While rated 
as a less important item in this study, statement 27 "Evaluating program outcomes" is also critical. In order to know if we truly are successful in program development and management, we need to evaluate the various components of the program and continue to modify to best meet the needs of all key stakeholders including children and their families.

Second, building intrinsic motivation involves energizing colleagues and stakeholders to carry out tasks associated with their work roles. Intrinsic motivation is a product of four factors including meaning, choice, competence, and impact. Cluster 1 "Teambuilding and Facilitating” includes many competencies that enable school leaders to build intrinsic motivation among their staff, faculty, colleagues and community stakeholders in order to encourage others to get involved, build relationships, and communicate effectively. Leaders can foster meaning by involving those who share the same core values. In this cluster, statement 20 "Leading and motivating a functional School Wellness Committee that can make collective decisions related to health promotion in the school" is one example of how a school leader can find other individuals that share the same values. Creating choice, or in this case selfdetermination, plays an important role in building intrinsic motivation. According to Hackman and Johnson (2013) "Those who have choice about how to carry out their jobs feel a greater sense of responsibility and are more flexible, creative and resilient." Engaging others in shared decision making as a way to increase involvement is important in building intrinsic motivation. Furthermore, competence is based on the individual's assessment that he or she can do the job required. Structuring tasks so that team members experience initial success is important, statements 32 "Understanding the capabilities of the school faculty and staff" and 21 "Delegating program responsibilities to others, such as classroom teachers" are competencies that the CSPAP leader needs to develop in order to build proficiency among other team members. If one truly doesn't understand the capabilities of their faculty or staff then they won't be able to put them in a situation where they can be successful. Finally, leaving an impact is crucial for building motivation so that the individual believes that he or she can actually influence the 
organizational environment. Leaders can facilitate this by including team members in strategic planning and encouraging new ideas.

Third, empowerment increases the demand for resources in order to sustain programming. Hackman and Johnson (2013) suggest that no stakeholder (or follower), no matter how motivated, can complete a task if she or he does not have adequate funds, supplies, time to devote to the job, and place to work. Cluster 2 "Capacity Building" includes the necessary skills, behaviors, and knowledge CSPAP leaders need in this area. School leaders can apply these competencies (i.e., raise funds needed to support programming, advocate for their programming, and provide education to school faculty/staff, students, parents and community members) to meet the resource demands associated with the administration of a CSPAP. In this case the school leader also supplies necessary resources when they publicly endorse the work of others by encouraging widespread "buy in" to the initiative.

As transformational leaders bring about systematic change in schools through actualization of the empowerment process, the resultant impact on academic performance is likely to remain the outcome of greatest interest for most school administrators, teachers, parents and community members. In 2010 the CDC completed a review of 50 studies that investigated the association between school-based physical activity and measures of academic performance, including indicators of cognitive skills and attitudes, academic behaviors (e.g., concentration, attentiveness, and time on task), and academic achievement (e.g., grade point average and test scores). Of the 251 associations found between school-based physical activity and academic performance, $50.5 \%$ were positive, $48 \%$ were not significant, and only $1.5 \%$ were negative (U.S. Department of Health and Human Services, 2010b). With evidence suggesting that physical activity has a positive influence on academic performance, school administrators need to develop the knowledge and skills to oversee effective school-based physical activity programs. Cluster 3 "Knowledge of Instructional Practices" includes knowledge competencies directly related to the understanding of the components of a CSPAP and their potential impacts on a school-wide community. Go zone statement 2 " Identifying the components of a CSPAP and how each contribute to maximizing 
physical activity opportunities for school age children," statement 34 "Knowing guidelines for developmentally appropriate practice in physical activity programming" and, statement 11 (not a go zone statement) "Understanding how the goals of a program contribute to the overall wellness and education of students from a school wide perspective" are concrete examples of the foundational pedagogical content knowledge that CSPAP leaders need to possess. Cluster 4 "Content Knowledge" including go zone statements 9 "Remaining current with the literature in the field including recommendations for best practice and related resources" and statement 26 "Maintaining extensive background knowledge in physical education including an awareness of contemporary research in the field" are competencies in which school leaders need to maintain awareness of evidence-based practices that have been found to be effective.

\section{Implications for PETE Programs}

A leading issue in PETE programs is that current national standards for beginning teachers do not include specific reference to skills, knowledge, and characteristics needed for successful implementation of programs such as a CSPAP; therefore many undergraduate programs do not include these skills within the curriculum (NASPE, 2008b). In many undergraduate programs, teacher development focuses on content knowledge, pedagogical knowledge, and pedagogical content knowledge. The go-zone statements from cluster 3 "Knowledge of Instructional Practices" include statements 2 "Identifying the components of a CSPAP and how each contributes to maximizing physical activity opportunities for school-aged children, 16 "Modeling effective physical activity programming for others to emulate," 34 “Knowing guidelines for developmentally appropriate practice in physical activity programming," and 37 "Understanding effective pedagogy and selecting instructional approaches to lead various physical activities." Cluster 4 "Content Knowledge" statements 9 "Remaining current with the literature in the field including recommendations for best practice and related resources," and 26 "Maintaining extensive background knowledge in physical education including an awareness of contemporary research in the 
field" can be used to provide a logical set of competencies undergraduates should learn to better prepare them to understand the components of a CSPAP.

As undergraduate students are introduced to the components and foundational knowledge associated with a CSPAP, an ideal time to apply their learned knowledge is through a student teaching internship or culminating capstone requirement. Arizona State University offers an example of how this might be accomplished: "In the initial certification PETE program at Arizona State University (ASU), faculty (with significant input from PETE doctoral students) are piloting new experiences for majors aimed at developing some basic skills as well as their understanding and acceptance of this more expansive role of physical education. For example pre service teaching interns are assigned to a single high school in groups of three or four. In addition to a weekly on-campus seminar, the interns conduct two sessions per week at a high school during which they practice the very skills that help to increase physical activity opportunities for all students during before-school and/or lunchtime periods by preparing the activity venues, providing equipment, periodically participating with students, and monitoring the various activity areas" (Metzler, McKenzie, Van Der Mars, Barrett-Williams, \& Ellis, 2013 p. 84). This represents an effective model for other undergraduate PETE programs to replicate and reinforces that student teaching represents an ideal time to apply foundational knowledge of CSPAP implementation. It seems reasonable to expect that PETE programs can provide an enhanced capstone experience by introducing pre-service teachers to the expanded role of the physical education teacher outside of their classroom responsibilities by requiring implementation of another component of a CSPAP in addition to quality physical education.

At the graduate level PETE programs can provide continuing education for in-service teachers to be better prepared as school leaders to implement a CSPAP. Cluster 2 "Capacity Building" focuses on the numerous competencies that in-service professionals can use to communicate the benefits that physical activity and quality physical education brings to the school community. Go-zone statement 3 "Advocating for the physical activity needs of children both at school and in the broader community," and 
statement 5 "Educating school faculty/staff, students, parents and community to understand the importance and health benefits of physical education, structured and unstructured play" relate to inservice professional's politicking skills that help to create a school environment that values physical activity.

Cluster \#5 "Program Development and Management" provides in-service teachers with competencies that build on prior knowledge of program development that is taught at the undergraduate level with respect to lesson and unit planning. Within this cluster the focus is transferred from a classroom setting to a school-wide approach. Go-zone statements 12 "Finding physical activity opportunities that can be made available to students, faculty/staff, and community members," 33 "Designing effective exercise and physical activity programs across varying developmental levels," and 35 "Modifying program features based on the characteristics of the students it is designed to impact" are concrete examples of competencies that in-service professionals can develop to increase the effectiveness of their programs. Graduate PETE programs can enhance the curriculum to better prepare future school leaders to implement a CSPAP by providing training with respect to program development at a school wide level.

Cluster 1 "Teambuilding/Facilitating" was the highest rated cluster by practitioners and higher education professionals/researchers based on the cluster rating map (see Figure 6). According to previous research by Olsen \& Chrispeels (2009) an essential aspect of changing the culture of the school is administrator support. Cluster 1 provides competencies that PETE programs can concentrate on developing within in-service professionals. The go-zone statements within this cluster help in-service teachers work on numerous leadership skills including communication and building relationships. Statement 22 "Establishing positive relationship with colleagues and administrators that foster schoolwide participation in physical activity promotion and implementation" is a validation by practitioners and higher education professioanls/researchers that administrative support is a key for success. Other actionable items in this cluster include: Statement 1 "Communicating effectively with colleagues and 
other stakeholders," statement 18 "Establishing relationships with individuals and organizations from the broader community," statement 47 "Leading school faculty/staff and students" and statement 50 "Providing access to opportunities for physical activity and encouraging others to participate." As discussed by Carson (2012), a supportive school administrator is fundamental to the successful implementation of a CSPAP, along with a school wellness committee led by a physical activity champion. Therefore teambuilding and facilitating skills are essential for the overall success of any champion who is leading the initiative to improve physical activity with their school community. Teacher education graduate programs can assign in-service teachers to work with their school wellness committee for example.

Castelli and Beighle (2007) stated that the most logical person with expertise and equipment access to serve as a physical activity champion or leader is the physical educator. Physical educators, however, often require further CSPAP training, which is not currently offered in many PETE programs (Beighle, Erwin, Castelli, \& Ernst, 2009). Therefore, PETE programs need to become an agent of change and better prepare future leaders with competencies that are included above. As a way to begin to provide foundational experiences in regards to leadership, graduate programs in PETE need to provide in-service teachers with an opportunity to be exposed to leadership style classes that are most commonly offered in educational leadership programs. Introducing in-service physical educators to foundational methods in leadership can help motivate as well as provide opportunities to gain insight on various educational leadership methods.

Finally, to be effective, professional development for in-service teachers must be provided in a variety of ways, preferably on a school site, and must be predominately teacher-initiated (Armour \& Yelling, 2007). PETE programs at the graduate level need to create multiple opportunities stranded throughout the program for these professionals to practice the selected competencies. While there are many various ways to evaluate these competencies, graduate programs need to provide opportunities for in-service teachers to practice these skills on a school site; ideally within the teacher's own district or 
school. An example could be for cluster 2 "Capacity Building” with the help of PETE faculty, school administrators and fellow teacher colleagues the in-service teacher can present to the district board of education the positive influences of physical activity within the in-services districts, what is currently being done and strategies to improve. An activity like this can help empower the teacher to continue to work to increase physical activity opportunities within their district and actively reinforce the competencies within the capacity building cluster.

\section{Implications for Educational Leadership Programs}

As stated by Hackman and Johnson (2004) sharing power fosters greater cooperation among group members and sharing power with followers can help them tackle new challenges, learn new skills, and find greater fulfillment. The clusters and competencies produced in this concept map study can help provide competencies that school leaders need to develop before obtaining a career in educational leadership in order to effectively implement and sustain new programming. Previous evidence suggests that school administrators lack familiarity with what quality physical education programming might look like (Lounsbery, Mckenzie, Trost, \& Smith, 2011); with the available evidence supporting physical activity and increased academic performance (Trudeau \& Shepard, 2008) it would behoove future school leaders to develop some of these competencies in order to be better prepared to lead school communities in this area.

Educational leadership programs can first provide a single course designed to develop transformational leadership in which the empowerment model is one of the frameworks used to teach the related knowledge, skills and behaviors. Within this course the performance indicators used for participants can be related to many of the go zone statements represented in this study as actionable items that are critical for a school leader to be able to implement and sustain programming, in this case a CSPAP. Second, to at least increase the content knowledge of teacher educators pursuing administrative certifications bringing in guess speakers that have knowledge of the benefits of physical activity and how 
to implement into a school setting can better prepare leaders to have prior knowledge of the programming and how it can positively affect the school environment within a building and community. Finally, educational leadership programs can provide field experiences in which leaders have the opportunity to work with school wellness committees under the guidance of their university supervisor. It is imperative that educational leadership programs collaborate with other graduate programs, such as PETE, in order to expose future leaders to areas outside of their own content; providing other possible avenues and programming that can positively impact the school environment and increase student achievement. The empowerment framework and the go zone statements can be used as a roadmap that pre-service leaders can use to help improve or begin a comprehensive school physical activity program within their school or district.

\section{Limitations of the Present Study}

There are a few limitations to the current study. The first involves the individual lens through which participants considered the prompts during brainstorming, structuring of ideas, and rating. The brainstorming prompt asked participants to name "one competency needed for a school leader to implement and sustain a comprehensive school physical activity program is..." It is probable that many participants were working under the basic assumption that a physical education teacher is best qualified to lead a CSPAP. A number of specific responses including statement 7 "Knowing the psychology of exercise adherence and the related importance of skill development" and statement 6 "Explaining exercise physiology principles and concepts (i.e., Components of Fitness, Basic Training Principles, FITT Guidelines)" are technical competencies important to the teaching of physical education, but some might argue, have limited influence on a school leader's readiness to lead a CSPAP. Similarly, if participants were assuming that the physical education teacher is the logical choice for school leader of a CSPAP, it is likely to have influenced their rating and sorting decisions. As with any shared decision making process, another group of participants could arrive at a very different conclusion when presented with the same series of prompts. 


\section{Conclusions and Future Directions}

As schools continue to adopt more comprehensive approaches to physical activity promotion; future leaders need to be equipped with adequate knowledge and the necessary tools to implement and sustain programming. As research has suggested the empowerment model provides a conceptual framework that enables a school leader to transfer power to his/her followers and develop other leaders within a school building or district. Teacher education and educational leadership programs have an opportunity to develop future transformational leaders in physical activity intervention by modifying curricula to provide opportunities for pre-service and in-service teachers to learn and apply the prerequisite knowledge, skills, and behaviors through use of the empowerment framework. Future research is needed to assess how PETE programs and/or educational leadership programs are incorporating these competencies to better prepare school leaders. 


\section{References}

A Position Statement from the National Association for Sport and Physical Education: Comprehensive School Physical Activity Program. (2008). Strategies: A Journal for Physical and Sport Educators, 21(6), 29-33.

American Alliance for Health, Physical Education, Recreation and Dance. (2011). 2011 Comprehensive school physical activity program(CSPAP) survey report. Reston, VA: American Alliance for Health, Physical Education, Recreation and Dance.

Anderson , K. D. (2008). Transformational Teacher Leadership in Rural Schools. Rural Educator, 29(3), $8-17$.

Armour, K., \& Yelling, M. (2007). Effective Professional Development for Physical Education Teachers: The Role of Informal, Collaborative Learning. Journal of Teaching in Physical education, 26(2), $177-200$.

Bass, B. M., \& Avolio, B. J. (1993). Transformational Leadership and Organizational Culture. Public Administration Quarterly, 17(1), 112-121. Retrieved June 26, 2013, from http://www.jstor.org/stable/40862298 .

Beighle, A., Castelli, D., Erwin, H., \& Ernst, M. (2009). Preparing Physical Educators for the Role of Physical Activity Director. The Journal of Physical Education, Recreation \& Dance, 80(4), 2429.

Bergh, I. H., Bjelland, M., Grydeland, M., Lien, N., Andersen, L. F., Klepp, K.-I., . . Ommundsen, Y. (2012). Mid-way and post-intervention effects on potential determinants of physical activity and sedentary behavior, results of the HEIA study- a multi-component school-based randomized trial. International Journal Of Behavioral Nutrition and Physical Activity, 9(63), 1-13.

Bryant, S. E. (2003). The Role of Transformational and Transactional Leadership in Creating, Sharing and Exploiting Organizational Knowledge. The Journal of Leadership and Organizational Studies, 9(4), 32-44. 
Bulger, S. M., \& Housner, L. D. (2007). Modified Delphi Investigation of Exercise Science in Physical Education Teacher Education. Journal Of Teaching In Physical Education, 26(1), 57-80.

Bulger, S.M., \& Housner, L.D. (2009). Relocating from easy street: strategies for moving physical education forward. Quest, 61, 442-469.

Carson, R. (2012). Certification and Duties of a Director of Physical Activity. The Journal of Physical Education, Recreation \& Dance, 16-29.

Castelli, D. M., \& Beighle, A. (2007). The Physical Education Teacher as School Activity Director. The Journal of Physical Education, Recreation \& Dance, 78(5), 25-28.

Conger, J. (1989). Leadership: The Art of Empowering Others. The Academy of Management Executive, 3(1), 17-24. Retrieved June 25, 2013, from http://www.jstor.org/stable/4164863

Conger, J. A., \& Kanungo, R. N. (1988). The Empowerment Process: Integrating Theory and Practice. The Academy of Management Review, 13(3), 471-482. Retrieved June 25, 2013, from http://www.jstor.org/stable/258093

Dwyer, J. J., Allison, K. R., LeMoine, K. N., Faulkner, G. J., Adlaf, E. M., Goodman, J., \& Lysy, D. C. (2007). A Survey of Opportunities for School-based Physical Activity in Ontario Elementary Schools. Physical \& Health Education Journal, 73(4), 36-42.

Eaton, D. K., Marx, E., \& Bowie, S. E. (2007). Faculty and staff health promotion: results from the school health policies and programs study 2006. Journal of School Health, 77(8), 557-566.

Hackman, M. Z., \& Johnson, C. E. (2004). Leadership: A Communication Perspective (4th ed.). Long Grove, IL: Waveland Press, Inc.

Hackman, M.Z., \& Johnson, C.E. (2013). Leadership: A Communication Perspective (6 ${ }^{\text {th }}$ ed.) Long Grove, IL: Waveland Press, Inc.

Institute of Medicine. (2013). Educating the Student body-Taking Physical Activity and Physical Education to School. Washington, DC: Institute of Medicine of The National Academies. 
Jago, R., \& Baranowski, T. (2004). Non-curricular Approaches for Increasing Physical Activity In Youth: A Review. Preventive Medicine, 39(1), 157-163.

Kane, M., \& Trochim, W. M. (2007). Concept Mapping for Planning and Evaluation. Thousand Oaks : Sage Publications, Inc.

Kelly, C. M., Baker, E. A., Brownson, R. C., \& Schootman, M. (2007). Translating research into practice: Using concept mapping to determine locally relevant intervention strategies to increase physical activity. Evaluation and Program Planning, 30, 282-293.

Lebel, A., Cantinotti, M., Pampalon, R., Theriault, M., Smith, L. A., \& Hamelin, A.-M. (2011). Concept mapping of diet and physical activity: Uncovering local stakeholders perceptions in the Quebec City region. Social Science \& Medicine, 72, 439-445.

Lee, S. M., Burgeson, C. R., Fulton, J. E., \& Spain, C. G. (2007). Physical Education and Physical Activity: Results From the School Health Policies and Programs Study 2006. Journal of School Health, 77(8), 435-463.

Let's Move. (2013, May 20). Retrieved from letsmove.gov: www.letsmove.gov/first-lady-columnhealthier-schools

Let's Move Active Schools. (2013, May 20). Retrieved from letsmoveschools: www.letsmoveschools.org Lounsbery, M.A.F., McKenzie, T.L., Trost, S., \& Smith, N.J. (2011). Facilitators and barriers to adopting evidence-based physical education in elementary schools. Journal of Physical Activity \& Health 8, S17-S25.

McKenzie, T. (2007). The Preparation of Physical Educators: A Public Health Perspective . Quest, 345357.

Metzler, M. W., McKenzie, T. L., Van Der Mars, H., Barrett-Williams, S. L., \& Ellis, R. (2013). Health Optimizing Physical Education (HOPE). The Journal Of Physical Education, Recreation \& Dance, 84(5), 25-34. 
Moving into the Future: National Standards for Physical Education, 2nd Edition. (2004a). Retrieved January 26, 2012, from National Association for Sport and Physical Educaiton: http://www.aahperd.org/naspe/standards/nationalStandards/PEstandards.cfm

National Education Association. (2013). U.S. Department of Education Discreationary Funding (excluding Federal Pell Grants): Fiscal Years 2003-2013. National Education Association. Retrieved June 26, 2013, from www.nea.org/assets/docs/FY2003-13-ED-Discretionary-ex-PellBaseline-vs-Actual.pdf

National Association for Sport and Physicla Education. (2008a). Comprehensive school physical activity programs [Position statement]. Reston, VA: Author.

National Association for Sport and Physical Education (2008b). National standards and guidelines for physical education teacher education ( $3^{\text {rd }}$ ed.). Reston VA: Author.

National Association for Sport and Physicla Education. (2013). Comprehensive school physical activity programs: Helping all students achieve 60 minutes of physical activity each day [Position statement]. Reston, VA: Author.

Ogden, C., Carroll, M., Curtin, L., Lamb, M., \& Flegal, K. (2010). Prevalence of High Body Mass Index in US Children and Adolscents 2007-2008. Journal of American Medical Association, 303(3), 242-249.

Olsen, E. \& Chrispeels, J. (2009). A pathway forward to school change: Leading together and achieving goals. Leadership and Policy in Schools, 8, 380-419.

Ostroff, C. (1992). The Relationship Betweeen Satisfaction, Attitudes, and Performance: An Organizational Level Analysis. Journal of Applied Psychology, 77, 963-974.

Pate, R. R., Davis, M. G., Robinson, T. N., Stone, E. J., McKenzie, T. L., \& Young, J. C. (2006). Promoting Physical Activity in Children and Youth: A Leadership Role for Schools. Circulation, $114,1214-1224$.

Patton, M.Q. (2002). Qualitative Research \& Evaluation Methods ( $3^{\text {rd }}$ ed.) Thousand Oaks, CA: Sage Publications, Inc. 
Physical Activity for Children: A Statement of Guidelines for Children Ages 5-12, 2nd Edition. (2004b).

Retrieved January 26, 2012, from National Association for Sport and Physical Education: http://www.aahperd.org/naspe/standards/nationalGuidelines/PA-Children-5-12.cfm

Ries, A. V., Voorhees, C. C., Gittelsohn, J., Roche, K. M., \& Astone, N. M. (2008). Adolescents' Perceptions of Environmental Influences on Physical Activity. American Journal of Health Behavior, 32(1), 26-39.

Rink , J. (2012). The Role of Directors of Comprehensive School Physical Activity Programs-Part 1: Introduction. JOPERD: The Journal of Physcial Education, Recreation \& Dance, 15-29.

Sallis, J. F., \& Glanz, K. (2006). The role of built environments in physical activity, eating, and obesity in childhood. Future Child, 16(1), 89-108.

Sallis, J. F., \& McKenzie, T. L. (1991). Physical Education's Role in Public Health. Research Quarterly for Exercise and Sport, 62, 124-137.

Sallis, J. F., McKenzie, T. L., Beets, M. W., Beighle, A., Erwin, H. \& Lee, S. (2012). Physical Education's Role in Public Health: Steps Forward and Backward Over 20 Years and Hope for the Future. Research Quarterly for Exercise and Sport, 83(2), 125-135.

Sallis, J., Cervero, R., Ascher, W., Henderson, K., Kraft, M., \& Kerr, J. (2006). An ecological approach to creating active living communities. Annual Review of Public health, 27, 297-322.

Siedentop, D. L. (2009). National Plan for Physical Activity: Education Sector. Journal of Physical Activity and Health, 6, S168-S180.

Strong, W., Malina, R., Blimkie, C., Daniels, S., Dishman, R., Gutin, B., . . Pivarnik, J. (2005). Evidence based physical activity for school-age youth. Journal of Pediatrics, 146(6), 732-737.

Trochim, W. \& Linton, R. (1986). Conceptualization for planning and evaluation. Evaluation and Program Planning, 9(4), 289-304.

Trochim, W. (1989). An introduction to concept mapping for planning and evaluation. Evaluation and Program Planning, 12(1), 1-16. 
Trochim, W. (1993). The reliability of concept mapping. Conference of the American Evaluation Association. Dallas.

Trudeau, F., \& Shephard, R. (2008). Physical Education, school physical activity, school sports and academic performance. International Journal of Behavioral Nutrition and Physical Activity, 1-12. doi:10.1186/1479-5868-5-10

U.S. Department of Health and Human Services. (2008). 2008 Physical activity guidelines for Americans. Washington, DC: United States Government Printing Office.

U.S. Department of Health and Human Services. (2010a). Strategies to Improve the Quality of Physical Education. Washington, DC: United States Government Printing Office.

US Department of Health and Human Services. (2010b). The association between school based physical activity, including physical education, and academic performance. Washington, DC: Author

U.S. Department of Health and Human Services. (2012). Physical Activity Guidelines For Americans Midcourse Report: Strategies to Increase Physical Activity Among Youth. Washington, DC: U.S. Department of Health and Human Services. Retrieved March 28, 2013, from www.health.gov/paguidelines/midcourse/pag-mid-course-report-final.pdf

Wang, J., Castelli, D. M., Liu, W., Bian, W., \& Tan, J. (2010). Re-Conceptualizing Physical Education Programs From An Ecological Perspective. Asian Journal Of Exercise \& Sports Science, 7(1), 43-53.

Wang, Y. C., Gortmaker, S. L., Sobol, A. M., \& Kuntz, K. M. (2006). Estimating The Energy Gap Among US Children: A Counterfactual Approach. Pediatrics, 118(6), 1721-1733.

Young, D. R., Felton, G. M., Grieser, M., Elder, J. P., Johnson, C., Lee, J., \& Kubik, M. Y. (2007). Policies and Opportunities for Physical Activity in Middle School Environments. Journal of School Health, 77(1), 41-47.

Zhang, T., Solomon, M. A., Gao, Z., \& Kosma, M. (2012). Promoting School Students' Physical Activity: A Social Ecological Perspective. Journal of Applied Sport Psychology, 24(1), 92-105. 
Table 1

Brainstorming Demographics

\begin{tabular}{|c|c|c|c|}
\hline Participant Question & Option or Statistic & Frequency & $\%$ \\
\hline \multirow[t]{3}{*}{ Gender } & Male & 21 & 41.18 \\
\hline & Female & 22 & 43.14 \\
\hline & did not respond & 8 & 15.69 \\
\hline \multicolumn{4}{|l|}{ Geographical } \\
\hline \multirow[t]{7}{*}{ Location } & Northeast & 21 & 41.18 \\
\hline & Southeast & 8 & 15.69 \\
\hline & Midwest & 4 & 7.84 \\
\hline & Northwest & 1 & 1.96 \\
\hline & Southwest & 4 & 7.84 \\
\hline & Mid-Atlantic & 5 & 9.8 \\
\hline & did not respond & 8 & 15.69 \\
\hline \multirow[t]{6}{*}{ Years of Service } & $1-5$ & 4 & 7.84 \\
\hline & $6-10$ & 1 & 1.96 \\
\hline & $11-15$ & 8 & 15.69 \\
\hline & $16-20$ & 6 & 11.76 \\
\hline & 20 or more & 24 & 47.06 \\
\hline & did not respond & 8 & 15.69 \\
\hline \multirow[t]{9}{*}{ Education } & some high school & 0 & 0 \\
\hline & high school graduate & 0 & 0 \\
\hline & some college & 0 & 0 \\
\hline & trade/technical/vocational training & 0 & 0 \\
\hline & college graduate & 1 & 1.96 \\
\hline & some postgraduate work & 1 & 1.96 \\
\hline & post graduate degree & 41 & 80.39 \\
\hline & did not respond & 8 & 15.69 \\
\hline & Higher Education & & \\
\hline \multirow[t]{3}{*}{ Job Description } & Professional/Researcher & 19 & 37.25 \\
\hline & K-12 Educator/Administrator & 23 & 45.1 \\
\hline & did not respond & 9 & 17.65 \\
\hline
\end{tabular}


Table 2

Structuring Demographics

\begin{tabular}{|c|c|c|c|}
\hline Participant Question & Option or Statistic & Frequency & $\%$ \\
\hline \multirow[t]{2}{*}{ Gender } & Male & 5 & 27.78 \\
\hline & Female & 13 & 72.22 \\
\hline \multicolumn{4}{|l|}{ Geographical } \\
\hline \multirow[t]{6}{*}{ Location } & Northeast & 9 & 50 \\
\hline & Southeast & 2 & 11.11 \\
\hline & Midwest & 3 & 16.67 \\
\hline & Northwest & 0 & 0 \\
\hline & Southwest & 3 & 16.67 \\
\hline & Mid-Atlantic & 1 & 5.56 \\
\hline \multirow[t]{5}{*}{ Years of Service } & $1-5$ & 1 & 5.56 \\
\hline & $6-10$ & 0 & 0 \\
\hline & $11-15$ & 2 & 11.11 \\
\hline & $16-20$ & 2 & 11.11 \\
\hline & 20 or more & 13 & 72.22 \\
\hline \multirow[t]{8}{*}{ Education } & some high school & 0 & 0 \\
\hline & high school graduate & 0 & 0 \\
\hline & some college & 0 & 0 \\
\hline & trade/technical/vocational training & 0 & 0 \\
\hline & college graduate & 0 & 0 \\
\hline & some postgraduate work & 0 & 0 \\
\hline & post graduate degree & 18 & 100 \\
\hline & Higher Education & & \\
\hline \multirow[t]{2}{*}{ Job Description } & Professional/Researcher & 6 & 33.33 \\
\hline & K-12 Educator/Administrator & 12 & 66.67 \\
\hline
\end{tabular}


Table 3

List of Statements

\# Statement

1. $\quad$ Communicating effectively with colleagues and other stakeholders.

2 Identifying the components of a CSPAP and how each contributes to maximizing physical activity opportunities for school-aged children.

3 Advocating for the physical activity needs of children both at school and in the broader community.

$4 \quad$ Differentiating between physical education and physical activity.

5 Educating school faculty/staff, students, parents and community to understand the importance and health benefits of physical education, structured and unstructured play.

6 Explaining exercise physiology principles and concepts (i.e., Components of Fitness, Basic Training Principles, FITT Guidelines).

$7 \quad$ Knowing the psychology of exercise adherence and the related importance of skill development.

8 Constructing collective strategic plans that serve as a guide or map to give physical activity programs short and long-term direction.

9 Remaining current with the literature in the field including recommendations for best practice and related resources.

10 Being flexible and creative in designing experiences for children that are contextually appropriate.

11 Understanding how the goals of a program contribute to the overall wellness and education of students from a school-wide perspective.

12 Finding physical activity opportunities that can be made available to students, faculty/staff, and community members.

13 Organizing, managing, and leading the various components of a program.

14 Facilitating solid working-relationships with other members of the school community based on mutual trust and respect.

15 Raising funds needed to support programming.

16 Modeling effective physical activity programming for others to emulate.

17 Encouraging others to get involved so the programming is sustainable even if the leader moves on.

18 Establishing relationships with individuals and organizations from the broader community.

19 Applying authentic assessment strategies to evaluate the efficacy of physical education and physical activity programs.

20 Leading and motivating a functional School Wellness Committee that can make collective decisions related to health promotion in the school.

21 Delegating program responsibilities to others, such as classroom teachers.

22 Establishing positive relationship with colleagues and administrators that foster school-wide participation in physical activity promotion and implementation.

23 Accessing and organizing multiple resources.

24 Desiring to increase one's involvement beyond simply teaching physical education.

25 Developing, implementing and sustaining a district-wide quality physical education program across all grade levels.

26 Maintaining extensive background knowledge in physical education including an awareness of contemporary research in the field.

27 Evaluating program outcomes.

28 Engaging others in shared decision making as a way to increase their involvement. 
29 Attending regular professional development opportunities (i.e., SHAPE America, state HPERD conferences, regional/local workshops).

30 Appreciating the benefit and impact that a physical activity program will have on all members of the school community.

31 Understanding the role of nutrition, hydration, sleep, and other health-related behaviors in effective physical activity programming.

32 Understanding the capabilities of the school faculty and staff.

33 Designing effective exercise and physical activity programs across varying developmental levels. Knowing guidelines for developmentally appropriate practice in physical activity programming. Modifying program features based on the characteristics of the students it is designed to impact. Identifying the ways in which the program can meet the individual needs of students in an integrated setting.

37 Understanding effective pedagogy and selecting instructional approaches to lead various physical activities.

38 Advocating and promoting the related programming.

39 Demonstrating skills to design and implement physical activity programs for others.

40 Maintaining knowledge of a broad range of traditional and non-traditional physical activity alternatives (i.e., competitive/cooperative, individual/group, adventure).

41 Writing grants to support ongoing programming in physical activity promotion.

42 Knowing the advantages of well-rounded approaches of physical activity programming compared to those delivered from a more narrow perspective.

43 Negotiating the politics of schools, communities, health organizations, and other organizations that may be involved in physical activity programming.

$44 \quad$ Sharing guidelines for developmentally appropriate practice with others (i.e., playground supervisors, classroom teachers, before and after school providers).

45 Identifying already available programs and related resources in physical activity promotion.

46 Selecting standards- and evidenced-based approaches to curriculum and instruction in physical education.

$47 \quad$ Leading school faculty/staff and students.

48 Knowing the processes by which students learn and the instructional environments that are most effective.

49 Modeling high levels of energy/passion for physical activity and leading others by example.

50 Providing access to opportunities for physical activity and encouraging others to participate.

51 Providing professional development training for school faculty/staff to improve sustainability if the leader moves on.

52 Believing it is his or her responsibility to lead program efforts.

53 Using creativity in considering how to best utilize available space.

$54 \quad$ Managing time properly to allow for sufficient program oversight.

55 Selecting standards- and evidenced-based approaches to curriculum and instruction in physical activity programming.

56 Building teams within and beyond the school setting with collaborators from recreation, physical education, medicine, health, the community, schools, etc. that can work with cohesion and sustained momentum. 
Table 4

Cluster 1 Teambuilding/Facilitation - Statements

\begin{tabular}{lll}
\hline$\#$ & Statement & Bridging
\end{tabular}

\section{Cluster 1-Teambuilding/Facilitating}

18 Establishing relationships with individuals and organizations from the broader community.

14 Facilitating solid working-relationships with other members of the school community based on mutual trust and respect.

22 Establishing positive relationship with colleagues and administrators that foster school-wide participation in physical activity promotion and implementation.

56 Building teams within and beyond the school setting with collaborators from recreation, physical education, medicine, health, the community, schools, etc. that can work with cohesion and sustained momentum.

28 Engaging others in shared decision making as a way to increase their involvement.

43 Negotiating the politics of schools, communities, health organizations, and other organizations that may be involved in physical activity programming.

20 Leading and motivating a functional School Wellness Committee that can make collective decisions related to health promotion in the school. $\quad 0.26$

17 Encouraging others to get involved so the programming is sustainable even if the leader moves on.

49 Modeling high levels of energy/passion for physical activity and leading others by example.

$50 \quad$ Providing access to opportunities for physical activity and encouraging others to participate.

32 Understanding the capabilities of the school faculty and staff.

$$
\text { Count } 14 \quad \text { SD: } 0.1 \quad \text { Mean: } 0.27 \quad \text { Med: } 0.25
$$

Note. Bridging values (0-1) are used to determine if a statement is considered to be an anchor or bridging statement. Statements that are anchor statements are considered to be reflective of the statements that are close to it on the map whereas bridging statements link areas on the map together. Lower values are indicative of anchor statements. 
Table 5

Cluster 2 Capacity Building - Statements

\begin{tabular}{lll}
\hline$\#$ & Statement & Bridging
\end{tabular}

\section{Cluster 2- Capacity Building}

3 Advocating for the physical activity needs of children both at school and in $\begin{array}{ll}\text { the broader community. } & 0.4\end{array}$

38 Advocating and promoting the related programming. $\quad 0.42$

$5 \quad$ Educating school faculty/staff, students, parents and community to understand the importance and health benefits of physical education, structured and unstructured play.

$44 \quad$ Sharing guidelines for developmentally appropriate practice with others (i.e., playground supervisors, classroom teachers, before and after school providers). $\quad 0.63$

51 Providing professional development training for school faculty/staff to improve sustainability if the leader moves on.

30 Appreciating the benefit and impact that a physical activity program will have on all members of the school community.

45 Identifying already available programs and related resources in physical activity promotion.

15 Raising funds needed to support programming.

$41 \quad$ Writing grants to support ongoing programming in physical activity promotion. $\quad 0.94$

24 Desiring to increase one's involvement beyond simply teaching physical education. $\quad 1.00$

$$
\text { Count } 10 \quad \text { SD: } 0.2 \quad \text { Mean: } 0.71 \quad \text { Med: } 0.71
$$

Note. Bridging values (0-1) are used to determine if a statement is considered to be an anchor or bridging statement. Statements that are anchor statements are considered to be reflective of the statements that are close to it on the map whereas bridging statements link areas on the map together. Lower values are indicative of anchor statements. 
Table 6

Cluster 3 Knowledge of Instructional Practices - Statements

\begin{tabular}{lll}
\hline$\#$ & Statement & Bridging
\end{tabular}

\section{Cluster 3- Knowledge of Instructional Practices}

\subsection{5}

$7 \quad$ Knowing the psychology of exercise adherence and the related importance of $\begin{array}{ll}\text { skill development. } & 0.0\end{array}$

$4 \quad$ Differentiating between physical education and physical activity. $\quad 0.02$

48 Knowing the processes by which students learn and the instructional environments that are most effective.

31 Understanding the role of nutrition, hydration, sleep, and other health-related behaviors in effective physical activity programming.

34 Knowing guidelines for developmentally appropriate practice in physical activity programming.

55 Selecting standards- and evidenced-based approaches to curriculum and instruction in physical activity programming.

37 Understanding effective pedagogy and selecting instructional approaches to lead various physical activities.

46 Selecting standards- and evidenced-based approaches to curriculum and instruction in physical education.

2 Identifying the components of a CSPAP and how each contributes to maximizing physical activity opportunities for school-aged children.

36 Identifying the ways in which the program can meet the individual needs of students in an integrated setting.

11 Understanding how the goals of a program contribute to the overall wellness and education of students from a school-wide perspective.

39 Demonstrating skills to design and implement physical activity programs for others. $\quad 0.28$

16 Modeling effective physical activity programming for others to emulate. 0.38

$$
\text { Count } 13 \text { SD: } 0.11 \quad \text { Mean: } 0.15 \text { Med: } 0.13
$$

Note. Bridging values (0-1) are used to determine if a statement is considered to be an anchor or bridging statement. Statements that are anchor statements are considered to be reflective of the statements that are close to it on the map whereas bridging statements link areas on the map together. Lower values are indicative of anchor statements. 
Table 7

Cluster 4 Content Knowledge - Statements

\#

Statement

Bridging

Cluster 4 - Content Knowledge (CK)

0.24

40 Maintaining knowledge of a broad range of traditional and non-traditional physical activity alternatives (i.e., competitive/cooperative, individual/group, adventure). 0.06

$6 \quad$ Explaining exercise physiology principles and concepts (i.e., Components of Fitness, Basic Training Principles, FITT Guidelines).

26 Maintaining extensive background knowledge in physical education including an awareness of contemporary research in the field.

42 Knowing the advantages of well-rounded approaches of physical activity programming compared to those delivered from a more narrow perspective.

0.18

9 Remaining current with the literature in the field including recommendations for best practice and related resources.

29 Attending regular professional development opportunities

(i.e., SHAPE America, state HPERD conferences, regional/local workshops).

0.58

Count $6 \quad$ SD: $0.18 \quad$ Mean: 0.24 Med: 0.16

Note. Bridging values (0-1) are used to determine if a statement is considered to be an anchor or bridging statement. Statements that are anchor statements are considered to be reflective of the statements that are close to it on the map whereas bridging statements link areas on the map together. Lower values are indicative of anchor statements. 
Table 8

Cluster 5 Program Development and Management - Statements

\begin{tabular}{lll}
\hline$\#$ & Statement & Bridging
\end{tabular}

\section{Cluster 5- Program Development and Management}

33 Designing effective exercise and physical activity programs across varying developmental levels.

35 Modifying program features based on the characteristics of the students it is designed to impact.

19 Applying authentic assessment strategies to evaluate the efficacy of physical education and physical activity programs.

25 Developing, implementing and sustaining a district-wide quality physical education program across all grade levels.

$8 \quad$ Constructing collective strategic plans that serve as a guide or map to give physical activity programs short and long-term direction.

54 Managing time properly to allow for sufficient program oversight.

10 Being flexible and creative in designing experiences for children that are contextually appropriate.

52 Believing it is his or her responsibility to lead program efforts.

12 Finding physical activity opportunities that can be made available to students, faculty/staff, and community members.

13 Organizing, managing, and leading the various components of a program. 0.5

23 Accessing and organizing multiple resources.
Count 13
SD: 0.09
Mean: 0.39 Med: 0.4

0.59

Note. Bridging values (0-1) are used to determine if a statement is considered to be an anchor or bridging statement. Statements that are anchor statements are considered to be reflective of the statements that are close to it on the map whereas bridging statements link areas on the map together. Lower values are indicative of anchor statements. 


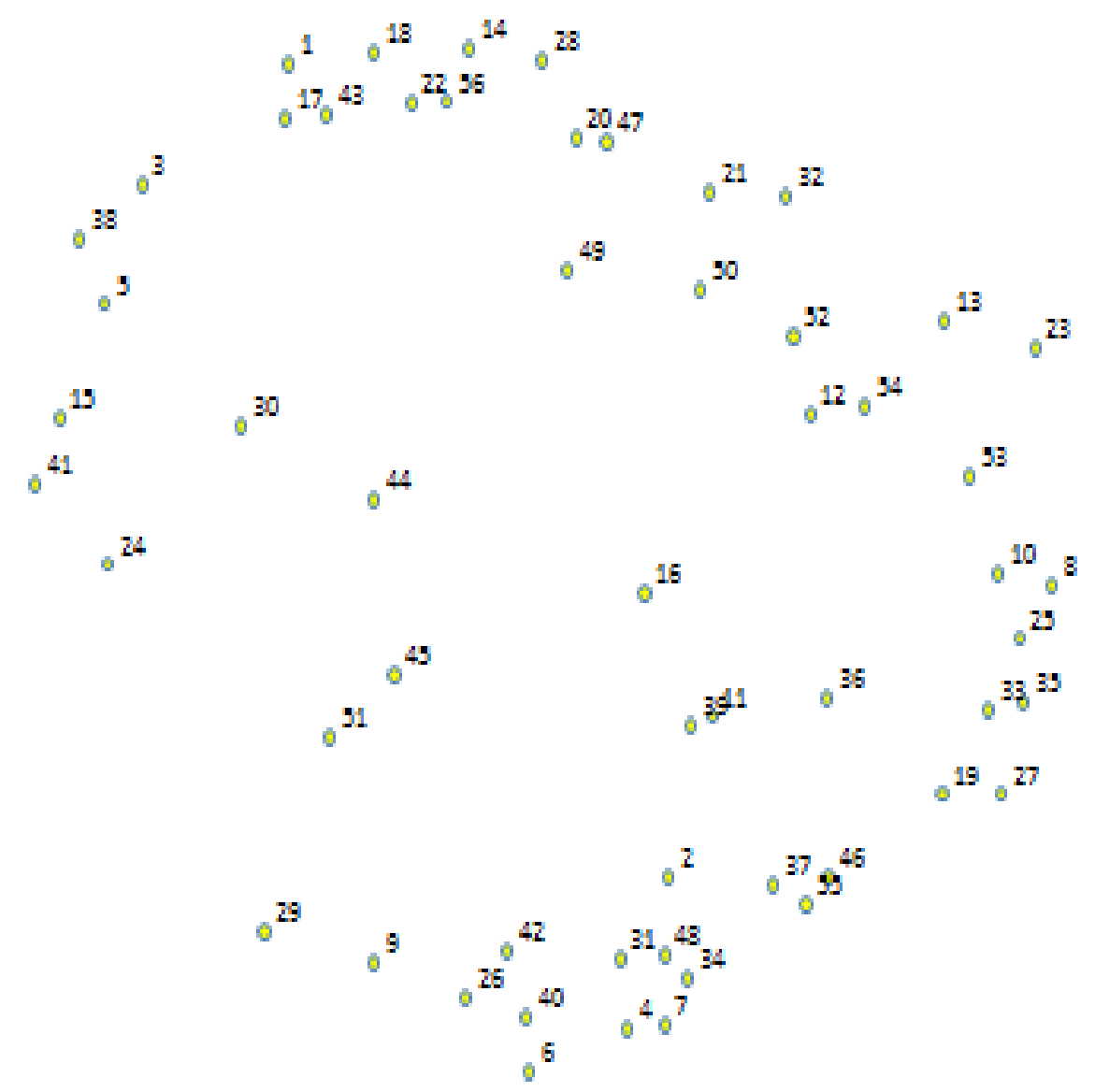

Figure 1. Point map of the statements. Each number refers to a statement. Statements that are close geographically on the map where sorted together often (e.g. statements 11 \& 39) whereas statements further apart were sorted together less often (e.g. statements $23 \& 41$ ) 


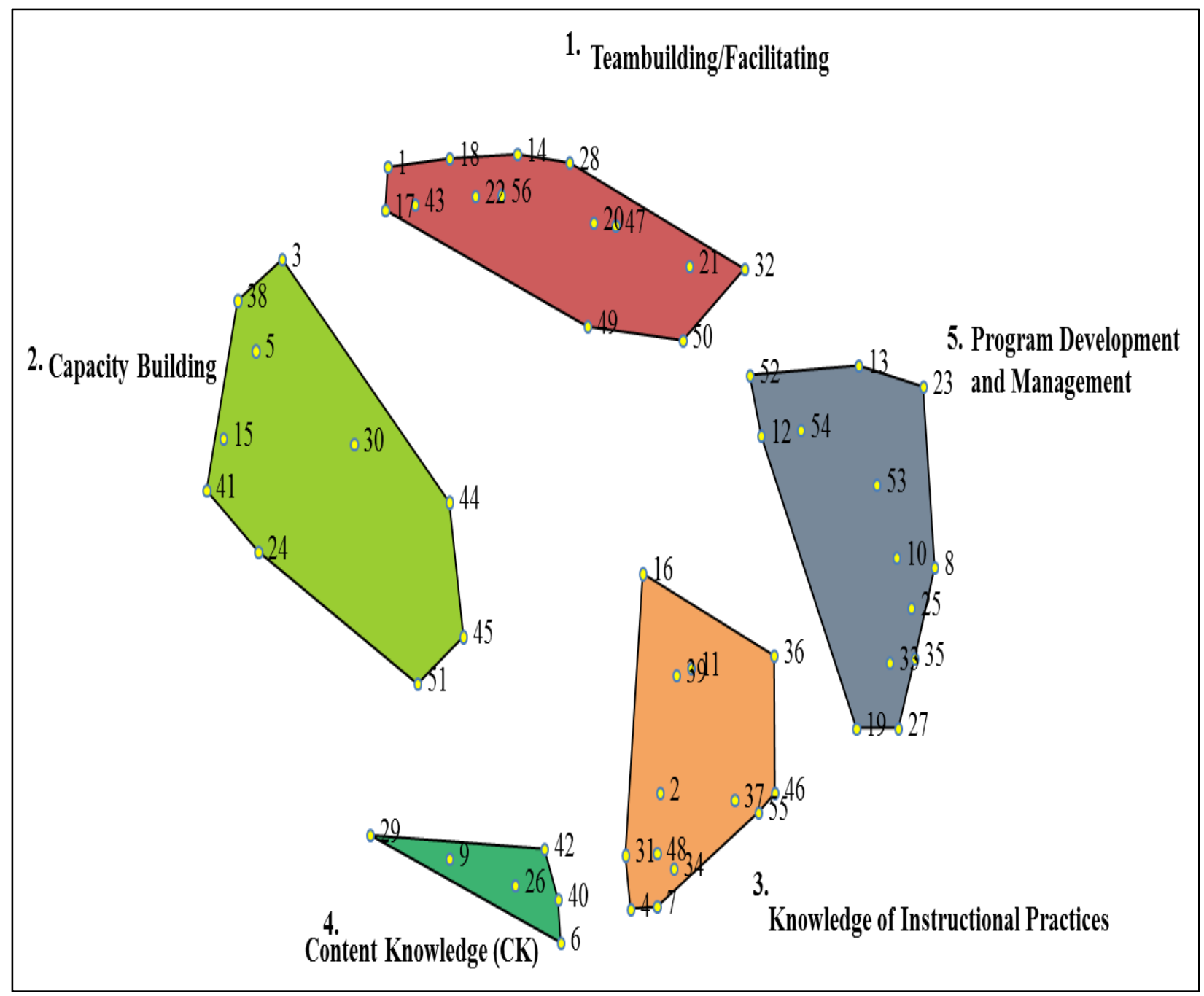

Figure 2. Five cluster solution cluster map. 


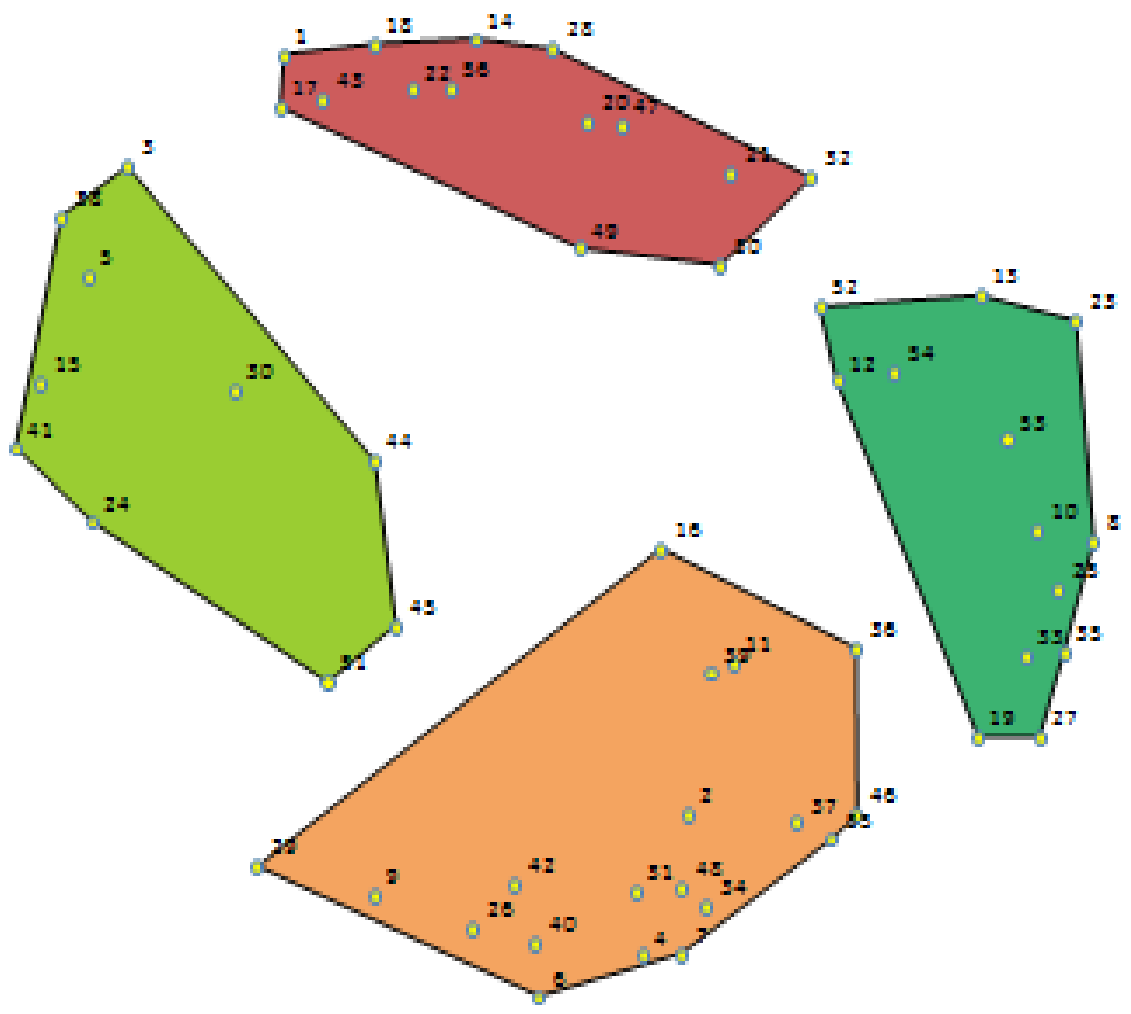

Figure 3. Four cluster solution cluster map 
CSPAP LEADERSHIP 56

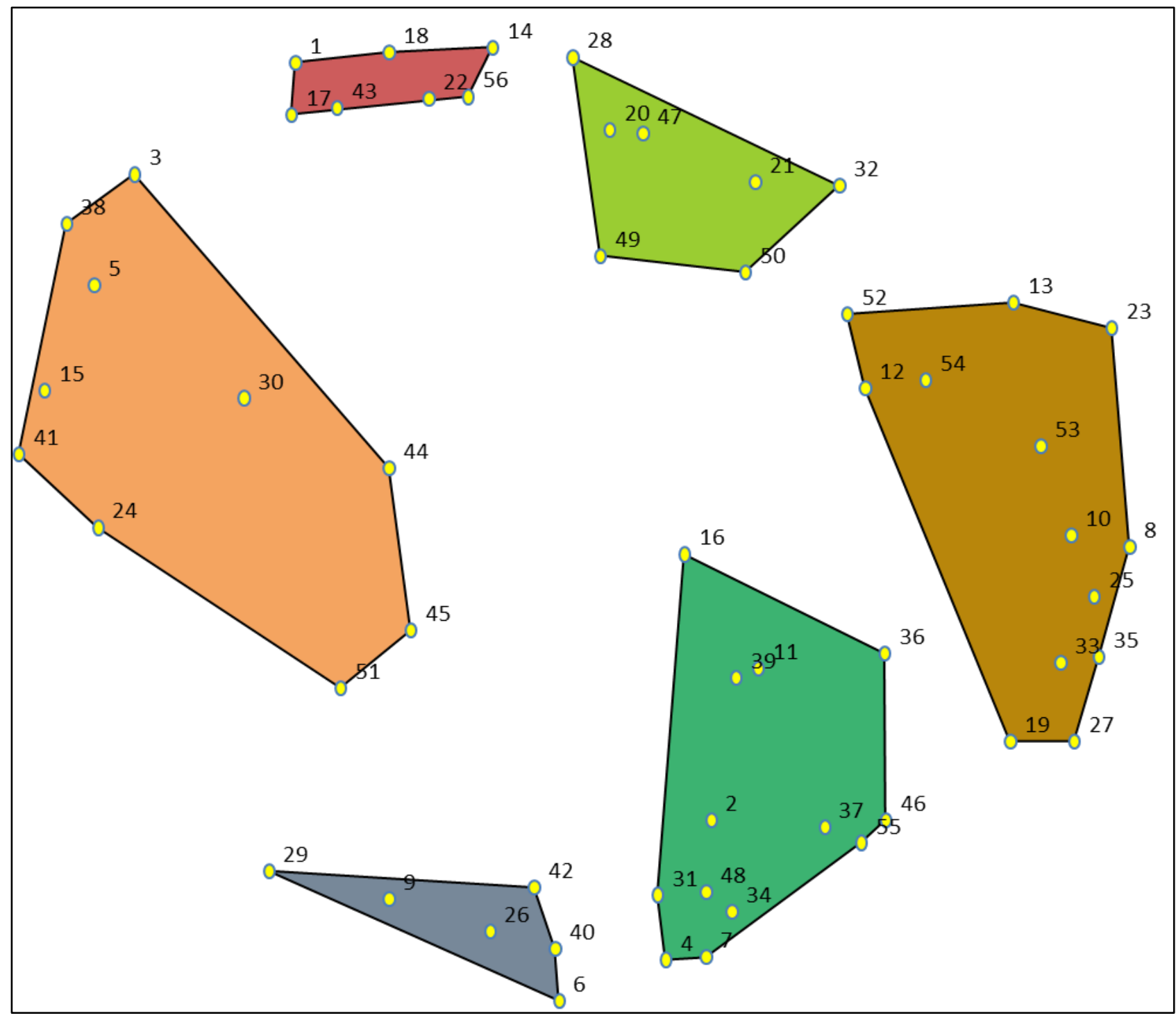

Figure 4. Six cluster solution cluster map. 


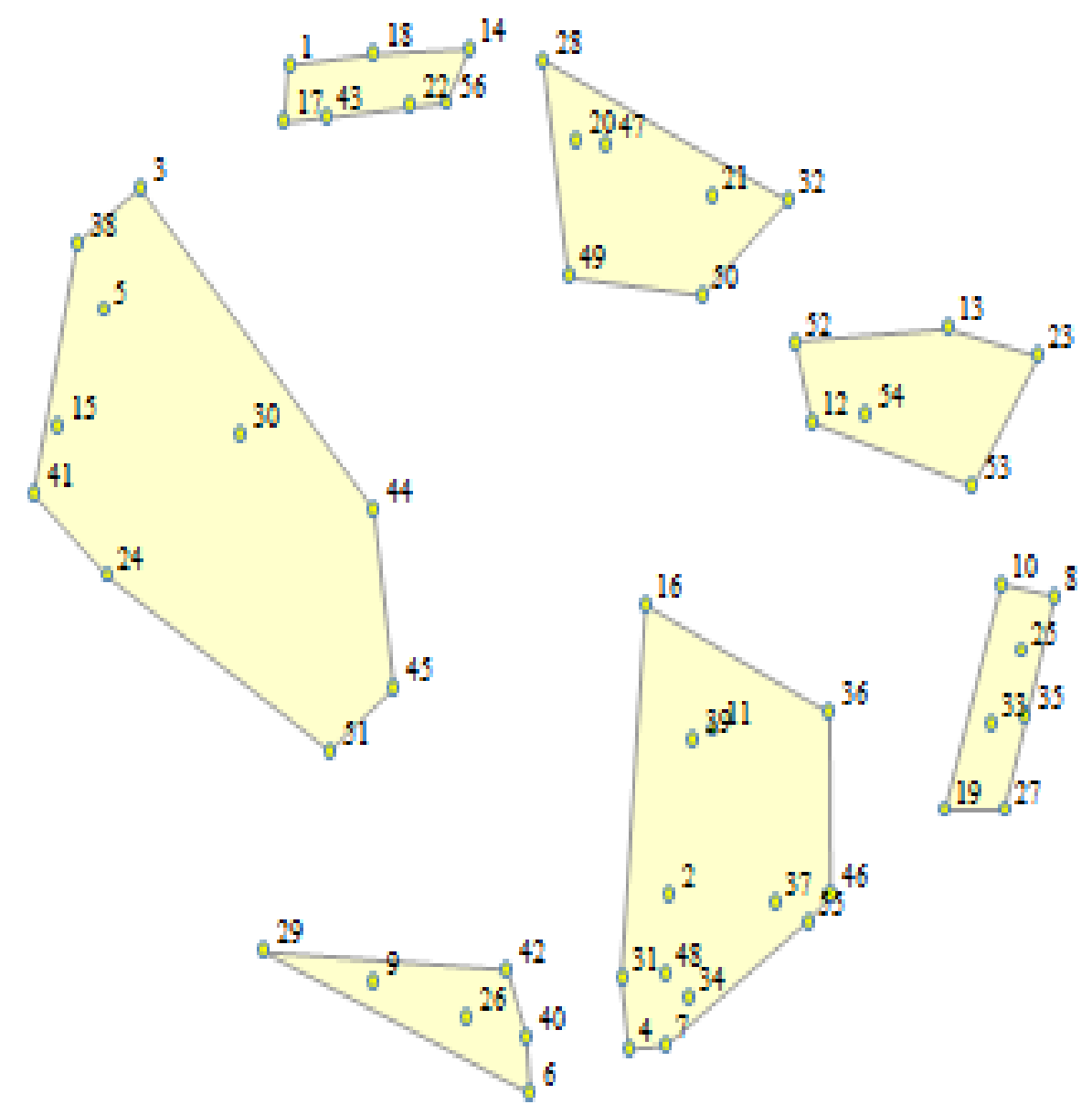

Figure 5. Seven cluster solution cluster map. 


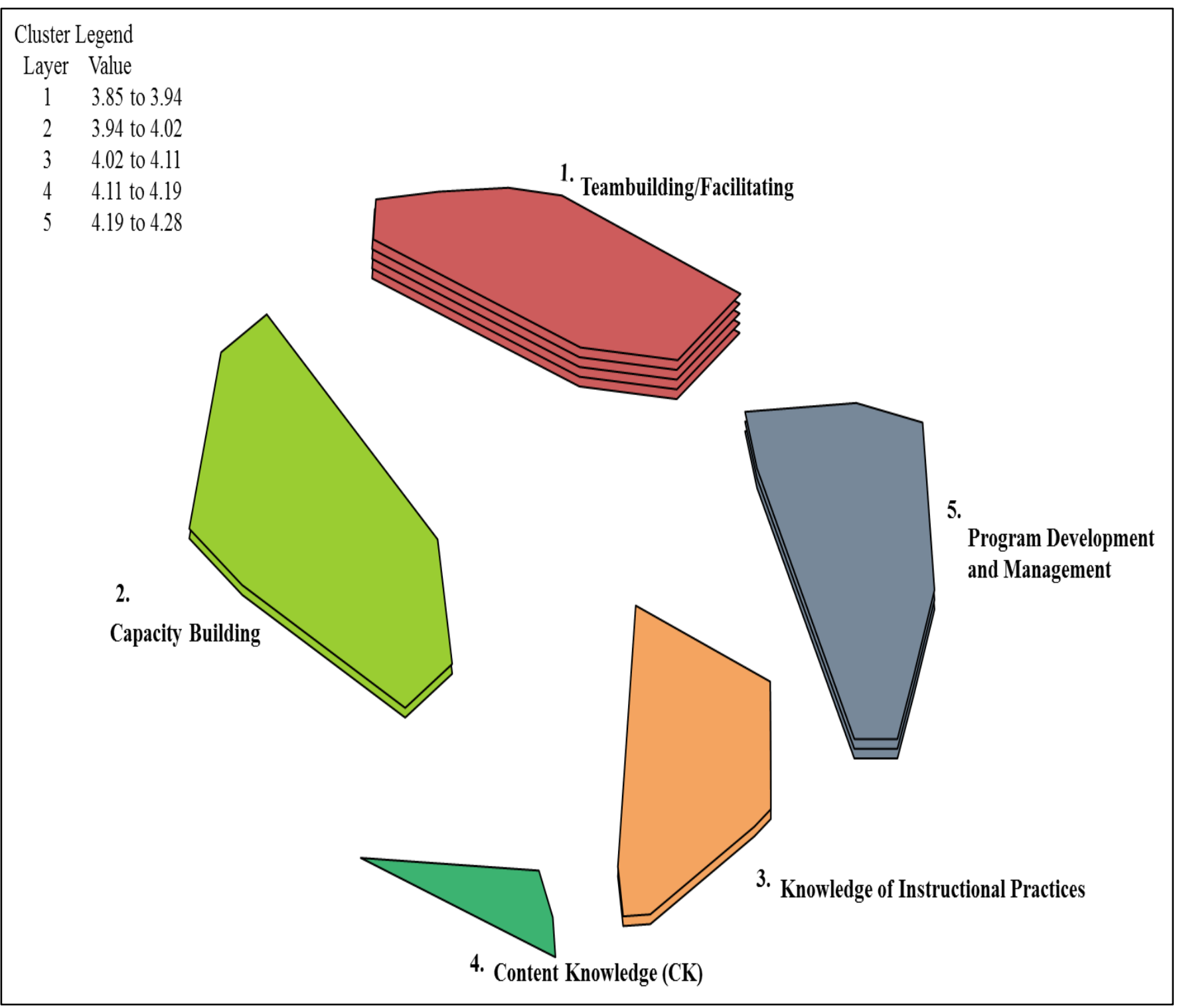

Figure 6. Cluster rating map for importance. Clusters which have more layers possess higher average ratings of importance. 


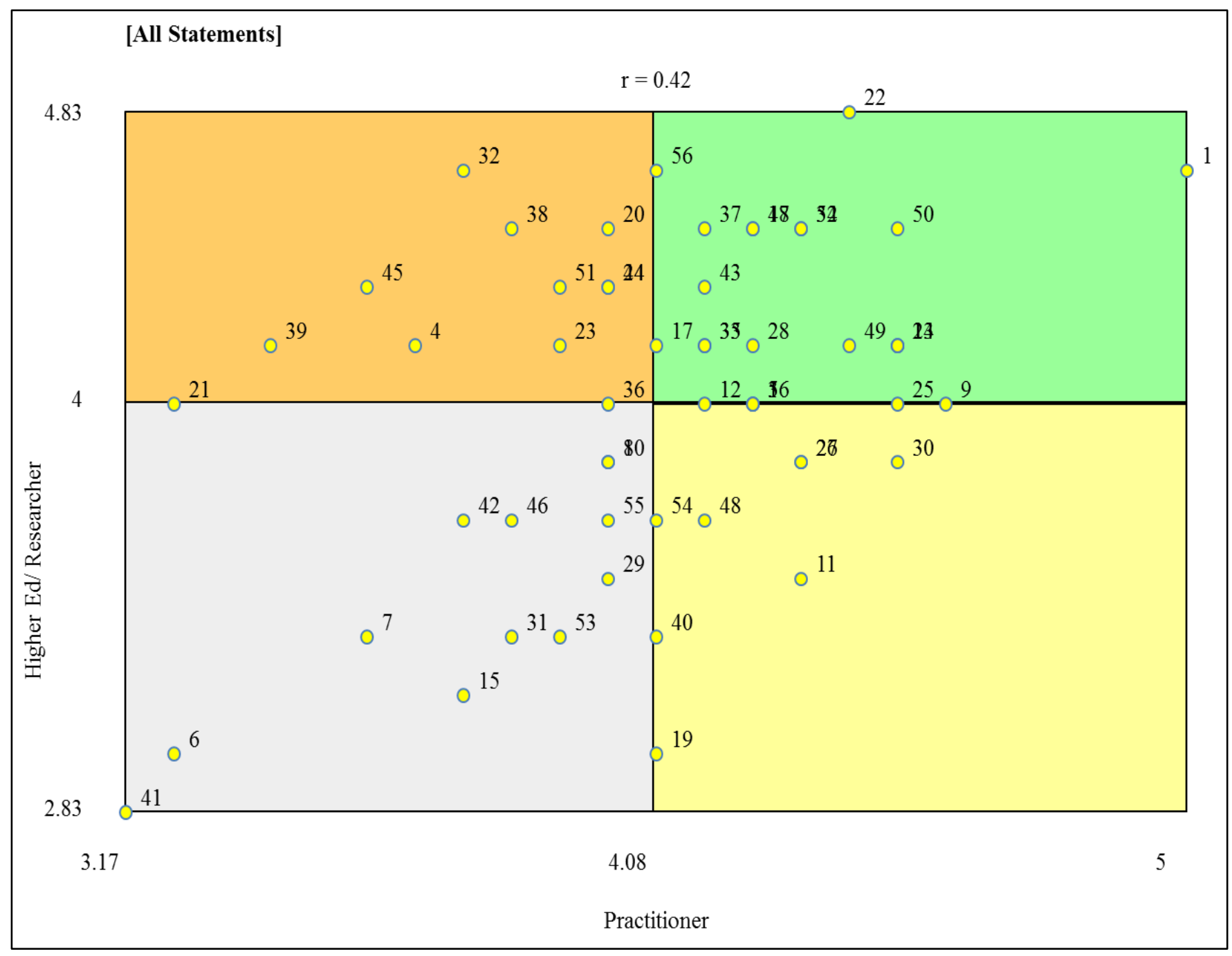

Figure 7. Go-zone display depicting the average rating of every statement on importance based upon practitioner (x-axis) and higher education/ researcher (y-axis). The display is broken into four quadrants based on the average rating of importance 4.00 (higher education/researcher0 and 4.08 (practitioner) based on responses. Statements in quadrant one (the upper right) possess higher than average ratings on importance and is therefore considered to be the most "actionable." 


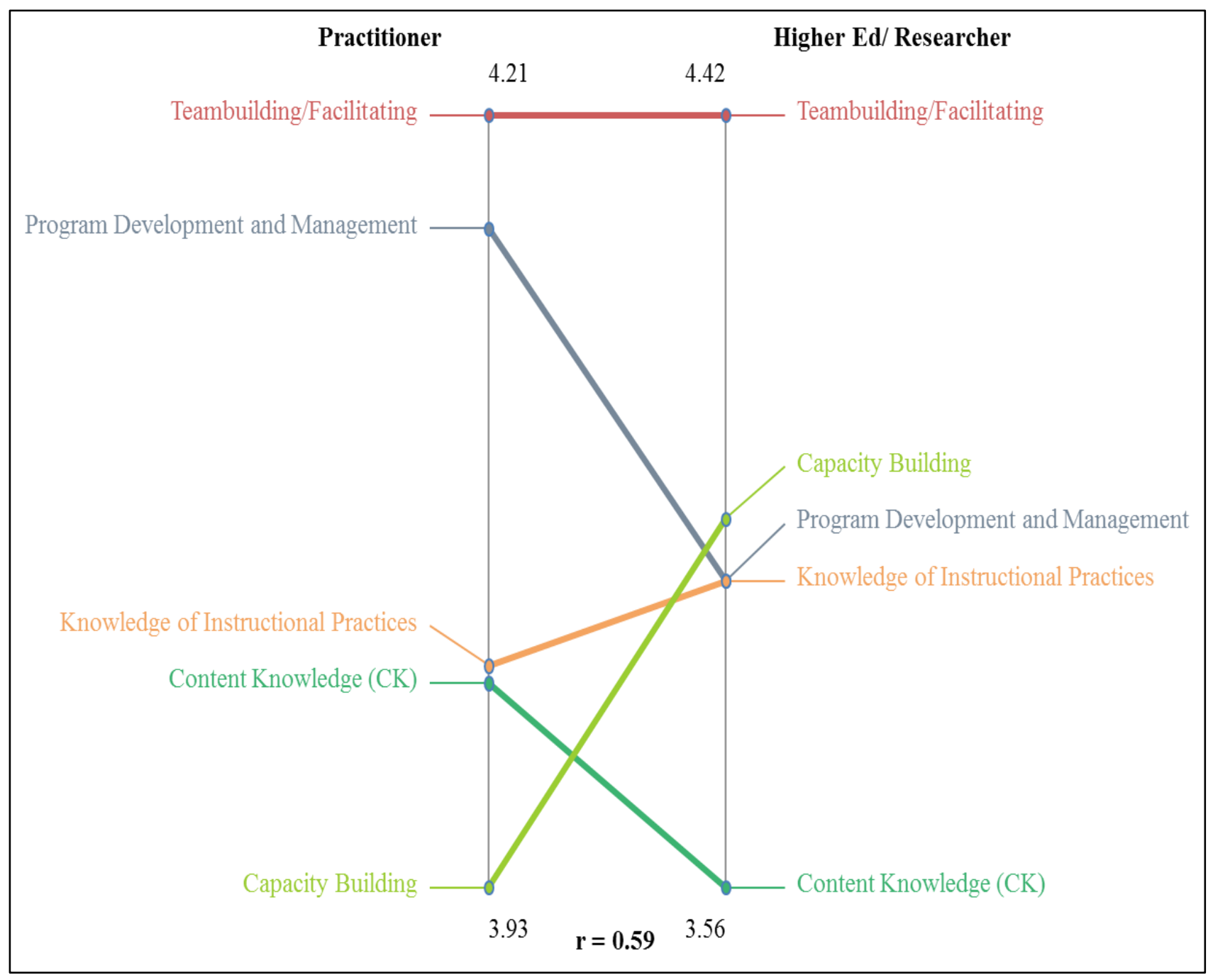

Figure 8. Patter-match display depicts importance ratings of the six clusters. Each cluster's position on the ladder graph is represented based on its average rating of importance by all participants who completed the rating step of this project. 


\section{Appendix A: Extended Literature Review}

The childhood obesity epidemic in America has become a national public health concern. The detrimental health consequences of this epidemic necessitate that communities take a critical look at a range of intervention strategies to help combat this crisis. This review of literature provides a rationale for this study and is organized into the following sections: (a) Children's Physical Activity and Health, (b) Social Ecological Model: A Framework for School-Based Physical Activity Intervention, and (c) The Question of Leadership in Comprehensive School Physical Activity Programs (CSPAP).

\section{Children's Physical Activity and Health}

The childhood obesity epidemic in America, as previously stated, has become a national health crisis. One in every three children ages 2-19 is overweight or obese (Ogden, Carroll, Curtin, Lamb \& Flegal, 2010). The increasing number of obese children and adults in this country over the past 50 years has been attributed not only to poor nutrition but also the lack of physical activity (Rink, Hall \& Williams, 2010). Physical activity is a foundational element in the healthy development and maturation of younger and older children, as well as adolescents approaching adulthood. Physical activity can be defined "as any bodily movement produced by skeletal muscles that result in energy expenditure" (Caspersen, Powell, \& Christenson, 1985, p. 126). Physical activity can be accumulated across various contexts including occupational, sports, conditioning, household, or other lifestyle activities (Ward, Saunders. \& Pate, 2007).

\section{Health Benefits of a Physically Active Lifestyle}

A consensus of expert opinion, information from the research base, and position statements from professional and government organizations (i.e., American Heart Association, National Association for Sport and Physical Education, U.S. Department of Health and Human Services) support that an increase in time spent being physically active, consumption of proper nutrition, and a decrease in sedentary activity contributes to the development of a healthier individual (McKenzie, 2007; National Association for Sport and Physical Education, 2004; U.S. Department of Health and Human Services, 2008). The positive outcomes associated with an active lifestyle include building and maintaining healthy bones, 
muscles and joints, increasing cardiovascular endurance, reducing body fat, prevention of the development of hypertension, and reducing blood pressure in some adolescents with hypertension (Center for disease Control and Prevention, 1999; U.S. Department of Health and Human Services, 1996, 2000, 2008, 2010). These important health benefits even present themselves within individuals who accumulate only moderate amounts of physical activity.

Given that physical activity habits are formed early in life and may continue into adulthood, regular participation in physical activity during childhood and adolescence is a key consideration; therefore it is encouraged for youth to know and appreciate the benefits of physical activity early in childhood with the expectation of maintaining a physically active lifestyle into adulthood (Center for Disease Control and Prevention, 1999). Although awareness of the relationship between physical activity and adult health is well documented, people must also understand how important physical activity is to the well-being of children and adolescents. Physical activity is essential to the normal development and growth of children and adolescents (Hills, King, \& Armstrong, 2007). The development of all systems of the body is impacted by the level of physical activity (Rink, Hall, Williams, 2010). Children's social and emotional well-being remains an additional health-related concern that is equally as important as their physical well-being. The term "play" refers to a spontaneous activity of children and adolescents, either formal or informal, and is considered an essential human behavior. Physically active play is important to the individual's emotional well-being and related studies have demonstrated that regular physical activity improves self-esteem and provides opportunities for children and adolescents to develop critical social skills (Pellegrini \& Smith, 1993; Pellegrini, Kato, Blatchford \& Baines, 2002). According to a study by Castelli, Hillman, Buch, and Erwin (2007), time spent engaged in increased amounts of physical activity also enhances cognitive functioning; while other studies have provided evidence that increased amounts of physical activity (moderate or vigorous) during the school day enhances academic performance (Sallis, McKenzie, Kolody, Lewis, Marshall, \& Rosengard 1999; Sibley \& Etnier, 2003; Strong et al., 2005; Trudeau \& Shepard, 2008). 
The various benefits of physical activity have been expressed in the development of physical, social, emotional, and mental characteristics for children, and many of those benefits are common knowledge in our society with respect to the adult population. Despite this widespread knowledge that physical activity is essential to overall health (e.g., weight control, reduction of heart disease risks and some cancers, bone and muscle strengthening, and mental health improvement) (U.S. Department of Health and Human Services, 2008); only $65 \%$ of American adults are considered to be physically active and 25 percent of the population do not participate in physical activity at all (Center for Disease Control and Prevention, 2010). A lack of physical activity and increased time spent in sedentary pursuits combined with poor nutrition has contributed to a higher prevalence of overweight and obesity within the United States. This trend is not just evident in the stages of adulthood, it has filtered down across generations to our children and adolescent population as well. A substantial increase in physical inactivity and an associated increased rate of adults, adolescents, and children being diagnosed as overweight or obese has been documented in the general population. According to estimates derived from the National Health and Nutrition Examination Survey (NHANES), between the period of 1976-1980 and 2007-2008, obesity has more than doubled among adults rising from $15 \%$ to $34 \%$, and more than tripled among children and adolescents rising from 5\% to $17 \%$ (Ogden et. al., 2010). In a recent report from the Surgeon General on the Visions for a Health and Fit Nation 2010, the surgeon general stated:

Today's epidemic of overweight and obesity threatens the historic progress we have made in increasing American's quality and years of healthy life... Although we have made some strides since 2001, the prevalence of obesity, obesity-related diseases and premature death remains too high. I am calling on all Americans to join me in a national grassroots effort to reverse this trend.... The real goal is not just a number on a scale, but optimal health for all Americans ate every stage of life (U.S. Department of Health and Human Services, 2010, p. 1).

\section{National Health Objectives in the United States}

In January 2000 the national initiative, Healthy People 2010, was issued that established health objectives for the first decade of this century (U.S. Department of Health and Human Services, 2000). Included in this report was a set of leading health indicators - ten high priority public health areas for enhanced public attention. The first leading health indicator was physical activity and the second was 
overweight and obesity; this is an indication of how important these issues were and still are to our nation. Several main objectives were to (a) increase the levels of moderate and vigorous physical activity among adolescents, (b) increase the proportion of trips made by walking and bicycling, and (c) decrease the amount of time young people spend watching television (U.S Department of Health and Human Services, 2000). In 2012, the U.S Department of Health and Human Services released their final review of the Healthy People 2010 results. According to final review, despite the progress Americans have made in the last decade, the analysis demonstrates that the nation still comes up short in several critical areas including efforts to reduce the obesity rate. The report found that obesity increased across all age groups during that time. Among children aged 6-11, obesity rates rose by over 54\% and among adolescents aged 12-19, the obesity rate rose 63\% (U.S. Department of Health and Human Services, 2012).

As the United States continues to work toward objectives set by the U.S. Department of Health and Human Services, we begin to transition into the second decade of the $21^{\text {st }}$ century; as part of this transition a new set of objectives has been established through Healthy People 2020. The goal remains the same as before: improve health, fitness, and the quality of life through daily physical activity while also attempting to reduce the rate of obesity among children, adolescents, and adults in America (U.S. Department of Health and Human Services, 2010). Taking the previous obesity statistics and information into account, we have to ask why has there been no significant progress made during the past decade? It is hypothesized that participation in physical activity as a young person influences physical activity as an adult and regular physical activity reduces risk for the development of overweight among youth; therefore one would recommend we look at the current physical activity levels of children in the United States (U.S. Department of Health and Human Services, 2008). The 2011 National Youth Risk Behavior Surveillance (YRBS) conducted by the Center for Disease Control and Prevention (CDC) reported the following physical activity participation rates by youth in America. Fourteen percent of students did not participate in at least 60 minutes of physical activity on any day in the week prior to survey distribution, $48 \%$ of students did not attend physical education classes in an average week when in school, $69 \%$ of students did not attend physical education classes daily when in school, $31 \%$ of students used computers 
three or more hours per day on an average school day, and $32 \%$ of students watched television three or more hours per day on an average school day (Center for Disease Control and Prevention, 2011). These statistics demonstrate that children and adolescents are not physically active enough to make a significant change in the rate of obesity and overweight. A number of government and professional organizations have produced recommendations to help guide Americans in making healthy choices to increase the amount of physical activity in their lives.

\section{Professional Guidelines and Recommendations for Youth Physical Activity}

The problems of children's physical inactivity and obesity are complex with multiple contributing individual (i.e., gender, age, ethnicity, self-efficacy) social (i.e., parental, sibling, peer support), and environmental (i.e. facility access, opportunities to be active) factors. In the interest of providing direction for those focused on promoting physical activity, a number of groups have established recommendations and guidelines for physical activity in children and adolescents (Fletcher et al., 1996; Center for Disease Control and Prevention, 1999; National Association of Sports and Physical Education, 2004b; U.S. Department of Health and Human Services, 2000, 2008, 2010).

American Heart Association. In 1996, the American Heart Association in conjunction with an expert panel produced a statement on exercise citing the benefits and recommendations for physical activity for all Americans. The expert panel stated that, "persons of all ages should include physical activity in a comprehensive program of health promotion and disease prevention and should increase their habitual physical activity to a level appropriate to their capacities, needs, and interest" (Fletcher et al., 1996, Implementation of Exercise Programs, section 1). More specifically, the expert panel suggested that children must be introduced to the principles of regular physical exercise and recreational activities at an early age. Children must be provided with numerous opportunities in school to learn skills that enable them to participate in health-enhancing physical activities within an environment that promotes positive attitudes toward physical activity and exercise (Fletcher et al., 1996).

Centers for Disease Control and Prevention. In 1999, a Report of the Surgeon General on Physical Activity and Health was authored with the main purpose of summarizing the existing literature 
on the role of physical activity in preventing disease and the status of interventions to increase physical activity. A contemporary view of physical activity was reinforced and toward that end the Surgeon General stated that:

...people who are usually inactive can improve their health and well-being by becoming even moderately active on regular basis; physical activity need not be strenuous to achieve health benefits; and greater health benefits can be achieved by increasing the amount (duration, frequency, or intensity) of physical activity (Center for Disease Control and Prevention, 1999, p.1).

Although this view primarily represented a summary of what had been learned about physical activity and health up until that point in time, recommendations and ideas for intervention were presented as well. Two major findings in the report identified promising strategies to help people incorporate more physical activity in their daily lives: (a) well-designed programs in schools to increase physical activity in physical education classes have shown to be effective and (b) carefully planned counseling by health care providers and worksite activity programs can increase individuals' physical activity levels (Center for Disease Control and Prevention, 1999).

National Association for Sport and Physical Education. In 2004, the National Association for Sport and Physical Education (NASPE) modified its earlier statement of guidelines for children ages 512. The purpose of the document was to present parents and educational professionals (including classroom, physical education teachers, and administrators) with usable recommendations to promote youth physical activity. These NASPE (2004a) guidelines included the following key recommendations:

1. Children should accumulate at least 60 minutes, and up to several hours, of age-appropriate physical activity on all, or most days of the week. The daily accumulation should include moderate and vigorous physical activity with the majority of the time being spent in activity that is intermittent in nature.

2. Children should participate in several bouts of activity lasting 15 minutes or more each day.

3. Children should participate each day in a variety of age appropriate physical activities designed to achieve optimal health, wellness, fitness, and performance benefits. 
4. Extended periods (periods of two hours or more) of inactivity are discouraged for children, especially during the daytime hours (p. 3-4).

Furthermore, NASPE released their National Standards for Physical Education which stated that "physical activity is critical to the development and maintenance of good health. The goal of physical education is to develop physically educated individuals who have the knowledge, skills and confidence to enjoy a lifetime of healthful physical activity" (National Association of Sports and Physical Education, 2004b, p.1). In August 2011, the NASPE Board of Directors appointed a task force to revise the K - 12 standards and develop a curriculum framework for physical education. Each one of the new five standards is focused on the comprehensive idea of physical activity in valuing, promoting, and participating as an individual. To pursue a lifetime of healthful physical activity our standards are used to help modify and shape behaviors in and out of schools to educate and mentor students into becoming physically literate individuals. According to NASPE National Standards for Physical Education a physically literate individual will have learned the skills necessary to participate in a variety of physical activities, know the implications and the benefits of involvement in various types of physical activities, participate regularly in physical activity, is physically fit and values physical activity and its contributions to a healthful lifestyle (American Alliance for Health, Physical Education and Dance, 2013). The following NASPE standards include:

1. The physically literate individual demonstrates competency in a variety of motor skills and movement patterns.

2. The physically literate individual applies knowledge of concepts, principles, strategies and tactics related to movement and performance.

3. The physically literate individual demonstrates the knowledge and skills to achieve and maintain a health-enhancing level of physical activity and fitness.

4. The physically literate individual exhibits responsible personal and social behavior that respects self and others. 
5. The physically literate individual recognizes the value of physical activity for health, enjoyment, challenge, self-expression and/or social interaction (p.1)

\section{U.S. Department of Agriculture and U.S. Department of Health and Human Services. Since}

1995, the U.S Department of Agriculture (USDA) and U.S. Department of Health and Human Services (USDHHS) have collaborated to implement guidelines for physical activity through their Dietary Guidelines for Americans. In 1995, physical activity guidelines were issued identifying physical activity as an important way to use food energy and that Americans should spend less time in sedentary activity and more time in moderate-to-vigorous physical activity which may help reduce body fat and risk for chronic degenerative disease. The dietary guidelines also recommend that individuals perform 30 minutes or more of moderate physical activity on most, preferably all, days of the week (U.S. Department of Agriculture \& U.S. Department of Health and Human Services, 1995).

As childhood obesity continued to increase since 1995, the recommended guidelines for children and adolescents have become more specific. According to a number of the previously described guidelines for youth physical activity, children should aim to accumulate at least 60 minutes of moderateto-vigorous physical activity most days of the week, preferably daily. The guidelines also provide a list of activities such as playing tag, jumping rope, riding a bicycle and walking, wheeling, skipping or running as activities that would help to meet the 60 minute target (U.S. Department of Agriculture \& U.S. Department of Health and Human Services, 2000). In 2008, the U.S. Department of Health and Human Services issued the Physical Activity Guidelines for Americans to complement the Dietary Guidelines for Americans; together the two documents were produced to help provide universal recommendations regarding the importance of physical activity and proper dietary behavior to promote good health and reduce the risk factors of chronic degenerative disease. The 2008 guidelines recommended that children and adolescents should perform 60 minutes or more of physical activity daily. Three major types of physical activity were recommended by the committee to be incorporated in that 60 minute total. Children and adolescents within their weekly physical activity should accumulate aerobic, muscle strengthening, and bone-strengthening physical activity as part of their accumulated 60 minutes or more 
of physical activity on at least three days of the week (U.S. Department of Health and Human Services, 2008).

\section{Achieving Recommendations for Youth Physical Activity}

In alignment with Healthy People 2020, other notable initiatives include First Lady Michelle Obama's Let's Move! Campaign, and the related partnership with the American Alliance for Health, Physical Education, Recreation, and Dance (AAHPERD), Let's Move Active Schools, which focuses on the ambitious goal of halting and reversing the epidemic of childhood obesity within one generation so that children today reach adulthood at a healthy weight. These types of large-scale initiatives call for a modification of behavioral and environmental factors by promoting active lifestyles and healthy eating through community involvement of schools, parents, healthcare providers, and other agents of change (U.S. Department of Health and Human Services, 2010). Where traditional physical activity promotion interventions that target individual factors have demonstrated limited success in promoting sustainable health-related behavior change (Marcus \& Forsyth, 1999; Marcus, Dubbert, Forsyth, McKenzie, \& Stone, 2000), we must move toward more comprehensive models of physical activity behavior intervention.

The National Physical Activity Plan for the United States, for example, provides a comprehensive set of policies, programs, and recommendations that aim to increase physical activity in all facets of the American population (National Physical Activity Plan, 2010). A coordinating committee consisting of representatives from numerous organizational partners collaborated to develop the strategies and tactics to help increase physical activity in the lives of Americans. The plan itself is organized by eight societal sectors including (a) Business, (b) Education, (c) Health Care, (d) Mass Media, (e) Parks, Recreation, Fitness and Sports, (f) Public Health, (g)Transportation, Land Use, and Community Design and (h)Volunteer and Non-Profit. During the plan development process, five overarching strategies emerged. The first strategy is to launch a grassroots advocacy effort to mobilize public support for the strategies and tactics included in the National Physical Activity Plan. Second, a national physical activity education program is needed to educate Americans about effective behavioral strategies for increasing physical activity and integrating these education efforts with other national health agencies. Third, the plan looks 
to disseminate best practices within physical activity frameworks, programs, and polices to help provide information for Americans to access and empower them to meet the federal physical activity guidelines suggested. The fourth overarching strategy is the creation of a resource center on physical activity and disease prevention to help provide Americans with effective tools for and resources to promote physical activity in their communities and schools. The fifth and final overarching strategy is to establish a center for physical activity policy development and to conduct future research across all eight sectors as the foundation for evidence-based practice. These overarching strategies highlight the need for increased collaboration across societal sectors and the need for theoretical frameworks that support these effort.

\section{Role of Schools from a Public Health Perspective}

Schools have played a crucial role in providing physical education and physical activity opportunities for American youth for more than a century. In a 1987 publication, a committee of sports medicine and school health professionals discussed the role of pediatricians as well as schools in promoting health related physical activity and fitness for children. Although many barriers were identified (e.g., access, academic performance standards, lack of facilities, concerns about safety) and

other factors have contributed to the physical inactivity of our youth, pediatricians at that time appealed to local school boards to maintain, if not increase, school physical education programming. In their recommendation, pediatricians stated that "school programs should emphasize the so-called lifetime athletic activities such as cycling, swimming, and tennis; while decreasing time spent teaching the skills used in team sports such as football, basketball, and baseball" (American Academy of Pediatrics, 1987, p. 449).

In their landmark paper, Sallis and McKenzie (1991) established the importance of school physical education from a public health perspective. The paper suggested a new rationale for teaching physical education in the schools based not only on the traditional psychomotor, cognitive, and affective domains, but also addressing a health-related component focused physical activity as the key outcome. This rationale was recommended to schools because of the evidence that emerged at that time demonstrating how the behavior of physical activity has a positive relationship with childhood, 
adolescent, and adult health. The two main goals that were proposed included preparing youth for a lifetime of physical activity and providing them with adequate amounts of moderate-to-vigorous physical activity during physical education classes. As recommendations from various organizations have described, moderate-to-vigorous physical activity has a positive effect on health and physical education is the only program within a school's curriculum that can theoretically provide every student with access to this opportunity (Sallis \& McKenzie, 1991).

In order to provide schools with an evidence-based resource to implement this contemporary view of physical education, various physical education interventions were designed, implemented, evaluated, and disseminated from a health-oriented perspective. One of the most well-documented attempts to infuse a health-related component into physical education is the Sports, Play, and Active Recreation for Kids (SPARK) program. The SPARK program was designed in response to a societal need to improve the observed low levels of children's physical fitness and activity (Sallis et al., 1997). The SPARK program was initiated in 1989 with a 7-year grant to San Diego State University from the National Institute of Health (NIH) to specifically develop and evaluate health-related PE programs for upper elementary students (McKenzie, Sallis \& Rosengard, 2009). The intended outcomes included increasing time spent in moderate-to-vigorous physical activity in physical education classes and promoting increased physical activity throughout daily routines. The SPARK program provides a coordinated curriculum package including highly active lessons and units for the physical education professional as well as classroom teachers, on-site staff development, evidence-based program resources, and expert selected content-matching equipment for each activity. The results of the SPARK intervention have been well documented and shown positive effects on physical activity and physical fitness levels among participating students (Marcoux, et al.,1999; McKenzie, Sallis, Kolody, \& Faucette, 1997; Sallis et al., 1993; Sallis et al., 1997).

A second major evidence-based physical education program that focused on incorporating a health-related component is The Child and Adolescent Trial for Cardiovascular Health (CATCH). The CATCH is a comprehensive elementary school physical activity and nutrition program. The intervention 
focuses on modifications in physical education classes, changes in school lunches, and developing an increase in family involvement. The physical education component focuses on children's enjoyment of and participation in moderate-to-vigorous physical activity during physical education classes. The results of the study indicated that moderate-to-vigorous physical activity increased by $39 \%$ and surpassed the national recommendation that $50 \%$ or more of each physical education lesson be engaged in moderate-tovigorous physical activity, compared to a 23\% increase for the control group (McKenzie et al., 1996).

The CATCH program not only concentrated on elementary programs within schools but also incorporated after-school programs, as well as early childhood centers, to help influence children and adolescents to take part in physical activity as a daily part of their lives.

Despite these advances related to comprehensive school-based intervention, alarming health trends regarding youth physical activity and fitness have continued to emerge. Researchers have reiterated that schools need to renew and expand their role in providing and promoting physical activity for our nation's youth (Pate et al., 2006; Pyle et al., 2006; Siedentop, 2009, U.S. Department of Health and Human Services, 2008). Children and adolescents spend more time in schools than any other setting with the exception of their homes. If young people are going to engage in adequate amounts of physical activity, it is essential that schools systematically and effectively provide and promote participation in physical activity (Pate et al., 2006). The school setting offers multiple opportunities for students to participate in physical activity in an enjoyable, safe, and supportive environment. Schools have the infrastructure and staffing that have the potential to promote, provide opportunities, and educate youth about the importance of physical activity and proper nutrition (Welchsler, McKenna, Lee \& Dietz, 2004).

In 2006, the American Heart Association (Pate et al., 2006) positioned a statement describing a renewed and expanded role for schools in the area of physical activity and summarizing the evidence supporting the potential of schools for effectively providing and promoting physical activity. The following recommended school policies and practices, if implemented nationally, would position America's schools into a more appropriate position of leadership in providing our youth with the physical activity needed for lifelong health. Schools should deliver evidenced-based, health-related physical 
education programs that meet the national standards for quality and quantity (i.e., 150 minutes per week for grades K-8 and 225 minutes per week for grades 9-12); are taught by a certified, highly qualified physical education teacher, and provide moderate-to-vigorous physical activity during $50 \%$ or more of class instruction. Schools must also expand physical activity opportunities to ensure that all children and youth participate in a minimum of 30 minutes of moderate-to-vigorous physical activity during the school day (i.e., physical education class, recess, classroom activity breaks) while also providing sufficient opportunities for physical activity before and after school (i.e., intramurals, walking and bicycling to school programs, interscholastic sports).

In 2007 during his Dudley Allen Sargent Commemorative Lecture, Thomas L. McKenzie presented on the preparation of physical educators from a public health perspective. Within this lecture, McKenzie acknowledged that schools are in a position to be the most cost-effective public resource to effectively address the emergent trend of physical inactivity among children and adolescents. In discussing health-related physical education (a term that commonly is used in McKenzie's SPARK research) he emphasized, "the greatest public health benefit would result from school programs increasing the activity levels of students who are sedentary, rather than directing resources to children who already physically fit and active, such as athletes" (p. 349). Reiterating the well-established position that all children need opportunities to be physically active, schools should provide that opportunity during the course of the school day in physical education classes and other activities. In order for schools to put themselves in a position to promote physical activity on their campuses and encourage progress toward lifelong physical activity, physical educators will need to learn skills that are not typically stressed in undergraduate programs. As a result schools need to play a major role in physical activity promotion and provide in-service staff development for physical educators and classroom teachers to help reverse the trend of sedentary behavior (McKenzie, 2007).

In February 2010, the First Lady of the United States launched the Let's Move! Initiative to solve the epidemic of childhood obesity within a generation (Let's Move! 2013). Within the first year of the initiative, several efforts have been initiated to engage schools in the fight against childhood obesity. The 
First Lady has called upon schools to redesign their physical education curriculum, implement more recess time for children, develop healthier ways to provide food for students, and create opportunities to partner up with community groups to provide safe places for children to play (Let's Move!, 2013). The Let's Move! Active Schools program is designed to help schools across the country make quality physical activity a part of every kid's day. The program is comprehensive and seeks to empower school champions including physical educators, classroom teachers, principals, administrators, and parents. The Let's Move! Active School program provides students with a guide to meet individual goals in physical activity in five key areas including (a) physical education, (b) physical activity during school, (c) physical activity before and after school, (d) family and community involvement, and (e) staff involvement (Let's Move! Active Schools, 2013).

After 20 years of promoting the need for a public health perspective in physical education, researchers reviewed the progress that physical education has made with respect to its impact on health, as well as the areas where progress is lacking. As demonstrated by many of the previous interventions mentioned, evidence-based research on the success of physical activity interventions (i.e. TAGG, CATCH, Let's MOVE!, SPARK) in physical education and the impact it has had on children's and adolescents health has been evident and well documented. However, it appears the physical education field as a whole have not fully embraced the public health goals that were set forth in 1991 (Sallis., McKenzie, Beets, Beighle, \& Erwin, 2012). The authors of this review discussed some of the positive developments that have occurred including: evidence-based research that has linked physical activity and fitness with positive outcomes of academic achievement amongst students (Basch, 2011; Trost \& van der Mars, 2010), federal support for school-based physical education programs including those of the First Lady in the Let's Move! initiative, state level support for school based physical education programs, and the surveillance of physical education quantity and quality through the CDC's Youth Risk Behavior Surveillance System (YRBSS). Although strides have been made, the authors have pointed out that in the United States not everyone has fully acknowledged the relationship of physical education to public health. Therefore, Sallis et al. (2012) proposed replacing the term "health-related physical education" with 
"health optimizing physical education" (HOPE). The intent of this new term is to define physical education as a framework that (a) encompasses curriculum and lessons focused on health-related physical activities and fitness, (b) keep students active for at least 50\% of class time, (c) engages all students, and (d) contributes to overall physical activity participation, thereby improving their health (Sallis et al., 2012). This new term and definition strives to slow and reverse the trend of childhood obesity while also calling on numerous stakeholders in education and public health to work together.

Recently Metzler et al. (2013) produced two articles describing this new public health perspective as in the HOPE method as a new curriculum for school programs. The article discusses the increased need for HOPE, major learning outcomes, its theoretical foundation, and program content (Metzler, McKenzie, van der Mars, Barrett-Williams \& Ellis, 2013). As a curriculum model the overall plan would guide a school or district physical education program. The model contains the program's major learning outcomes, content units, necessary resources, program policies and management, instructional methods, and assessment strategies. The overarching objective of the HOPE curriculum model is to help P-12 students acquire knowledge and skills for lifelong participation in physical activity for optimal health benefits. Additionally, the central focus on promoting lifelong physical activity behaviors is unique to physical education, compared to other school subjects. The HOPE model is designed by the programs eight strands: before-, during-, and after-school extended PA programming, sport, games, dance, and other movement forms, family/home education, community-based PA programming, health-related fitness, diet and nutrition for physical activity, physical activity literacy (consumerism, technology, advocacy) and integration of HOPE across all school subjects (Metzler, McKenzie, van der Mars, BarrettWilliams \& Ellis, 2013). As the program begins to circulate amongst physical education curriculums nationwide teachers in HOPE programs will need a greater knowledge base than what is now typically provided to pre-service teachers and available for practicing (in-service) teachers (Metzler, McKenzie, van der Mars, Barrett-Williams \& Ellis, 2013b).

In a recent collaboration with the Robert Wood Johnson foundation the Institute of Medicine (IOM) examined the status of physical activity and physical education efforts in schools, how physical 
activity and fitness affect health outcomes, and what can be done to help schools get students to become more active. The report Educating the Student Body-Taking Physical Activity and Physical Education to School was released in May of 2013. Given the exhaustive challenges and the existing evidence on physical activity interventions the committee concluded that a "whole-of-school" approach is needed to obtain maximum benefits for students. This approach will require cooperation and participation from all parties involved in a school setting, including teachers, principals, school administrators, superintendents, students, and parents. The committee suggests that to set the tone, schools need to be supported by district policies, administrators, and parents to provide access to at least 60 minutes per day of vigorous or moderate-intensity physical activity, in which more than half of which should be accomplished during regular school hours (IOM, 2013 p.2).

Within this report the policy acknowledged that schools are an ideal setting in meeting the needs of students from a public health perspective, but that some considerations or recommendations need to be acknowledged in doing so. First, the committee found that physical education should be designated as a core subject because it has appropriate values that are foundational for learning and consequently essential. Second, the committee recommended that education and public health agencies develop and analytically install data systems to monitor policies and performance pertaining to physical activity and physical education in a school setting much like English Language Arts and Mathematic data in a K-12 setting. The committee also recognized that schools have historically supported the well-being of youth from a public health perspective by providing health screenings, immunizations, and nutritional programs; consequently it follows that schools can and should play a major role in efforts to make children and adolescents more active by positioning them on a track toward better health and improved performance in their classes and life (Institute Of Medicine, 2013).

If the trend of childhood obesity has any chance to be stopped then individual school districts need to play a major role in the promotion of physical activity, and an assortment of educational agencies and state education programs need to build partnerships with schools. Various recommendations have been made across the education sector to increase the accountability for the prevention and intervention of 
physical inactivity as well as overweight and obesity rates among school-aged children and adolescents. Researchers (Lee, Burgeson, Fulton, \& Spain, 2007; Siedentop, 2009) recommended that not only are schools responsible, but federal as well as state legislators, need to improve the quantity and quality of physical education and physical activity programs in schools. A comprehensive approach to school-based physical activity intervention represents one possible way to influence our youth to demonstrate healthier lifestyles. As Lee, Burgeson, Fulton, and Spain (2007) described:

To enhance and expand physical education and physical activity programs for young people, a comprehensive approach at the state, district, school, and classroom levels is necessary. States and districts can provide more leadership by requiring schools to provide daily physical education and other physical activity opportunities before, during, and after school and by enabling schools to establish health-promoting environments that support physical activity.... With strong multilevel policies and practices, many more of our young people will be given the opportunity to become physically educated individuals and thereby establish healthy, active lifestyles as they enter adulthood (p. 462).

If schools are going to take a leadership role in promoting physical activity in children and youth a multi-level approach needs to be taken in order to influence children at various levels through the school. As we have seen over the past 40 years, the increase of overweight and obesity in our population has increased and no significant decreasing trend has been observed for any age group (Ogden, Carroll, Curtin, Lamb \& Flegal, 2010). Therefore, schools and policy leaders should adopt theoretical frameworks that focus on emphasizing the importance of multiple levels of influence and the role of the environment (school) on readiness for behavior among children and adolescents.

\section{Social Ecological Model: Framework for Physical Activity Intervention in Schools}

Initiatives such as the Let's Move! campaign and The National Physical Activity Plan are dedicated to solving the obesity epidemic within the United States while also attempting to change behavior of children through multiple influences. A common model known to change physical activity behavior using multiple levels of influence is the social ecological model. The social ecological model helps organize evidence-based influences on behavior into various levels such as intrapersonal, interpersonal, organizational, community, and policy (McLeroy, Bibeau, Steckler \& Glanz, 1988). 
Ward, Saunders, and Pate (2007) have provided the following framework to help organize influences on behavior with examples in the various levels applied to the context of physical activity (See Figure 1). The first level of the social ecological model is the individual or intrapersonal level; at this level, influences that directly affect the individual come from perceived self-efficacy or self-expectations. Increased activity is proposed to come when individuals have confidence in their ability to be active and expect or perceive benefits from being physically active.

The second interpersonal level is categorized as influences from relationships, or the way people interact in small groups or both. Common influences on behavior that have been suggested based upon theory are one's social environment, social support systems, and social influences. At this designated level, increased physical activity is proposed to come when significant others (e.g., friends, family, coworkers) provide support such as being active together or providing transportation or resources to engage in physical activity. The third level consists of organizational influences from institutions in which children or adolescents spend time (e.g., schools) and common influences on behavior are based upon the organization's policies or changes that may occur. The schools and other organizations within this level provide access to fun and enjoyable opportunities for children to engage in physical activity or have policies in place that support physical activity. The fourth level is the community level; within this level, influences form the community and environment in which children or adolescents live or spend time. Relationships between multiple organizations within the community, community development, and advocacy approaches all influence physical activity behavior when the community provides safe access to fun physical activity opportunities, reduces barriers to existing facilities, and creates new facilities or areas for additional physical activity opportunities. The last level refers to public policy at the local, state, and federal level. Regulations or policies on physical activity opportunities for children provide necessary checks and balances to help ensure that children and adolescents are receiving opportunities to engage in physical activity. Policy not only can provide regulations to impose but also necessary funding to help promote physical activity behavior change. As described above there are multiple levels of influence on physical activity in youth, multilevel interventions or programs that target these influences 
are more likely to be effective in changing behavior than those that do not, assuming that resources are sufficient to implement a multilevel approach (Ward, Saunders, Pate, 2007). Therefore, if we are going to attempt to change physical activity behaviors in children, a social ecological model needs to be implemented.

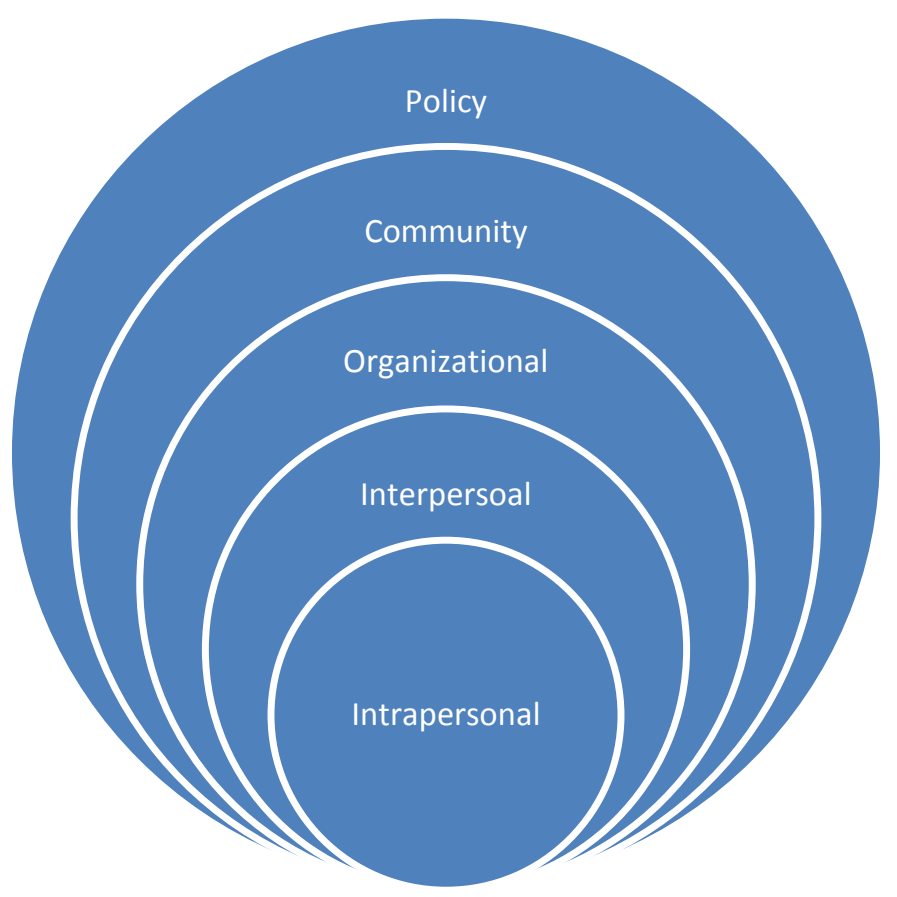

Figure 1: Graphic organizer of an ecological model for behavior change

Ecological models help us to understand how people interact with their environments. The social ecological models of health recognize that individuals bear responsibility for engaging in healthful behaviors, but the models also recognize other levels of influence on health behavior, including the physical environment, the community, society, and government (Stokols, 1996). This understanding can be used to develop effective multi-level approaches to improve certain health behaviors. The ecological model has provided public health professionals with a theoretical framework to study the complex nature of individuals' physical activity engagement (Langille \& Rodgers, 2010). More specifically, ecological theory allows public health professionals to examine and understand multiple personal and environmental 
factors and their interactive effects on youth physical activity behavior (Wang Castelli, Liu, Bian, \& Tan, 2010).

In public health, ecological models refer to individual's interaction with their physical and sociocultural surroundings (Stokols, 1992). Ecological models are known for the fact that the model calls on environmental and policy variables to help influence a change in youth physical activity behavior, while incorporating a wide range of influences at multiple levels (Sallis, Owen \& Fisher, 2008). According to Sallis et al. (2008), four core principles of ecological models of health behavior should be considered: (a) There are multiple influences on specific health behaviors, including factors at the intrapersonal, interpersonal, organizational, community, and public policy levels; (b) Influences on behaviors interact across these different levels; (c) Ecological models should be behavior-specific, identifying the most relevant potential influences at each level; and (d) Multi-level interventions should be most effective in changing behavior.

Ultimately, the main purpose of ecological models of health behavior is to influence the development of comprehensive intervention approaches that can systematically target behavior change at several levels of influence. An ecological perspective directs attention to a wide range of political and environmental factors that help mold individual and interpersonal characteristics within a community and organizational settings, such as schools (Sallis et al., 2006). Programs and interventions to improve children's health have frequently been rooted in "comprehensive school health programs" that address physical activity behaviors by making changes to the school environment (Deschensnes, Martin, Jomphe Hill, 2003).

A well-documented and evidence-based intervention that has used the social-ecological framework to address physical activity behavior has been the Trial of Activity for Adolescent Girls (TAAG). The National Heart, Lung and Blood Institute (NHLBI) sponsored TAAG, a randomized, multi-center field trial of 36 middle schools located in six different areas in the United States (Arizona, California, Louisiana, Maryland, Minnesota and South Carolina) with six schools per site, of which three were randomized to receive the TAAG intervention and measurements while three received the 
measurements only. The intervention was designed to promote physical activity in middle school students with the goal of averting the trend of a sedentary lifestyle often seen in physical activity among girls at this age level. The TAAG's primary aim was to determine if an intervention that links schools to community organizations mitigating the age-related decline in moderate-to-vigorous physical activity in middle school-aged girls.

The TAAG intervention was based in the social-ecological model, in which the intervention targeted intrapersonal variables but stressed interpersonal, organizational, policy, and other environmental factors that influence behavior change; in this case structured and unstructured physical activities in and out of school. The intervention consisted of four major components: physical education, health education with activity challenges, partnerships among TAAG investigators, schools, and community agencies for physical activity, and promotional activities (Elder et. al., 2007). Process evaluation was used to look at dose, reach and fidelity in assessing the environmental factors and quality control of the intervention. The results indicated that the intervention components were delivered from intervention staff to teachers with high fidelity in the range of 84-97\%; however lower fidelity was found in conjunction with the physical education staff using the intervention practices with students. The second objective of TAAG health education was met with $90 \%$ of TAAG lessons taught in the two-year trial, while sixty-two percent of the activity challenges were completed by the adolescent girls. The third objective concentrated on TAAG physical activity programs. Intervention schools found an increase in community collaborations with the school at $83 \%$ compared to the $44 \%$ at baseline, while opportunities for physical activity increased between the school and community, the girls involved rated the physical activity programs as highly enjoyable. The fourth objective studied was based on TAAG promotion; the first intervention used a passport challenge in which girls received stamps for participating in physical activities, only $22 \%$ of the girls participated. However, in the second year intervention, a pedometer challenge $71 \%$ of eighth grade girls participated in the promotion which met the $70 \%$ target that was originally set. The process evaluation results determined that a multi-component school and community-based physical activity intervention (the TAAG approach) of providing physical activity opportunities is feasible and acceptable 
in increasing physical activity among adolescent females (Young, Steckler, Cohen, Pratt, Felton, Moe, et. al., 2008).

In a recent study Golden and Earp (2012) analyzed previous literature concentrating on health education and behavior including interventions that have used the social ecological model. The authors developed a coding system designed to capture identified intervention activities, targets for change, behavioral health topics, program setting and theoretical bases for the interventions described in each of the articles. The results of the 157 articles reviewed suggested that 42 articles coded as physical activity as the specific behavior and the intervention setting of a school was coded in 65 articles. Overall, the authors found that articles were more likely to describe interventions focusing on the individual and interpersonal levels rather than organizational, community, and policy factors. Interventions that focused on nutrition and physical activity as well as the interventions that occurred in a school setting were able to more successfully adopt and implement a social ecological approach (Golden \& Earp, 2012).

Consequently, schools may provide an ideal environment to implement an intervention to affect physical activity change in children and adolescents from an ecological perspective.

\section{Comprehensive School Physical Activity Programs}

Schools play a major role in public health and the physical, mental, and social benefits of regular physical activity for youth have been well documented (Janssen \& LeBlanc, 2010). A multiple level physical activity intervention approach that has been recently introduced in the literature is titled Comprehensive School Physical Activity Programming (CSPAP). In 2008, National Association of Sport and Physical Education introduced a position statement recommending that all schools implement a CSPAP (A Position Statement from the National Association for Sport and Physical Education: Comprehensive School Physical Activity Program, 2008). The goal of a CSPAP is to develop a school culture that is helpful in promoting lifelong physical activity using four essential components or themes of intervention: the physical education program, before and after-school programming, staff wellness, and involvement and family and community involvement. 
Quality physical education has been documented as the foundation for CSPAP. In 2000, the Secretary of Health and Human Services along with the Secretary of Education offered a position statement in which they emphasized the importance of quality physical education in helping obtain the goals of Healthy People 2010. Within this position statement, they acknowledged that a quality physical education program is needed to provide the following elements: (a) provide intense instruction in motor skills needed to enjoy a variety of physical activities, (b) keep students active for most of the class period, (c) build students' confidence in their physical abilities, (d) influence moral development by proving opportunities to assume leadership, work with other students, and accept responsibility for their own behavior, and (e) that the program is fun (U.S. Department of Health and Human Services, \& U.S. Department of Education, 2000).

A quality physical education program can contribute to students' increased participation in physical activity as well as increased student participation in moderate-to-vigorous physical activity (Fairclough \& Stratton, 2005; Le Masurier \& Corbin, 2006; Rink, Hall, \& Williams, 2010; Sallis et al., 1997). According to the National Association of Sport and Physical Education (NASPE, 2004b), a quality physical education program should include the following:

1. Daily physical education (at least 150 minutes per week for elementary, and 225 minutes per week for middle/high school)

2. A curriculum that meets the National Standards for Physical Education

3. Student assessment aligned with instruction

4. A certified physical education teacher providing meaningful content through standards-based instruction

5. A pupil-teacher ratio equivalent to that in the classroom context

6. Adequate equipment to promote maximum practice time

Recent studies have looked at implementing these recommendations and evaluating physical activity based upon these indicators. In one particular study, Bevans, Fitzpatrick, Sanchez, Riley \& Forrest (2010) evaluated behavior of students, curriculum, and resources that were available to students 
during physical education class time. Their study identified common indicators that influence the frequency of physical education as well as the intensity of physical activity during physical education. The results of the study found that students who attended schools with a low student-to physical educator ratio had more physical education time and engaged in higher levels of physical activity during class time. Students had access to appropriate equipment and facilities were engaged in activity levels higher than those students who did not. The study demonstrated that physical education quality can be enhanced by establishing, protecting, and improving both activity promoting resources and instructional practices. As was found at the conclusion of the study providing the appropriate facilities, equipment, class size, and a certified physical educator will help enhance students' opportunities for adequate physical activity (Bevans et al., 2010). As a quality physical education program continues to be the cornerstone of CSPAP, multiple influences still are presented to increase physical activity levels in children outside the gymnasium.

The second aspect of a CSPAP, alongside a quality physical education program, is school based physical activity opportunities for children. As quality physical education is the cornerstone of a CSPAP, recent studies have shown that physical activity opportunities throughout the school day and programs occurring before and after the regular school day increase the potential for students to reach their recommended daily physical activity levels (Fuller, Sabiston, Karp, Barnett, \& O'Loughlin, 2011; Pano \& Markola, 2012; Pate et al., 2006). As children begin to progress through the educational setting different programs and strategies are provided at each level to help increase daily physical activity in children and adolescents. Common strategies used to increase physical activity opportunities during the school day at the elementary level include recess and physical activity breaks during instruction in the classroom (Dwyer et al., 2007; Rink, Hall \& Williams, 2010). Recent studies have shown that recess can be utilized to provide opportunities to accumulate an increased amount of physical activity during the course of the school day (Saint-Maurice, Welk, Silva, Siahpush, \& Huberty, 2011; Beighle, Morgan, Le Masurier, \& Pangrazi, 2006), while physical activity breaks provide an innovative strategy to promote physical activity among school children within the classroom setting (Stewart, Dennison, Kohl, \& Doyle, 2004). 
An earlier intervention Promoting Lifetime Activity for Youth (PLAY) was used to increase the physical activity rates of students in the classroom by classroom teachers. It targeted fouth, fifth and sixth grade students; activity breaks were incorporated into each school day by classroom teachers. The PLAY intervention was successful in increasing physical activity levels for both boys and girls in the tested age groups (Ernst \& Pangrazi, 1999). Active transport is another initiative that many organizations and schools have presented as the most practical and sustainable way to increase physical activity on a daily basis. Students who walk or bike to school have been shown to expend more energy overall throughout the day (Cooper, Page, Foster, \& Qahwaji, 2003). Active transportation events as well as walking initiatives have been established to help provide students with more opportunities to be physically active during the course of a school day.

As sports continue to become a part of the American household, schools can provide sporting opportunities including interscholastic sports and intramurals as a common strategy to provide before and after school opportunities to increase daily physical activity. This is one common strategy that has been used in the middle and high school level to provide more opportunities for students to participate in physical activity. Although this is a common strategy, many schools are falling short in efforts to provide extracurricular physical activity programming recommended by researchers and policy groups (Edwards, Kanters, \& Bocarro, 2011; Young et al., 2007). Although the opportunities have diminished, studies have found that intramural and interscholastic programs held before and after school can be used as an effective strategy to increase the physical activity opportunities provided by the school for its students (Beighle \& Moore, 2012; Edwards, Kanters \& Bocarro, 2011; Fuller, Sabiston, Karp, Barnett, \& O'Loughlin, 2011). Therefore, opportunities before school, during school, and after school should be accessible for children and adolescents in order for students to meet their daily physical activity needs.

School employee wellness and employee involvement is the third component of a CSPAP which plays an essential role as an influence on students, as well as an influence on the school environment to promote physical activity. Among the nation's workforce, more than 5.6 million of all working citizens in the United States are employed by school systems including teachers, administrators, support staff, 
nurses, counselors, psychologists, social workers, bus drivers, food service workers, and maintenance staff (U.S. Department of Education, 2011). These professionals form one of the most valuable workforces in the nation because of their impact and role they have in the daily interaction of shaping the health-related behavior of our children and future generations. School employee wellness programs can improve staff health, increase physical activity levels of employees, and be cost effective to both the school and healthcare costs (Eaton, Marx, \& Bowie, 2007). As schools have been identified as an environment for motivating students to lead a healthy lifestyle, school personnel have been identified as agents to model how to adopt as well as maintain healthy behaviors. The many advantages of employee wellness and involvement is that not only will faculty and staff have opportunities to maintain their health and engage in physical activity, but those who do become good role models for students as well as promote physical activity programs within the school (Rink, Hall, \& Williams, 2010).

A number of studies have documented the benefits of investing in school employee wellness programs; districts with such programs have found that participating employees where programs concentrated on physical activity, stress management, and nutrition increased teacher morale, reduced absenteesism, and resulted in higher levels of general well-being and the ability to handle job stress among teachers (Blair, et al., 1984; Green, Bush, Eldridge, \& Murray, 2010). In 2001, Washoe County School District in Nevada offered their district as a pilot for a school employee wellness program. Within this study, Aldana, Merrill, Price, Hardy, and Hager (2005) found the district offered 11 different programs to encourage school employees to engage in healthy active lifestyles. The programs focused on a variety of topics including sensible eating during holidays, reducing TV time, the importance of water, excersing for life as well as fitness challenges. The results of the study indicated that nonparticipants in the voluntary health programs had higher rates of illness-related absenteeism than employees that did participate. As for the school district itself, a cost-benefit analysis was used withing the methodology of the study and found that the district saved $\$ 15.60$ for every dollar spent on the wellness program itself. Overall, the program as a whole over a two-year period saved the district \$2.5 million dollars and employees expressed improved health and quality of life (Aldana et al., 2005). As health insurance costs 
continue to rise and educational funding is being cut in many districts, employers as well as employees need to work together to help provide health enhancing opportunities for themselves as well as the studnets within their schools.

The final component of a CSPAP is the involvement of families and the community. This concept involves making connections between the school and community in order to create and support physical activity opportunities, as well as providing access to school facilities outside school hours (American Alliance for Health, 2011). Multiple levels of influences on children to increase physical activity can be conducted at the school, inside the gymnasium, and through the faculty and staff; yet another and crucial influence is that of families and the community. The role of the school as the site based facility for students to participate is evident as we have discussed before, but schools can help promote additional physical activity opportunities for students in collaboration with community-based providers of physical activity including local YMCA's, community recreation programs, and other various community organizations.

As previously discussed, students spend a majority of their time at school, but in order to provide more opportunities for students to increase the amounts of physical activity throughout the day there needs to be exposure and increased access to children when they are not at school to set a foundation for a lifetime pursuit of physical activity (AAHPERD, 2011). Parents and families are an essential part of children's lives and can impact their physical activity opportunities as well as physical activity levels.

Research investigating the relationship among physical activity, family and community involvement, and various health outcomes in children has been scarce. Although there is limited research, studies have shown that strategies including parental engagement, increasing levels of family cohesion, and parent-child communication are essential in promoting physical activity among adolescents (Bois, Sarrazin, Brustad, Trouilloud, \& Cury, 2005; Kirby, Levin, \& Inchley, 2011; Ornelas, Perreira, \& Ayala, 2007). A recent study looking at various sociocultural correlates of physical activity in children and adolescents found four factors that are found to be significantly associated with higher physical activity levels in children. The study used a cross sectional association between sociocultural factors and 
objectively-measured physical activity in a sample of 397 children (age 9), and 213 adolescents (age 15) in which four factors were found to be associated with higher physical activity levels. The four factors included higher reported physical activity of the mother, increased parental participation and facilitation, lower age of the mother, and, higher reported activity of the father of girls (McMinn, Van Sluijs, Wedderkopp, Froberg, \& Griffin , 2008). Although parental involvement and participation were positively associated with children's physical activity in the study, parental encouragement was not, which signifies the importance of parents being involved in physical activity events with their children (McMinn et al., 2008). Many other national initiatives besides a CSPAP support the concept of family and community involvement including the National Physical Activity Plan, and Healthy People 2020 (National Physical Activity Plan, 2010; Siedentop , 2009).

\section{The Role of Leadership in a Comprehensive School Physical Activity Program.}

In order for a program to target multiple levels of influence as required in any comprehensive approach to physical activity intervention, the involved leaders need to develop a pre-requisite set of skills that will enable them to manage the various program components in an effective and engaging manner while also meeting the needs of all stakeholders. Because quality physical education represents the cornerstone of a CSPAP one might argue that the physical education teacher is ideally positioned to organize, guide, and lead this type of program for a school and community. Castelli and Beighle (2007) have suggested that physical education teachers are best positioned within the school community to address issues of physical activity and take on the role of leader within a CSPAP (Castelli \& Beighle, 2007); ultimately the physical education teacher is the only individual in the school formally trained to provide developmentally appropriate physical activity opportunites. However, no matter how wellpositioned the physical educator may be, most physical educators do not see directing a CSPAP as their responsibility, nor have they been prepared for this type of leadership position (Rink, 2012).

The future readiness of physical educators and other personnel to provide comprehensive physical activity interventions in schools is likely to be dependent on a number of factors including the revision of "undergraduate and graduate courses of study to reflect contemporary health needs, and prepare teachers 
to implement evidence-based HOPE [health-optimizing physical education]) (Sallis, McKenzie, Beets, Beighle, Erwin, \& Lee, 2012, p. 132). For example, McKenzie (2007) argued that the preparation of physical educators to address societal expectations regarding this new public health role would require the (a) modification of content preparation in teacher education programs to include behavioral theories and strategies, determinants of childhood physical activity, and environmental factors and modifications impacting health-related behavior; (b) increased diversity of field placements to include community-based and family-based physical activity programs; and (c) development of the promotion, advocacy, and politicking skills needed to influence decision-makers at various levels. Many of these recommendations are supported by Bulger and Housner (2007) who employed a modified Delphi method "to determine the critical exercise science competencies and associated instructional methods recommended for inclusion in the physical education teacher education curriculum" (p. 57)

In 2009, Beighle et al. proposed an overview of the pre-requisite basic skills and knowledge base that a Director of Physical Activity (DPA) would need in order to sucessfully implement a CSPAP concentrating on the following four topic areas: organization and administration, advocacy, physical activity, and public health. The organization and administration skills highlight the need for the DPA to be widely versed in (a) orgranizing and managing events, tasks, and groups, (b) understanding basic concepts related to marketing physical activity to students, and (c) having strong communication skills related to verbal and written interaction with multiple audiences ranging from parents, faculty, administrators, physicians, and students.

Advocacy refers to the cause of supporting an increase in physical activity for all major stakeholders served by a CSPAP including students, faculty, staff, and families. The DPA must possess competencies related to collaboration, staff development, and networking in order to motivate all stakeholders to support the initiative. As the literature has indicated, a CSPAP initiative needs to involve various stakeholders to help bring about sustainable change (Carson, 2012; Rink, Hall, \& Williams, 2010). The DPA must be able to gain support from school administrators, influential community leaders, and various community groups in order to establish and develop the program. The DPA also needs to 
train staff in order to improve the school culture as related physical activity during the school day, before and after school activites, and opportunities for faculty and staff to increase physical activity in their daily routines (Heidorn \& Centeio, 2012 ).

Physical activity is another requisite topic that a DPA should have knowledge and understanding about, it is also the driving force of a CSPAP. As research has shown increased amounts of physical activity can benefit the health of people of all ages (McKenzie, 2007; National Association for Sport and Physical Education, 2004b; U.S. Department of Health and Human Services, 2008). In the United States individuals are not engaging in enough minutes of moderate-to-vigorous physical activity, while our schools are not providing enough physical activity opportunities for children. The role of the DPA then needs to have requisite skills to offer physical activity opportunities before,during, and after school school without disrupting the educational environment. As Beighle et al. (2009) suggested, the DPA's many roles require an array of skills and competencies to foster physical activity in school, community, and family homes (Beighle et al., 2009).

The fourth major requisite topic calls for DPAs to be proficient in understanding the importance of physical activity promotion from a physical educaiton and public health perspective. Educators need to be prepared to teach goal setting and self management skills that students can use to monitor their own behaviors, including physical activity levels (McKenzie, 2007). Mckenzie (2007) also suggested that for schools to play a major role in physical activity promotion, in-service staff development programs require significant revision.

Recently, the National Association of Sport and Physical Education created a certification program based upon an ecological perspective with the purpose of providing professional development for inservice teachers. Upon completition of the certification process physical education teachers will be able to immplement the CSPAP model. Participants will also learn to understand physical activity from a public health perspective; enhance the existing physical education program bycoordinating physical activity opportunities across the curriculum, advocate for physical activity programming, effectively communicate and market physical activity programming, foster community collaborations while being 
able to plan physical activity events and train other adults to provide and supervise physical activity opportunities (NASPE Director of Physical Activity (DPA) Certificate Program, 2013).

While these initial efforts to develop school personnel to bring about transformational changes regarding physical activity intervention in schools represents an important staring point, there is a need for additional research related to the leadership of these types of comprehensive approaches from a more theoretical perspective. The general research suggests that the ideal type of leadership framework that would be effective in implementing school change would be that of a transformational leader. Proposed by Leithwood and colleagues in the late 1980s and early 1990s, studies have demonstrated the positive relationships between transformational leadership and various school and teacher organizational conditions (Anderson, 2008). Transformational leadership can be described as a process of influencing major changes in the attitudes and assumptions of organization members and building commitment for the organization's mission or objectives. Transformational leadership is empowering and inspirational; it elevates leaders and followers to higher levels of motivation and morality (Hackman \& Johnson, 2004). Transformational leadership has four primary functions. First, transformational leaders serve the needs of others, empower them and inspire followers to achieve success. Second, they charismatically lead, set a vision that provides people with a sense of purpose, instill trust, and ultimately provide pride in the workforce. Third, with the intellectual stimulation presented in this framework, leaders promote innovative ways of viewing situations and working with follwers to stimulate intelligent problem solving and decision making. Finally, leaders provide personal attention and encouragement to their employees, in which they devote significant energy in leading and respect the gifts and talents of their workers (Bryant, 2003). Within this framework, the school becomes less bureaucratic and it functions as its own agent of change. Instead of empowering selected indiviuals, the school as a whole becomes empowered as an organization.

Recent articles have emphasized that in order for CSPAP to meet its full potential, a director of physical activity (DPA) needs to assume this role (Beighle et al., 2009; Castelli \& Beighle, 2007; Rink, Hall, \& Williams, 2010). The DPA serves as the school leader who coordinates, oversees, and ultimately 
initiates the CSPAP efforts. Carson (2012) stated, "a major aspect of this leadership role is the recruitment of teachers, parents, students, and community stakeholders who are willing to collaborate in these efforts" (p. 17). Accordingly, the leader's transformational leadership behaviors become more important especially within a school environment where, as an agent of change, they influence not only faculty, staff, and students but also the society in which the school is located. Although some researchers have suggested that the physical education teacher is the ideal agent of change within the school, a recent survey on CSPAP suggests otherwise. The 2011 CSPAP Survey was created to better understand the extent to which schools across the United States have been implementing components of a CSPAP. The 2011 CSPAP survey was a baseline survey that measured progress and assessed trends related to physical activity in an eduational setting. The identified key findings indicated that less than one sixth of the schools, $16 \%$ of elementary schools, $13 \%$ of middle schools, and $6 \%$ of high schools were currently providing all components of CSPAP. Recent strategies from the survey suggest that districts can provide much needed coordination and support for their schools by employing a district physical education coordinator, while within individual schools, the principal can set the tone that physical education and physical activity are valued by requesting that teachers incorporate physical activity into each day (American Alliance for Health, 2011). As educational funding across the United States continues to be cut, schools face budgeting concerns, as well as the reality of reducing programs, faculty, and staff. Therefore, the the realistic implementation of a DPA seems unfeasible in many schools and school districts across the United States.

As previously suggested, the school or district administrator needs to be a key leader to help implement a coordinated program. Coordinated programs in school settings are often comprehensive such as a CSPAP and they need to include both intsructional and policy changes to encourgae youth to be more physically active. A coordinated program will have a committee or team that serves as a coordinating body and is made up of teachers, school officials, parents, and other community members. The district or school leader would be the ideal candidate to lead and implement the importance of physical activity in the educational setting through an empowerment process. 
Empowerment is a major characteristic of a transformational leader and has also been a key topic discussed within educational leadership and school change. The most general definition of the concept of empowerment was proposed by Vash (1991), who described empowerment as anything that is contrued as being motivating can be regarded as empowering. Early research on empowerment was conducted by Zimmerman and colleagues (1988) who proposed a conceptual model of psychological empowerment consisting of three components: intrapersonal, interactional, and behavioral. The intrapersonal component refers to how people think about their capacity to influence social and polictal systems that are important to them. The interactional component includes knowledge about needed resources and problem-solving skills, whereas the behavioral component denotes the actions that are taken to apply influence through participation in organizations and activities (Zimmerman, 1990; Zimmerman \& Rappaport, 1988; Zimmerman, Israel, Schulz, \& Checkoway, 1992). Although the concept is not easily defined, Page and Czuba (1999) define empowerment as a multi-dimensional social process that helps people gain control over their own lives. It is a process that fosters power in people for use in their own lives, their communites and in their society, by acting on issues they define as important (Page \& Czuba, 1999). With a working definition, school leaders can help inluence members of the community and key staff or faculty of the school to begin the process of implementation and sustainability through empowerment.

Empowerment is key to organizational survival and in many cases, reducing power differentials often enhaces group performance. In a coordinated setting such as the CSPAP, empowering others from one leader can be a daunting task, but Hackman and Johnson (2004) explained five major reasons why leaders not only choose to share power but ultimately need to do so in an organizational setting. First, in an organizational setting distributing power increases the job satisfaction and performance of employees. People who ultimately enjoy their jobs become more invested, feel they have a significant voice in making decisions, and work to accomplish goals (Ostroff, 1992). Second, sharing power fosters greater cooperation among group members. Cooperation in turn, increases group accomplishment. Third, distributing power means collective survival; the group endures rather than fails. Fourth, effective 
leadership helps personal growth and learning. Empowerment is one way to encourage growth; sharing power with others can help them tackle new challenges, learn new skills, and find gratification. Fifth, sharing power prevents power abuses. Leaders who distribute power are less likely to abuse their positions or to take advantage of their workers (Hackman \& Johnson, 2004). In many casses sharing power or empowering others can work best when leaders understand the components of the empowerment process and are prepared with proposed strategies to help guide and implement.

The major empowerment approach that this proposed study will concentrate on is the leadership approach to empowerment. The research on the leadership approach emphasizes the energizing aspect of empowerment on employees. Leaders are energetic, charsimatic, and vibrant in an empowerment process and provide a vision for the future that their employees relate to and work to obtain. Major contributors to the resarch on the leadership approach have found that the leaders empower followers by providing direction and necessary resources for followers to be successful within the organization (Bass \& Avolio, 1993; Conger, 1989).

Within the leadership approach framework, the empowerment process consists of three major components. The first refers to the environment. In this process the environment is described as the setting where work occurs. Important elements of the environment include aspects such as reward systems, job tasks, organizational structure and workflow, and the physical layout. The first step in the empowerment process is often the elimination of situational factors that create feelings of powerlessness (Conger, 1989). In this case "modifying the environment" shifts the decision making authority to followers within the group. Second, is supplying necessary resources for your followers to be successful. Hackman and Johnson (2004) stated, "that no follower, no matter how motivated, can complete a task if she/he does not have adequate funds and supplies, enough time to devote to the job, and a place to work" (Hackman \& Johnson, 2004, p. 142). Within the supplying resource component, the leader needs to provide adequate training, political support of the group, and provide necessary materials and data that will assist the group in making quaility data driven infomred decisions. The final compement consists of the leader helping the follower or worker in building a sense of personal power (intrinsic motiviation). 
Workers who believe that they can deal with people, events, or situations within their environment and who have a sense of self-efficacy or personal power are more likely to succeed in difficult situations. Leaders can build followers' perceptions of their personal power by providing positive emotional support during times of stress and anxiety, expressing confidence, modeling successful performance and structuring tasks so that followers experience success. (Conger \& Kanungo, 1988). With all of these components in place, the leader can concentrate on a leadership approach to empower his or her followers.

If change is going to occur on a large scale in schools, a transformational leader needs to be at the forefront creating a vision and implementing policies. Researchers have indicated a transformational leader is one who can influence major changes in the attitudes and assumptions of an organization since these leaders can be empowering, inspirational, and they can elevate individuals to higher levels of motivation and morality (Anderson, 2008; Bryant, 2003; Hackman \& Johnson, 2004). This designated leader, through the use of the empowerment process, can work to coordinate an effort to help implement a CSPAP within his/her individual school or district. The empowerment process emphasizes three major components in which the leader influentially energizes his/her followers to ultimately obtain goals and the vision of the organization. The first component consists of modifying the environment, the second is supplying necessary resources for followers to be successful and the third consists of the leader helping the follower or workers in building a sense of personal power (Conger, 1989; Conger \& Kanungo, 1988). Researchers have found that shared power through the empowerment process can help elevate the organization, increase job satisfaction of followers, and create a sense of shared decision making (Bass \& Avolio, 1993; Conger, 1989; Hackman \& Johnson, 2004, Ostroff, 1992). 


\section{References}

A Position Statement from the National Association for Sport and Physical Education: Comprehensive School Physical Activity Program. (2008). Strategies: A Journal for Physical and Sport Educators, 21(6), 29-33.

Aldana, S. G., Merrill, R. M., Price, K., Hardy, A., \& Hager, R. (2005). Financial impact of a comprehensive multisite workplace health promotion program. Preventive Medicine, 40(2), 131137.

American Academy of Pediatrics . (1987). Physical Fitness And The Schools. Pediatrics, 80(3), 449-450.

American Alliance for Health, Physical Education, Recreation and Dance. (2011). 2011 Comprehensive school physical activity program(CSPAP) survey report. Reston, VA: American Alliance for Health, Physical Education, Recreation and Dance.

American Alliance for Health, Physical Education, Recreation and Dance. (2013). Grade-level outcomes for K-12 physical education. Reston, VA: Author.

Anderson , K. D. (2008). Transformational Teacher Leadership in Rural Schools. Rural Educator, 29(3), $8-17$.

Basch, C. E. (2011, October). Healthier Students Are Better learners: A Missing Link in School Reforms to Close the Achievement Gap. Journal of School Health, 81(10), 593-598.

Bass, B. M., \& Avolio, B. J. (1993). Transformational Leadership and Organizational Culture. Public Administration Quarterly, 17(1), 112-121. Retrieved June 26, 2013, from http://www.jstor.org/stable/40862298 .

Beighle, A., \& Moore, M. (2012). Physical Activity Before and After School . The Journal of Physical Education, Recreation \& Dance, 25-28.

Beighle, A., Castelli, D., Erwin, H., \& Ernst, M. (2009). Preparing Physical Educators for the Role of Physical Activity Director. The Journal of Physical Education, Recreation \& Dance, 80(4), 2429. 
Beighle, A., Morgan, C. F., Le Masurier, G., \& Pangrazi, R. P. (2006). Children's Physical Activity During Recess and Outside of School. Journal of School Health, 76(10), 516-520.

Bergh, I. H., Bjelland, M., Grydeland, M., Lien, N., Andersen, L. F., Klepp, K.-I., . . Ommundsen, Y. (2012). Mid-way and post-intervention effects on potential determinants of physical activity and sedentary behavior, results of the HEIA study- a multi-component school-based randomized trial. International Journal Of Behavioral Nutrition and Physical Activity, 9(63), 1-13.

Bevans, K. B., Fitzpatrick, L.-A., Sanchez, B. M., Riley, A. W., \& Forrest, C. (2010). Physical Education Resources, Class Management, and Student Physical Activity Levels: A Structure-ProcessOutcome Approach to Evaluating Physical Educaiton Effectiveness. Journal of School Health, 80(12), 573-580.

Blair, S. N., Collingwood, T. R., Reynolds, R., Smith, M., Hagan, R., \& Sterling, C. L. (1984). Health Promotion for Educators: Impact on Health Behaviors, Satisfaction, and General Well-Being. American Journal Of Public Health, 74(2), 147-149.

Bois , J., Sarrazin, P. G., Brustad, R. J., Trouilloud, D. O., \& Cury, F. (2005). Elementary schoolchildren's perceived competence and physical activity involvement: the influence of parents' role modelling behaviors and perceptions of their child's competence . Psychology of Sport and Exercise, 381397.

Bryant, S. E. (2003). The Role of Transformational and Transactional Leadership in Creating, Sharing and Exploiting Organizational Knowledge. The Journal of Leadership and Organizational Studies, 9(4), 32-44.

Bulger, S. M., \& Housner, L. D. (2007). Modified Delphi Investigation of Exercise Science in Physical Education Teacher Education. Journal Of Teaching In Physical Education, 26(1), 57-80.

Bulger, S.M., \& Housner, L.D. (2009). Relocating from easy street: strategies for moving physical education forward. Quest, 61, 442-469.

Carson, R. (2012). Certification and Duties of a Director of Physical Activity. The Journal of Physical Education, Recreation \& Dance, 16-29. 
Caspersen, C. J., Powell, K. E., \& Christenson, G. M. (1985, March-April ). Physical Activity, Exercise, and Physical Fitness: Definitions and Distinctions for Health-Related Research. Public Health Reports (1974-), 100(2), 126-131.

Castelli, D. M., \& Beighle, A. (2007). The Physical Education Teacher as School Activity Director. The Journal of Physical Education, Recreation \& Dance, 78(5), 25-28.

Castelli, D., Hillmann, C., Buck, S., \& Erwin, H. (2007). Physical fitness and academic achievement in third and fifth grade students. Journal of Sport and Exercise Pscychology, 29, 239-252.

Center for Disease Control and Prevention . (1999). 1999 Physical Activity and health: a Report of the Surgeon General . Washington, DC: U.S. Department of Health and Human Services .

Centers for Disease Control and Prevention. (2010). State Indicator Report on Physical Activity. Atlanta, GA: U.S. Department of Health and Human Services.

Centers for Disease Control and Prevention. (2011). Youth Risk Behavior Survey. Retrieved February 2, 2013, from Centers for Disease Control and Prevention: http://www.cdc.gov/HealthyYouth/yrbs/index.htm

Conger, J. (1989). Leadership: The Art of Empowering Others. The Academy of Management Executive, 3(1), 17-24. Retrieved June 25, 2013, from http://www.jstor.org/stable/4164863

Conger, J. A., \& Kanungo, R. N. (1988). The Empowerment Process: Integrating Theory and Practice. The Academy of Management Review, 13(3), 471-482. Retrieved June 25, 2013, from http://www.jstor.org/stable/258093

Cooper, A. R., Page, A. S., Foster, I. J., \& Qahwaji, D. (2003). Commuting to school: Are children who walk more physically active? American Journal of Preventive Medicine, 273-276.

Deschensnes, M., Martin, C., \& Jomphe Hill, A. (2003). Comprehensive approaches to school health promotion: How to achieve broader implementation? Health Promotion International, 18, 387396. 
Dwyer, J. J., Allison, K. R., LeMoine, K. N., Faulkner, G. J., Adlaf, E. M., Goodman, J., \& Lysy, D. C. (2007). A Survey of Opportunities for School-based Physical Activity in Ontario Elementary Schools. Physical \& Health Education Journal, 73(4), 36-42.

Eaton, D. K., Marx, E., \& Bowie, S. E. (2007). Faculty and staff health promotion: results from the school health policies and programs study 2006. Journal of School Health, 77(8), 557-566.

Edwards, M. B., Kanters, M. A., \& Bocarro, J. N. (2011). Opportunities for Extracurricular Physical Activity in North Carolina Middle Schools. Journal of Physical Activity \& Health, 8(5), 597-606.

Elder, J. P., Lytle, L., Sallis, J. F., Young, D. R., Steckler, A., Simons-Morton, D., . . Ribisl, K. (2007). A description of the social-ecological framework used in the trial of activity for adolescent girls (TAAG). Health Education Research, 22(2), 155-165.

Ernst, M. P., \& Pangrazi, R. P. (1999). Effects of a physical activity program on children's activity levels and attraction to physical activity. Pediatric Exercise Science, 11, 393-405.

Fairclough, S., \& Stratton, G. (2005). Physical education makes you fit and healthy: Physical education's contribution to young people's physical activity levels. Health Education Research, 20(1), 14-23.

Fletcher, G., Balady, G., Blair, S., Blumenthal, J., Caspersen, C., Chaitman, B., . . Pollack, M. (1996). Statement on Exercise: Benefits and Recommendations for Physical Activity Programs for All Americans. Circulation(94), 857-862. doi:10.1161/01.CIR.94.4.857

Fuller, D., Sabiston, C., Karp, I., Barnett, T., \& O'Loughlin, J. (2011). School Sports Opportunities Influence Physical Activity in Secondary School and Beyond. Journal of School Health, 81(8), 449-454.

Golden, S. D., \& Earp, J. L. (2012). Social Ecological Approaches to Individuals and Their Contexts: Twenty Years of health Education \& Behavior Health Promotion Interventions. Health Education \& Behavior, 39(3), 364-372.

Green, T., Bush, C. L., Eldridge, J. Z., \& Murray, T. D. (2010). Absenteeism and Presenteeism Considerations for School-site Health Promotion and Employee Wellness in Texas. TAHPERD Journal, 78(2), 8-10. 
Hackman, M. Z., \& Johnson, C. E. (2004). Leadership: A Communication Perspective (4th ed.). Long Grove, IL: Waveland Press, Inc.

Hackman, M.Z., \& Johnson, C.E. (2013). Leadership: A Communication Perspective (6 ${ }^{\text {th }}$ ed.) Long Grove, IL: Waveland Press, Inc.

Heidorn, B., \& Centeio, E. (2012). The Director of Physical Activity and Staff Involvement. The Journal of Physical Education, Recreation \& Dance, 83(7), 13-26.

Hills, A., King, N., \& Armstrong, T. (2007). The Contribution of Physical Activity and Sedentary Behaviours to the Growth and Development of Children and Adolescents: Implications for Overweight and Obesity. Sports Medicine, 37(6), 533-546.

Institute of Medicine. (2013). Educating the Student body-Taking Physical Activity and Physical Education to School. Washington, DC: Institute of Medicine of The National Academies.

Jago, R., \& Baranowski, T. (2004). Non-curricular Approaches for Increasing Physical Activity In Youth: A Review. Preventive Medicine, 39(1), 157-163.

Janssen, I., \& LeBlanc, A. (2010). Systematic review of health benefits of physical activity and fitness in school aged children and youth. International Journal of Behavioral Nutrition and Physical Activity, 1-16.

Kane, M., \& Trochim, W. M. (2007). Concept Mapping for Planning and Evaluation. Thousand Oaks : Sage Publications, Inc.

Kelly, C. M., Baker, E. A., Brownson, R. C., \& Schootman, M. (2007). Translating research into practice: Using concept mapping to determine locally relevant intervention strategies to increase physical activity. Evaluation and Program Planning, 30, 282-293.

Kirby, J., Levin, K. A., \& Inchley, J. (2011). Parental and Peer Influences on Physical Activity Among Scottish Adolescents: A Longitudinal Study. Journal of Physical Activity \& Health, 8(6), $785-$ 793. 
Langille, J. D., \& Rodgers, W. M. (2010). Exploring the Influence of a Social Ecological Model on School Based Physical Activity. Health Education \& Behavior, 37(6), 879-894.

Le Masurier, G., \& Corbin, C. (2006). Top 10 reasons for quality physical education. Journal of Physical Education, Recreation and Dance, 77(6), 44-53.

Lebel, A., Cantinotti, M., Pampalon, R., Theriault, M., Smith, L. A., \& Hamelin, A.-M. (2011). Concept mapping of diet and physical activity: Uncovering local stakeholders perceptions in the Quebec City region. Social Science \& Medicine, 72, 439-445.

Lee, S. M., Burgeson, C. R., Fulton, J. E., \& Spain, C. G. (2007). Physical Education and Physical Activity: Results From the School Health Policies and Programs Study 2006. Journal of School Health, 77(8), 435-463.

Let's Move. (2013, May 20). Retrieved from letsmove.gov: www.letsmove.gov/first-lady-columnhealthier-schools

Let's Move Active Schools. (2013, May 20). Retrieved from letsmoveschools: www.letsmoveschools.org Lounsbery, M.A.F., McKenzie, T.L., Trost, S., \& Smith, N.J. (2011). Facilitators and barriers to adopting evidence-based physical education in elementary schools. Journal of Physical Activity \& Health 8, S17-S25.

Marcoux, M. F., Sallis, J. F., McKenzie, T. L., Marshall, S., Armstrong, C. A., \& Goggin, K. (1999). Process Evaluation of Physical Activity Self-Managment Program For Children: SPARK. Psychology \& Health, 14(4), 659-677.

Marcus, B. H., \& Forsyth, L. H. (1999). How are we doing with physical activity? American Journal of Health Promotion, 14(2), 118-124.

Marcus, B., Dubbert, P., Forsyth, L., McKenzie, T., \& Stone, E. J. (2000). Physical activity behavior change: issues in adoption and maintenance. Health Psychology, 19, 17-32.

McKenzie , T. L., Nader, P. R., Strikmiller, P. K., Yang, M., Stone, E. J., Perry, C. L., \& Kelder, S. H. (1996). School physcial education: Efect of the Child and Adolscent Trial for Cardiovascular Health. Preventive Medicine, 25, 423-431. 
McKenzie, T. (2007). The Preparation of Physical Educators: A Public Health Perspective . Quest, 345357.

McKenzie, T. L., Sallis, J. F., \& Rosengard, P. (2009). Beyond the Stucco Tower: Design, Development, and Dissemination of the SPARK Physical Education Programs. Quest, 61(1), 114-127.

McKenzie, T. L., Sallis, J. F., Kolody, B. B., \& Faucette, F. N. (1997). Long-term effects of a physical education curriculum and staff developemnt program: SPARK. Research Quarterly for Exercise \& Sport, 68(4), 280-291.

McLeroy, K., Bibeau, D., Steckler, A., \& Glanz, K. (1988). An ecological perspective on health promotion programs. Health Education Quarterly, 15(4), 351-377.

McMinn, A. M., Van Sluijs, E. F., Wedderkopp, N., Froberg, K., \& Griffin , S. J. (2008). Sociocultural Correlates of Physical Activity in Children and Adolescents: Findings From the Danish Arm of the European Youth Heart Study. Pediatric Exercise Science, 20(3), 319-322.

Metzler, M. W., Mckenzie, T. L., Van Der Mars, H., Barrett-Williams, S. L., \& Ellis, R. (2013). A New Curriculum for School Programs Part I: Establishing the Need and Describing the Model. JOPERD: The Journal Of Physical Education, Recreation \& Dance, 84(4), 41-47.

Metzler, M. W., Mckenzie, T. L., Van Der Mars, H., Barrett-Williams, S. L., \&

Ellis, R. (2013b). HEALTH OPTIMIZING PHYSICAL EDUCATION (HOPE). JOPERD: The Journal Of Physical Education, Recreation \& Dance, 84(5), 25-34.

Moving into the Future: National Standards for Physical Education, 2nd Edition. (2004a). Retrieved January 26, 2012, from National Association for Sport and Physical Educaiton: http://www.aahperd.org/naspe/standards/nationalStandards/PEstandards.cfm NASPE Director of Physical Activity (DPA) Certificate Program . (2013, January 20). Retrieved from National Association for Sport and Physical Education : http://www.aahperd.org/naspe/professionaldevelopment/dpa/ 
National Education Association. (2013). U.S. Department of Education Discreationary Funding (excluding Federal Pell Grants): Fiscal Years 2003-2013. National Education Association. Retrieved June 26, 2013, from www.nea.org/assets/docs/FY2003-13-ED-Discretionary-ex-PellBaseline-vs-Actual.pdf

National Association for Sport and Physicla Education. (2008a). Comprehensive school physical activity programs [Position statement]. Reston, VA: Author.

National Association for Sport and Physical Education (2008b). National standards and guidelines for physical education teacher education ( $3^{\text {rd }}$ ed.). Reston VA: Author.

National Physical Activity Plan. (2010, May). Retrieved March 19, 2013, from The US National Physical Activity Plan: http://www.physicalactivityplan.org/NationalPhysicalActivityPlan.pdf

Ogden, C., Carroll, M., Curtin, L., Lamb, M., \& Flegal, K. (2010). Prevalence of High Body Mass Index in US Children and Adolscents 2007-2008. Journal of American Medical Association, 303(3), 242-249.

Olsen, E. \& Chrispeels, J. (2009). A pathway forward to school change: Leading together and achieving goals. Leadership and Policy in Schools, 8, 380-419.

Ornelas , I., Perreira, K. M., \& Ayala, G. X. (2007). Parental influences on adolescent physical activity: a longitudinal study. International Journal of Behavioral Nutrition \& Physical Activity, 43(10). doi:doi:10.1186/1479-5868-4-3

Ostroff, C. (1992). The Relationship Betweeen Satisfaction, Attitudes, and Performance: An Organizational Level Analysis. Journal of Applied Psychology, 77, 963-974.

Page, N., \& Czuba, C. (1999). Empowerment: What Is It? The Jouranl of Extension, 37(5), 1-5.

Pano, G., \& Markola, L. (2012). 14-18 Years old children attitudes, perception and motivation towards extra curricular physical activity and sport. Journal of Human Sport \& Exercise, 7(1), S51-S66.

Pate, R. R., Davis, M. G., Robinson, T. N., Stone, E. J., McKenzie, T. L., \& Young, J. C. (2006). Promoting Physical Activity in Children and Youth: A Leadership Role for Schools. Circulation, $114,1214-1224$. 
Patel , M. X., Doku, V., \& Tennakoon, L. (2003). Challenges in recruitment of research participants. Advances in psychiatric treatment journal of continuing professional development, 229-238.

Patton, M.Q. (2002). Qualitative Research \& Evaluation Methods $\left(3^{\text {rd }}\right.$ ed.) Thousand Oaks, CA: Sage Publications, Inc.

Pellegrini, A., \& Smith , K. (1993). School recess: implications for education and development. Review of educational research, 63(1), 51-67.

Pellegrini, A., Kato, K., Blatchford, P., \& Baines, E. (2002). A short-term longitudinal study of childrnen's playground games across the first year of school: implications for social competence and adjustment to school. American Educational Research Journal, 39(4), 991-1015.

Physical Activity for Children: A Statement of Guidelines for Children Ages 5-12, 2nd Edition. (2004b). Retrieved January 26, 2012, from National Association for Sport and Physical Education: http://www.aahperd.org/naspe/standards/nationalGuidelines/PA-Children-5-12.cfm

Pyle, S. A., Sharkey, J., Yetter, G., Felix, E., Furlong, M. J., \& Poston, W. C. (2006). Fighting An Epidemic: The Role of Schools In Reducing Childhood Obesity. Psychology in the Schools, 43(3), 361-376. doi:10.1002/pits.20146

Ries, A. V., Voorhees, C. C., Gittelsohn, J., Roche, K. M., \& Astone, N. M. (2008). Adolescents' Perceptions of Environmental Influences on Physical Activity. American Journal of Health Behavior, 32(1), 26-39.

Rink , J. (2012). The Role of Directors of Comprehensive School Physical Activity Programs-Part 1: Introduction. JOPERD: The Journal of Physcial Education, Recreation \& Dance, 15-29.

Rink, J., Hall, T., \& Williams, L. (2010). Schoolwide Physical Activity: A Comprehensive Guide to Designing and Conducting Programs. Champaign: Human Kinetics .

Saint-Maurice, P., Welk, G., Silva, P., Siahpush, M., \& Huberty, J. (2011). Assessing Children's Physical Activity Behaviors at Recess: A Multi-Method Approach. Pediatric Exercise Science, 23(4), 585599. 
Sallis , J. F., McKenzie, T. L., Alcaraz, J. E., Kolody, B. B., Hovell, M. F., \& Nader, P. R. (1993). Project SPARK: effects of physical educaiton on adiposity in children. Annals Of The New York Academy of Sciences, 699, 127-136.

Sallis , J., Owen , N., \& Fisher, E. (2008). Ecological models of health behavior. Health behavior and health education: Theory, research, and practice, 4, 465-486.

Sallis, J. F., \& Glanz, K. (2006). The role of built environments in physical activity, eating, and obesity in childhood. Future Child, 16(1), 89-108.

Sallis, J. F., \& McKenzie, T. L. (1991). Physical Education's Role in Public Health. Research Quarterly for Exercise and Sport, 62, 124-137.

Sallis, J. F., McKenzie, T. L., Alcaraz, J., Kolody, B., Faucette, N., \& Hovell, M. (1997). The effects of a 2-year physical education program (SPARK on physical activity and fitness in elementary school students. American Journal of Public Health, 87, 1328-1334.

Sallis, J. F., McKenzie, T. L., Beets, M. W., Beighle, A., Erwin, H. \& Lee, S. (2012). Physical Education's Role in Public Health: Steps Forward and Backward Over 20 Years and Hope for the Future. Research Quarterly for Exercise and Sport, 83(2), 125-135.

Sallis, J., Cervero, R., Ascher, W., Henderson, K., Kraft, M., \& Kerr, J. (2006). An ecological approach to creating active living communities. Annual Review of Public health, 27, 297-322.

Sallis, J., McKenzie, T., Kolody, B., Lewis, M., Marshall, S., \& Rosengard, P. (1999). Effects of healthrelated physical education on academic achievement: Project SPARK. Research Quarterly in Sport and Exercise, 70(2), 127-134.

Sibley, B., \& Etnier, J. (2003). The relationship between physical activity and cognition in children: a meta-analysis. Pediatric Exercise Science, 15(3), 243-256.

Siedentop , D. L. (2009). National Plan for Physical Activity: Education Sector. Journal of Physical Activity and Health, 6, S168-S180. 
Stewart, J. A., Dennison , D. A., Kohl III, H. W., \& Doyle, J. A. (2004). Exercise Level and Energy Expenditure in the Take 10! In-Class Physical Activity Program. Journal of School Health, 74(10), 397-400.

Stokols. (1992). Establishing and maintaing healthy environments: toward a scoial ecology of health promotion. American Psychologist, 47, 6-22.

Stokols, D. D. (1996). Translating social ecological theory into guidelines for community health promotion. American Journal of Health Promotion, 10(4), 282-298.

Strong, W., Malina, R., Blimkie, C., Daniels, S., Dishman, R., Gutin, B., . . Pivarnik, J. (2005). Evidence based physical activity for school-age youth. Journal of Pediatrics, 146(6), 732-737.

Trochim, W. \& Linton, R. (1986). Conceptualization for planning and evalution. Evaluation and Program Planning, 9(4), 289-304.

Trochim, W. (1989). An introduction to concept mapping for planning and evaluation. Evaluation and Program Planning, 12(1), 1-16.

Trochim, W. (1993). The reliability of concept mapping. Conference of the American Evaluation Association. Dallas.

Trost, S. G., \& van der Mars, H. (2010). Why We Should Not Cut P.E. Educational Leadership, 67(4), $60-65$.

Trudeau, F., \& Shephard, R. (2008). Physical Education, school physical activity, school sports and academic performance. International Journal of Behavioral Nutrition and Physical Activity, 1-12. doi:10.1186/1479-5868-5-10

U.S. Department of Agriculture \& U.S Department of Health and Human Services . (1995). Dietary Guidelines For Americans. Retrieved February 1, 2013, from Health.Gov: http://www.health.gov/dietaryguidelines/dga95/9dietgui.htm

U.S. Department of Education. (2011). U.S. Department of Education, National Center for Education Statistics. Retrieved May 2013, from Digest of education statistics tables and figures: http://nces.ed.gov/programs/digest/d11 
U.S. Department of Health and Human Services . (1996). Physical activity and health: A report of the Surgeon General . Atlanta: Center for disease control and Prevention.

U.S. Department of Health and Human Services. (2008). 2008 Physical activity guidelines for Americans. Washington, DC: United States Government Printing Office.

U.S. Department of Health and Human Services. (2000). Health people 2010: Understanding and improving health (2nd ed). Washington, DC: United States Government Printing Office.

U.S. Department of Health and Human Services. (2010). Healthy People 2020. Retrieved January 18, 2013, from Healthy People.gov: http://www.healthypeople.gov/2020/topicsobjectives2020/overview.aspx?topicId=33

U.S. Department of Health and Human Services. (2010). The Surgeon General's Vision for a Healthy and Fit Nation. Rockville, MD: U.S. Department of Helath and Human Services, Office of the Surgeon General.

U.S. Department of Health and Human Services. (2010). Strategies to Improve the Quality of Physical Education. Washington, DC: United States Government Printing Office.

U.S. Department of Health and Human Services. (2012). Healthy People 2010 Final Review. Hyattsville: National Center for Health Statistics.

U.S. Department of Health and Human Services. (2012). Physical Activity Guidelines For Americans Midcourse Report: Strategies to Increase Physical Activity Among Youth. Washington, DC: U.S. Department of Health and Human Services. Retrieved March 28, 2013, from www.health.gov/paguidelines/midcourse/pag-mid-course-report-final.pdf

U.S. Department of Health and Human Services, \& U.S. Department of Education. (2000). Promoting better health for young people through physical activity and sports. Retrieved May 29, 2013, from Centers for Disease Control and Prevention: www2.ed.gov/offices/osdfs/physedrpt.pdf United States Department of Agriculture \& United States Department of Health and Human Services. (2000). Nutrition and Your Health: Dietary Guidelines for Americans. Retrieved February 1, 
2013, from

http://www.cnpp.usda.gov/Publications/DietaryGuidelines/2000/2000DGProfessionalBooklet.pdf

Vash, C. L. (1991). More Thoughts on Empowerment. Journal of Rehabilitation, 57(4), 13-16.

Wang, J., Castelli, D. M., Liu, W., Bian, W., \& Tan, J. (2010). Re-Conceptualizing Physical Education Programs From An Ecological Perspective. Asian Journal Of Exercise \& Sports Science, 7(1), 43-53.

Wang, Y. C., Gortmaker, S. L., Sobol, A. M., \& Kuntz, K. M. (2006). Estimating The Energy Gap Among US Children: A Counterfactual Approach. Pediatrics, 118(6), 1721-1733.

Ward, D. S., Saunders, R. P., \& Pate, R. R. (2007). Physical Activity Interventions in Children and Adolescents . Champaign: Human Kinetics .

Wechsler, H., McKenna, M. L., Lee, S. M., \& Dietz, W. H. (2004). The role of schools in preventing childhood obesity. State Education Standard, 5(2), 4-12.

Young, D. R., Felton, G. M., Grieser, M., Elder, J. P., Johnson, C., Lee, J., \& Kubik, M. Y. (2007). Policies and Opportunities for Physical Activity in Middle School Environments. Journal of School Health, 77(1), 41-47.

Young, D. R., Steckler, A., Cohen, S., Pratt, C., Felton, G., Moe, S. G., . . Raburn, B. (2008). Process Evaluation Results from a School- and Community-Linked Intervention: The Trial of Activity for Adolescent Girls (TAAG). Health Education Research, 23(6), 976-986.

Zhang, T., Solomon, M. A., Gao, Z., \& Kosma, M. (2012). Promoting School Students' Physical Activity: A Social Ecological Perspective. Journal of Applied Sport Psychology, 24(1), 92-105.

Zimmerman, M. A. (1990). Taking Aim On Empowerment Research: On the Distinction Between Psychological and Indiviual Conceptions. American Journal of Community Psychology, 18, 169177.

Zimmerman, M. A., \& Rappaport, J. (1988). Citizen Participation, Percevied Control, and Psychological Empowerment. American Jouranl of Community Psychology, 16, 725-750. 
Zimmerman, M. A., Israel, B. A., Schulz, A., \& Checkoway, B. (1992). Further Exploration In Empowerment Theory: An Emperical Analysis of Psychological Empowerment. American Jouranl of Community Psychology, 20, 707-727. 


\section{Appendix B: Brainstorming Protocol}

\section{Pre Notification Email:}

Dear Colleague,

I am writing to request your participation as an expert respondent for my dissertation research, being conducted at West Virginia University, which focuses on the identification of the knowledge, skills, and behavioral competencies that a school leader needs to develop in order to implement a comprehensive school physical activity program (CSPAP). You were selected to participate based on your knowledge of school-based physical activity interventions.

The concept mapping method being employed is a structured process for organizing the ideas of a group of key stakeholders and facilitating the development of a common framework that can be used for resultant decision-making. The initial phase of the concept mapping process allows for the generation of ideas in response to a single open-ended prompt using an online survey platform. Your contribution to this initial phase of the research project is of critical importance and it will take approximately 15 minutes to complete the online survey.

The list of ideas that you help to brainstorm or generate will be sorted and rated by a select panel of experts including researchers and K-12 practitioners during the second phase of the concept mapping process. Participants in the brainstorming phase will have the option of contributing to the sorting and rating phase at a later date.

You must be 18 years of age or older to participate. Your participation in any part of this research is completely voluntary and greatly appreciated. You may skip any questions that you do not wish to answer during the process and may discontinue at any time. West Virginia University's Institutional Review Board acknowledgement of this project is on file.

Within the next week, you will receive a follow-up e-mail with a link to the previously described survey. I also invite you to forward this pre-notification email and the forthcoming survey link to any K-12 practitioners you know who are or have successfully implemented components of a CSPAP within their individual schools and/or school districts.

Should you have any questions about this letter or the research project, please contact me directly at (716) 868-1479 or by e-mail at killg@amherstschools.org

Sincerely,

Kiel Illg, Ph.D., PhD Candidate

West Virginia University

Sean M. Bulger, Associate Professor

West Virginia University 


\section{Phase I Letter:}

Dear Colleague,

This letter is to request your participation in a research project to identify the knowledge, skills, and behavioral competencies that a school leader needs to develop in order to implement a comprehensive school physical activity program (CSPAP). This project is being conducted by Kiel Illg, M.S. in the College of Physical Activity and Sport Sciences at West Virginia University, with supervision of Dr. Sean M. Bulger, an associate professor in the College of Physical Activity and Sport Sciences, for a Ph.D. in Kinesiology.

Your participation in this initial phase of the research project is greatly appreciated and it will take approximately 15 minutes to fill out the linked survey which asks your response to a single open-ended prompt: http://conceptsystemsglobal.com/physicalactivityprogram/brainstorm

The survey will be available for 2 weeks and we request that you complete it no later than $3 / 21 / 14$. We also invite you to forward this email to any K-12 practitioners you know who are or have successfully implemented components of a CSPAP within their individual schools and/or school districts. Their very important input is also required!

Your involvement in this project will be kept as confidential as legally possible. All data will be reported in the aggregate. You must be 18 years of age or older to participate. I will not ask any information that should lead back to your identity as a participant. Your participation is completely voluntary. You may skip any question that you do not wish to answer and you may discontinue at any time. West Virginia University's Institutional Review Board acknowledgement of this project is on file.

I hope that you will participate in this research project, as it could be beneficial in understanding the professional development needs of pre-service and in-service teachers related to the comprehensive school physical activity programming. Thank you very much for your time. Should you have any questions about this letter or the research project, please feel free to contact Kiel Illg at (716) 868-1479 or by e-mail at killg@amherstschools.org.

Thank you for your time and help with this project.

Sincerely,

Kiel Illg, M.S.

Ph.D. Candidate

Sean M. Bulger Ph.D. Associate Professor

Sean.Bulger@mail.wvu.edu 304-293-0845 


\section{Phase I Reminder Letter:}

Dear Participant,

We recently contacted you about participating in a research study to identify the knowledge, skills, and behavioral competencies that a school leader needs to develop in order to implement a comprehensive school physical activity program (CSPAP). This is just a reminder that the survey is still available online for you to complete until 3/23/14.

Your participation in this initial phase of the research project is greatly appreciated and will take approximately 15 minutes to fill out the linked survey. The survey involves your response to a single open-ended prompt: http://conceptsystemsglobal.com/physicalactivityprogram/brainstorm

If you have already completed Phase I, I strongly encourage you to participate in phase II-Sorting and Rating of statements of the study by filling out the google survey at the following link: http://docs.google.com/a/amherstschools.org/forms/d/1Sz_V7G8XbMX8CMhp9ygS9xcLQ1oU3bzAo_6 nv_F3hjs/viewform

Your involvement in this project will be kept as confidential as legally possible. All data will be reported in the aggregate. You must be 18 years of age or older to participate. I will not ask any information that should lead back to your identity as a participant. Your participation is completely voluntary. You may skip any question that you do not wish to answer and you may discontinue at any time. West Virginia University's Institutional Review Board acknowledgement of this project is on file.

I hope that you will participate in this research project, as it could be beneficial in understanding the professional development needs of pre-service and in-service teachers related to the comprehensive school physical activity programming. Thank you very much for your time. Should you have any questions about this letter or the research project, please feel free to contact Kiel Illg at (716) 868-1479 or by e-mail at killg@amherstschools.org

Thank you for your time and help with this project.

Sincerely,

Kiel Illg, M.S.

Ph.D. Candidate

College of Physical Activity and Sport Sciences 


\section{Telephone Recruitment Script:}

If calling the potential participant:

Sample Phone Script

"May I speak to (state name)? This is from the WVU College of Physical Activity

and Sport Sciences. I am a (researcher or research assistant) working with the "Competencies of a School Leader Implementing a Comprehensive School Physical Activity Program: A Concept Map Design" study. I recently contacted you by email with information about the research study and wanted to see if you were interested in participating. It will involve completing two rounds of a concept mapping design, which will ask you to generate statements in regards to leadership in a comprehensive school physical activity program and also to rate and sort those statements. The process will take about 20 minutes to complete each phase. Would you be willing to participate in the two rounds of the study?"

- If yes: "Great! We will be in touch via email with the electronic link to the website".

- If no: Thank the subject and end the phone call.

If leaving message on voicemail:

Sample Voicemail Script

"Hello, this message is for (say name). It is (say the date) at (say the time). My name is from the WVU College of Physical Activity and Sport Sciences. I am a (researcher or research assistant) working with the "Competencies of a School Leader Implementing a Comprehensive School Physical Activity Program: A Concept Map Design” study. I recently sent you an email describing the research study and I was calling see if you would be interested in participating. It will involve completing two rounds of a concept mapping design, which will ask you to generate statements in regards to leadership in a comprehensive school physical activity program and also to rate and sort those statements. The process will take about 20 minutes to complete each phase Please contact us at 716-868-1479 or email at killg@amherstschools.org if you are interested. We hope to hear from you soon." 
If the potential subject calls back, proceed with the following:

Thank you for calling us back. We would like to see if you would be interested in participating in this research to assist in the identification of relevant leadership competencies that should be integrated into a comprehensive school physical activity program being conducted by WVU College of Physical Activity and Sport Sciences. It would involve completing two phases of an electronic concept mapping software which will ask you to provide your expert opinion about competencies related to comprehensive school physical activity programming and then rating and sorting those statements. Each phase should take about 20 minutes to complete. Would you be willing to participate?

- If yes: "Great! We will be in touch via email with the electronic link to the website".

- If no: Thank the subject and end the phone call. 


\section{Brainstorming Software:}

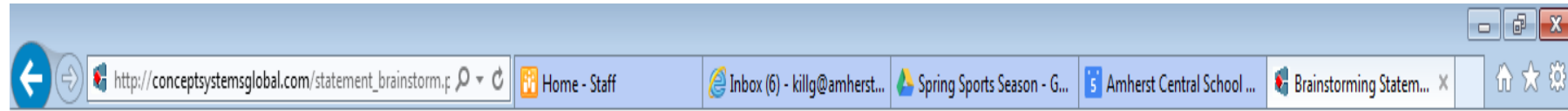
File Edit View Favorites Tools Help

X 国鹖

Competencies of a School Leader Implementing a Comprehensive School Physical Activity Program: A Co...

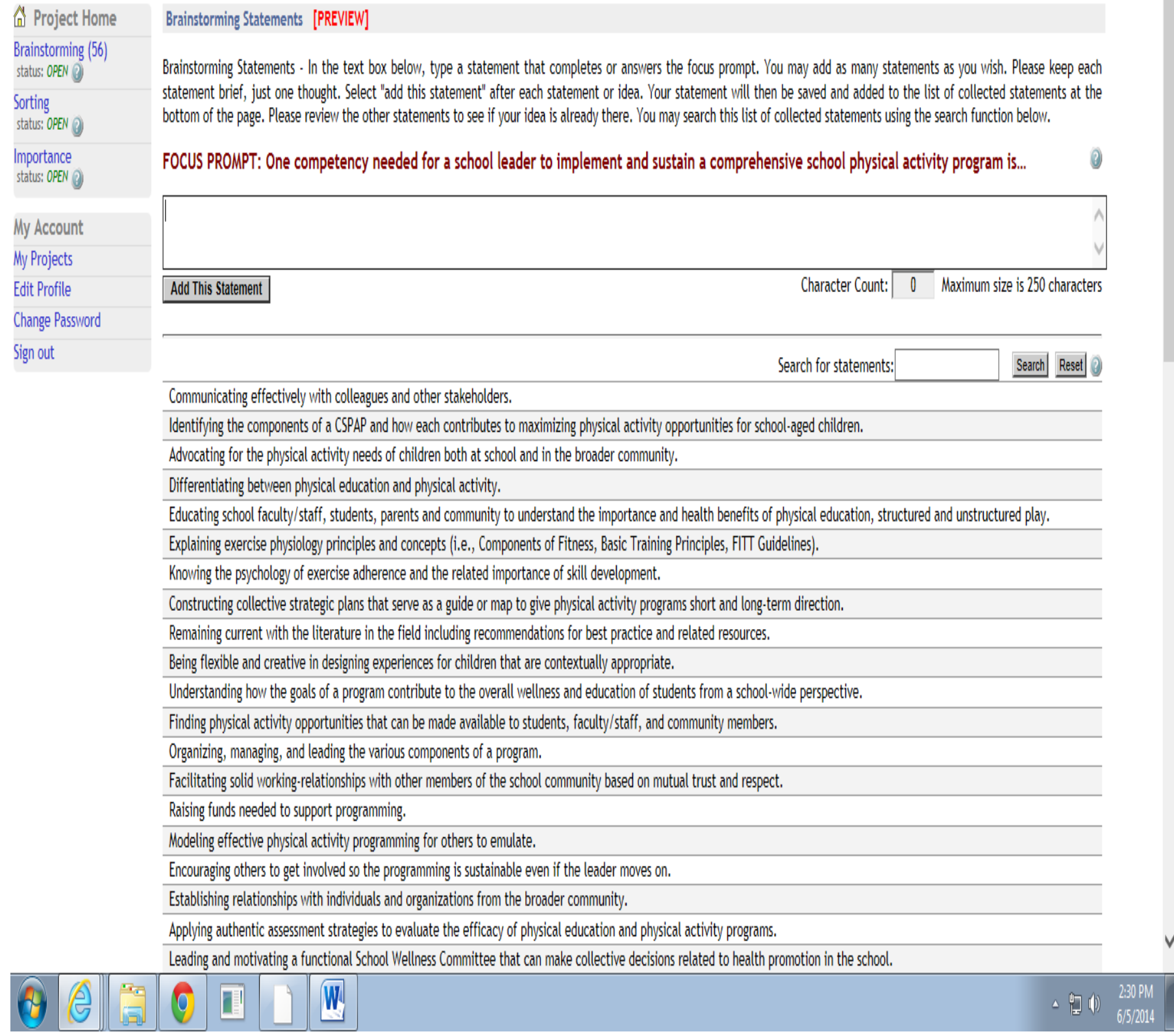




\section{Appendix C: Structuring Ideas Protocol}

\section{Phase II Letter:}

Dear Participant,

We recently contacted you about participating in a research study to identify the knowledge, skills, and behavioral competencies that a school leader needs to develop in order to implement a comprehensive school physical activity program (CSPAP). Thanks again for agreeing to serve as an expert panel member for Phase II of that process. Your contribution and expertise are greatly appreciated!

We invite you to complete a second online survey where you will be prompted to sort and rate a set of previously brainstormed competencies related to the implementation of a CSPAP. This research study has been reviewed and acknowledged by the West Virginia University IRB and your participation in this phase of the research project will take approximately 20 minutes.

You will designate a username and password that will allow you to access the survey. You do not have to answer all of the questions, and you can quit at any time. Participation in the study is voluntary and your responses will be kept confidential. There is no penalty if you choose not to participate in the research study. Your contact information will not be shared for any purpose outside of this study.

The survey will be available for 2 weeks after today; we ask that you please complete it no later than $4 / 22 / 2014$. You need not complete the survey in one sitting. In order to complete the survey, please click on the following link: http://conceptsystemsglobal.com/physicalactivityprogram/sort/rate

I hope that you will participate in this research project, as it could be beneficial in understanding the professional development needs of pre-service and in-service teachers related to the comprehensive school physical activity programming. Thank you very much for your time. Should you have any questions about this letter or the research project, please feel free to contact Kiel Illg at (716) 868-1479 or by e-mail at killg@amherstschools.org .

Sincerely,

Kiel Illg, M.S.

Ph.D. Candidate

College of Physical Activity and Sport Sciences 


\section{Phase II Reminder Letter:}

Dear

We recently contacted you regarding participating in the second phase of our research study to develop competences for successful implementation and sustainability of a Comprehensive School Physical Activity Program (CSPAP). This is just a reminder that the second survey is still available online for you to complete. Please disregard this notice if you have already completed the survey. This research study has been reviewed and acknowledged by the West Virginia University IRB.

We invite you to complete a second online survey where you will be asked to sort and rank a set of statements with respect to the impact and sustainability in implementing a CSPAP in 21st century schools. These statements are the recommendations that emerged from the first survey.

Your participation in the study would involve completing an online survey and should take approximately 30 minutes to complete. You will designate a username and password that will allow you to access the survey. You do not have to answer all of the questions, and you can quit at any time. Participation in the study is voluntary and your responses will be kept confidential. There is no penalty if you choose not to participate in the research study. Your contact information will not be shared for any purpose.

We ask that you please complete the survey no later than You need not complete the survey in one sitting. In order to complete the survey, please click on the following link: http://conceptsystemsglobal.com/physicalactivityprogram/sort/rate

If you have any questions or concerns, please don't hesitate to contact me via email or phone. Thank you for your time and consideration.

Sincerely,

Kiel Illg 


\section{Concept Map Sorting Software:}

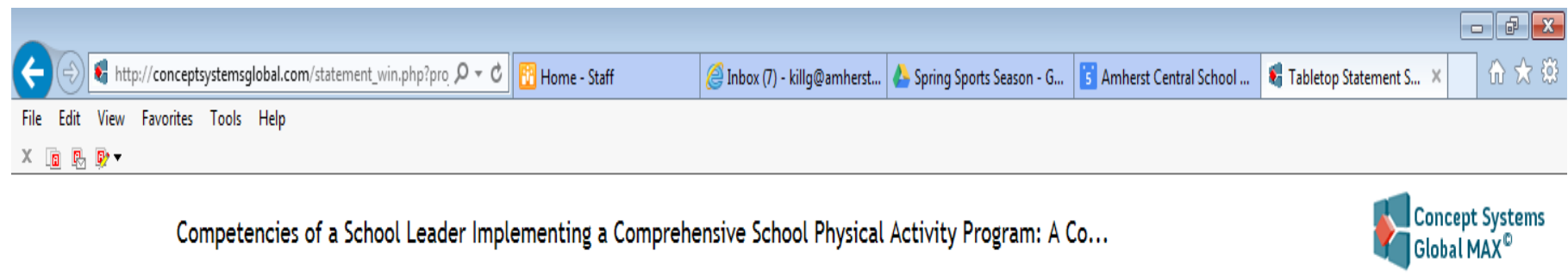

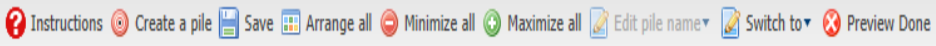

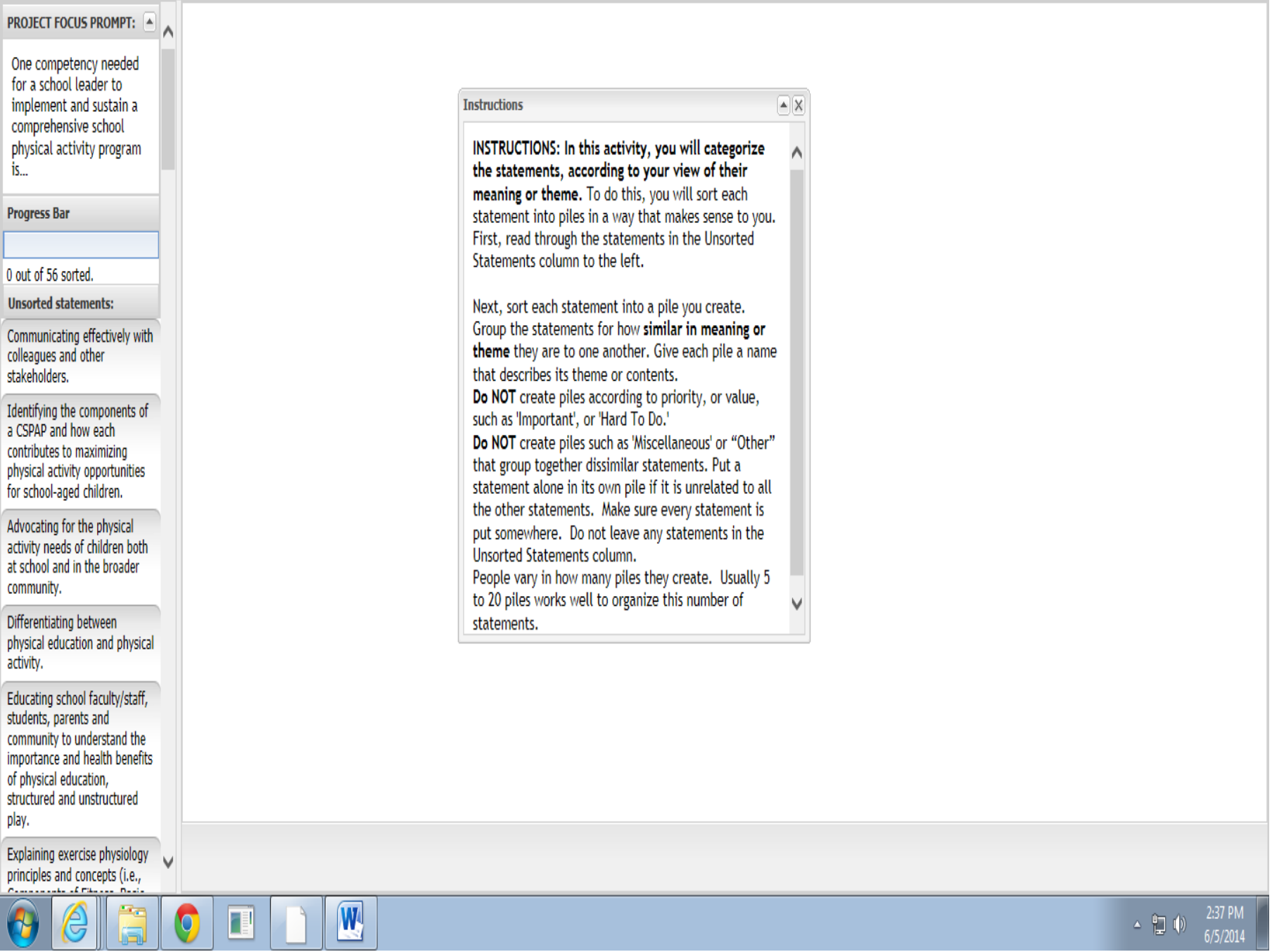




\section{Concept Map Rating Software:}

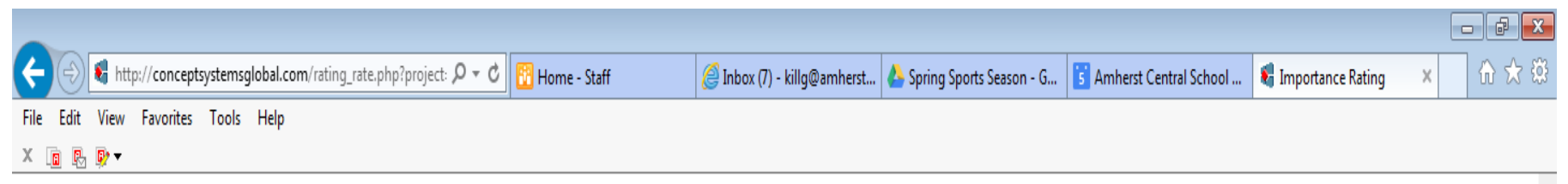

Competencies of a School Leader Implementing a Comprehensive School Physical Activity Program: A Co...

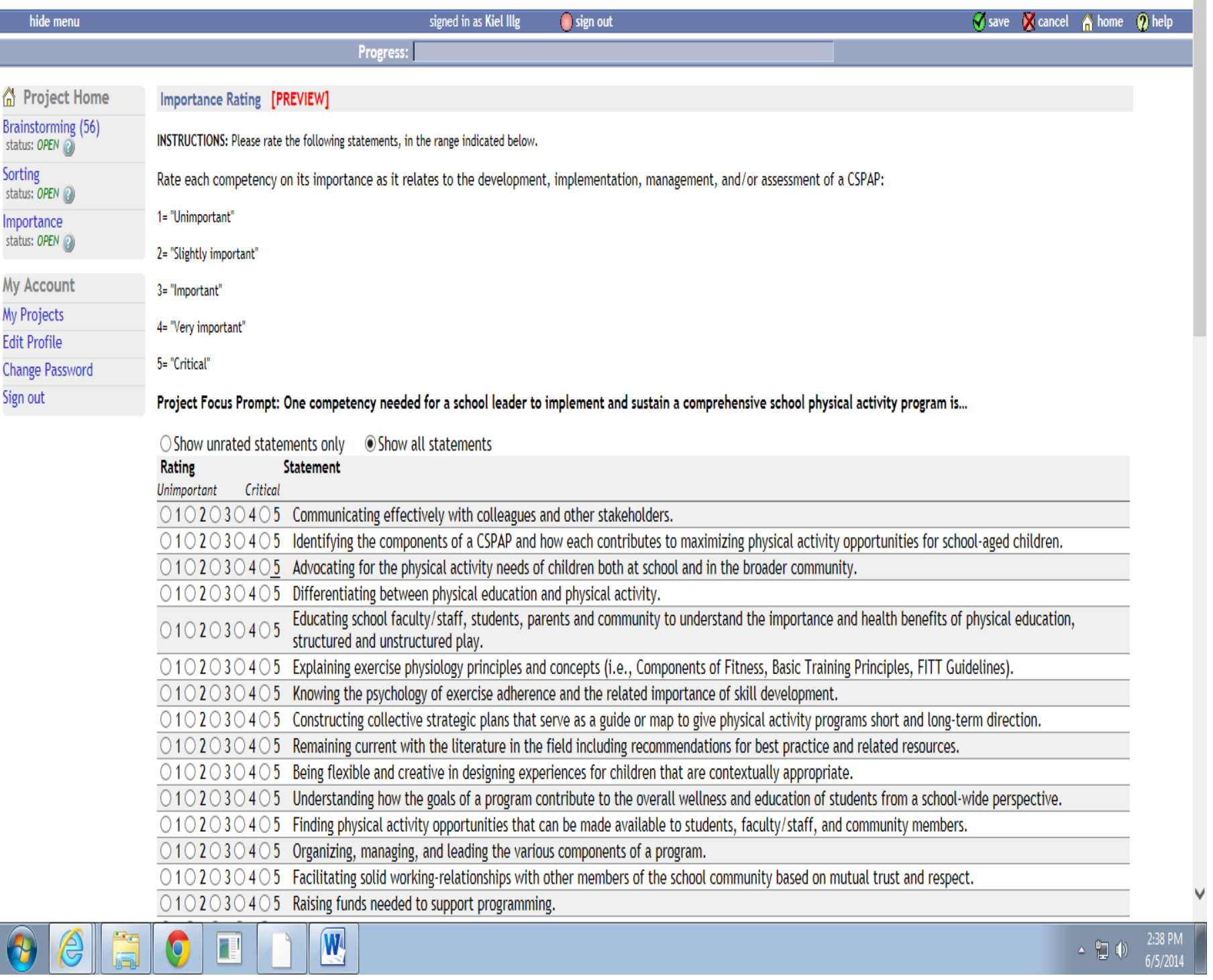




\section{Appendix D: Interview Protocol}

\section{Interview Email:}

Dear Participant,

Good Afternoon. You have been selected to participate in a semi-structured interview to verify the clustering of results and to discuss approaches for preparing professionals to implement a comprehensive school physical activity program. The interviews will be audio recorded and I will be using handwritten notes to capture your responses as well. I was hoping to set up an interview time with you as soon as possible preferably during 5/12/14-5/18/14. If you can send some available dates and times that you would be available I would greatly appreciate it. Hope to hear from you soon. Once again thank you for taking the time to participate in this final phase of the study.

Sincerely,

Kiel Illg, M.S.

Ph.D. Candidate

College of Physical Activity and Sport Sciences 


\section{Interview Script:}

Good Morning or Afternoon,

First, thank you for taking the time to participate in this semi structured interview. The purpose of this interview will be structured around verifying the cluster groupings that the results of the survey yielded and second to discuss approaches for preparing professionals at pre-service and in-service levels to adapt and embed these competencies into their professions.

- Have you had an opportunity to review the executive summary? (If not give time to find and make sure participant has as a resource)

- We will be using the executive summary as a reference to verify the cluster groups.

\section{Validation/Verification of Go Zone Maps and Cluster Groupings:}

1. Looking at the first cluster grouping (Teambuilding/Facilitating Skills) would you say that the title adequately represents the competencies that were sorted together in that grouping? (Yes or No)

a. If not what recommendations do you have as a title?

b. Holistically looking at this cluster what does this grouping mean to you? (ie. Job, CSPAP)

i. Could you tell me more about your thinking on that?

2. Looking at the second cluster grouping (Funding) would you say that the title adequately represents the competencies that were sorted together in that grouping? (Yes or No)

a. If not what recommendations do you have as a title?

b. Holistically looking at this cluster what does this grouping mean to you? (ie. Job, CSPAP)

i. Could you tell me more about your thinking on that?

3. Looking at the third cluster grouping (Knowledge of Pedagogy) would you say that the title adequately represents the competencies that were sorted together in that grouping? (Yes or No)

a. If not what recommendations do you have as a title?

b. Holistically looking at this cluster what does this grouping mean to you (ie. Job, CSPAP)

i. Could you tell me more about your thinking on that?

4. Looking at the fourth cluster grouping (Content Knowledge) would you say that the title adequately represents the competencies that were sorted together in that grouping? (Yes or No)

a. If not what recommendations do you have as a title?

b. Holistically looking at this cluster what does this grouping mean to you (ie. Job, CSPAP)

i. Could you tell me more about your thinking on that? 
5. Looking at the fifth cluster grouping (Creating and Implementing) would you say that the title adequately represents the competencies that were sorted together in that grouping? (Yes or No)

a. If not what recommendations do you have as a title?

b. Holistically looking at this cluster what does this grouping mean to you (ie. Job, CSPAP)

i. Could you tell me more about your thinking on that?

\section{Implications for Professional Preparation:}

1. What practical implications do the cluster or go zone statements have for the professional preparation of educators at the undergraduate or graduate level in physical education teacher education programs?

2. What implications would these results have on the continuing professional development for all personnel including administrators, classroom teachers, coaches, teacher assistants etc?

3. Are you aware of any physical education teacher education programs that are doing well in preparing educators to be physical activity leaders?

4. Can you give an example of any continuing professional development in your districts or higher education programs to continue developing physical activity leaders?

5. Are there any innovative programs that can you provide examples of that are doing this well? (ie. implementing CSPAP, Clusters, preparing PAL etc.)

Are there any other thoughts you would like to share in relevance to this study?

Thank you for your time, I appreciate the information you have provided, just to make you aware I hope to share my findings at upcoming national and state conferences in order to help provide more support in advocating and politicking for comprehensive school physical activity programming. 


\section{Executive Summary:}

\section{Point Map}

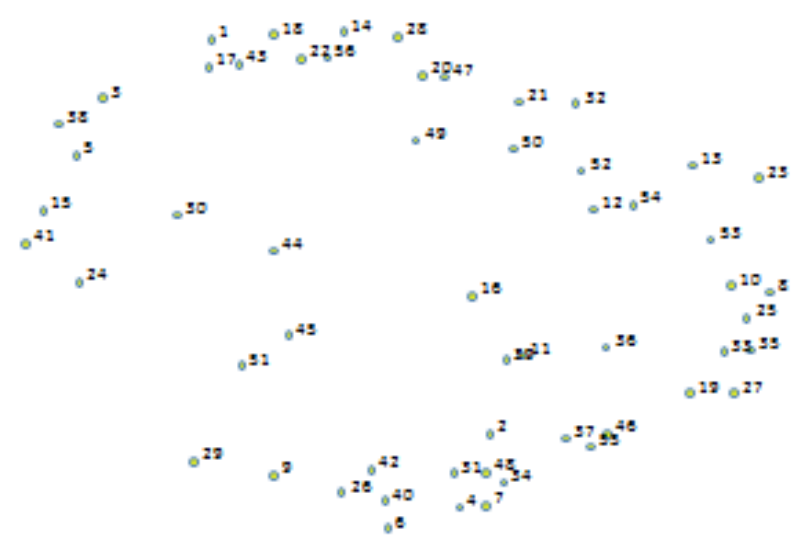

Displays relationship of the statements in proximity of ideas to one another placed by multidimensionalscaling.

\section{Cluster Map 1}

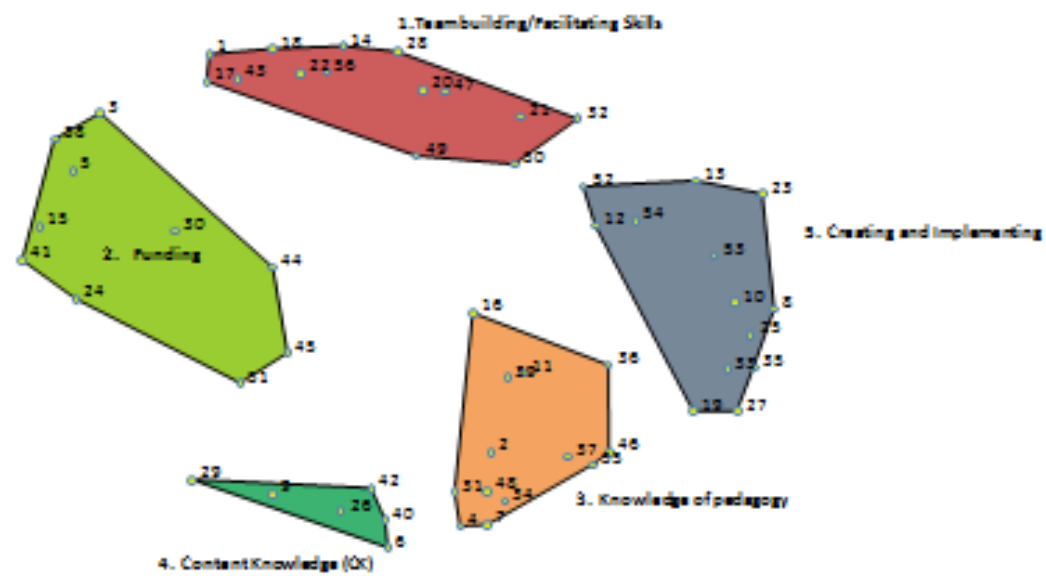

Displays how statements were grouped together based upon the cluster anaiysis. 


\section{Cluster Rating Map 1}

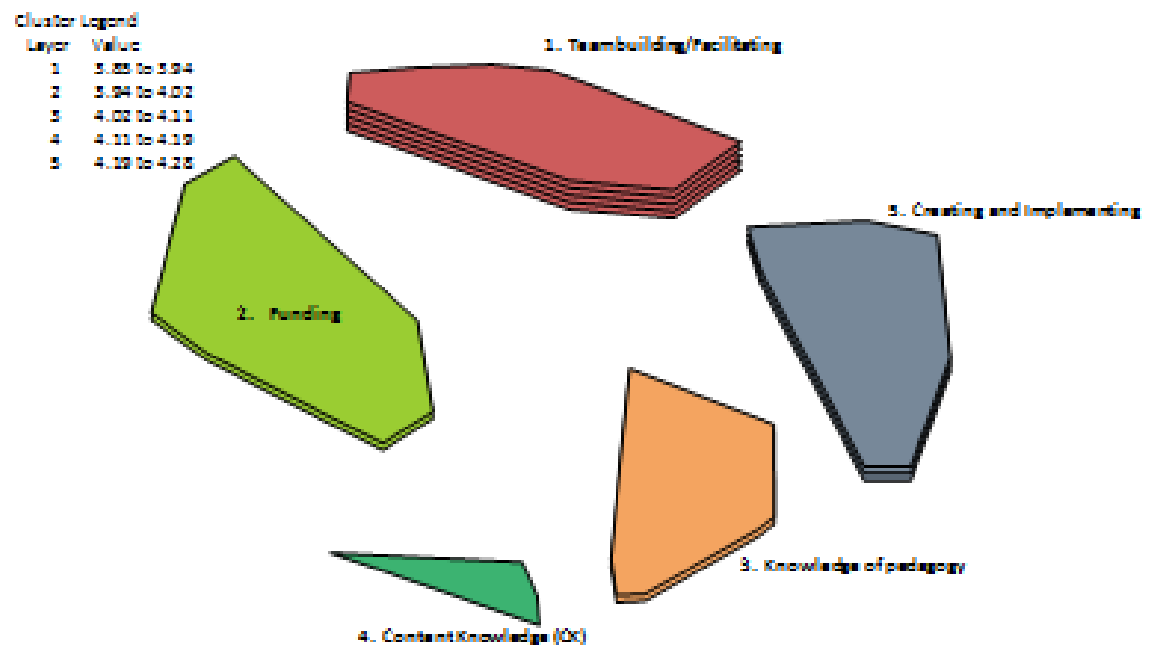

The cluster mapwith average cluster ratings overlaid.

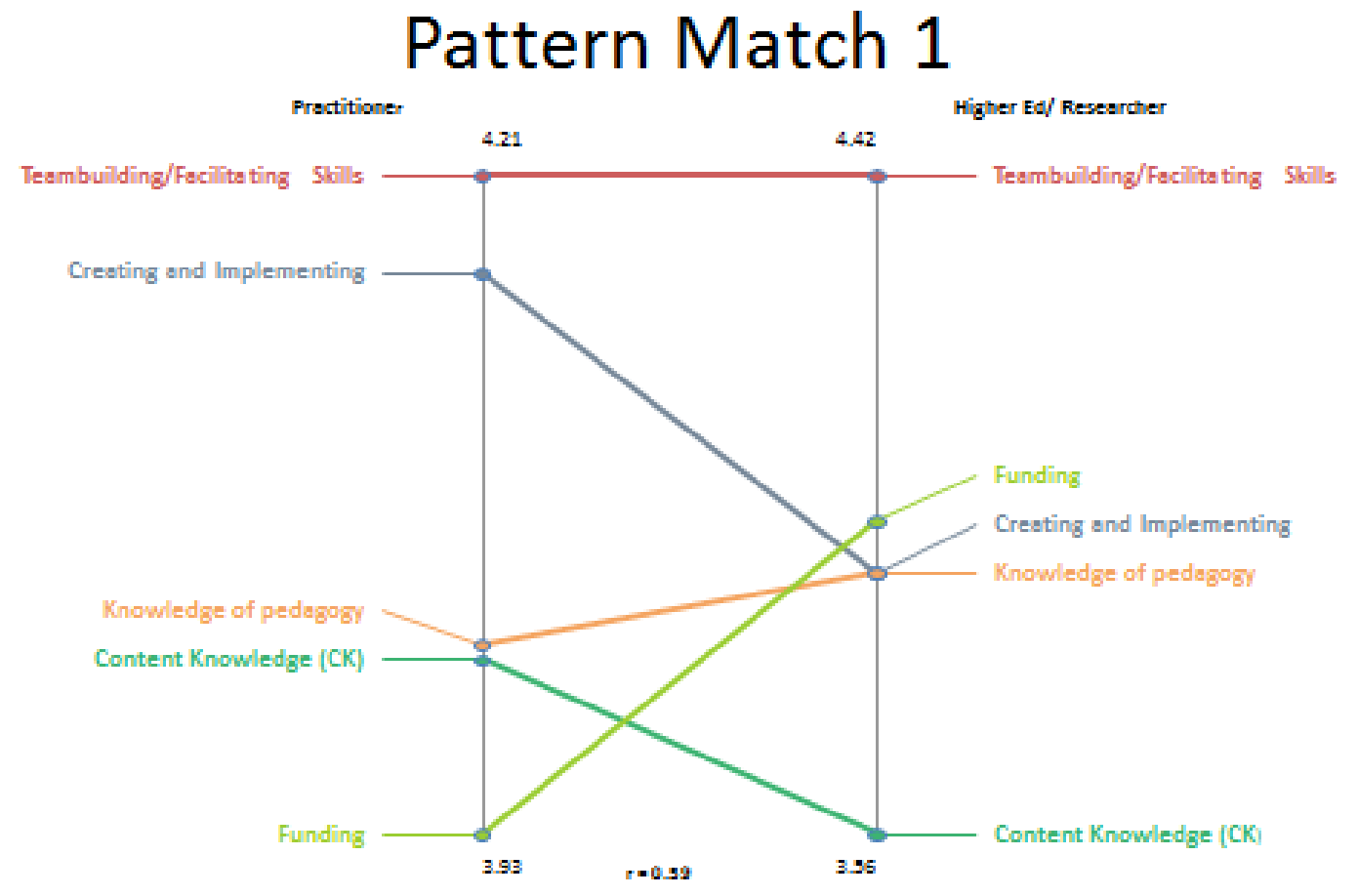

Is a pairwise comparison of cluster ratings across the participant criteria (ie. Practitioners vs. Higher Ed/ Researcher). 


\section{Go Zone-All Statements}

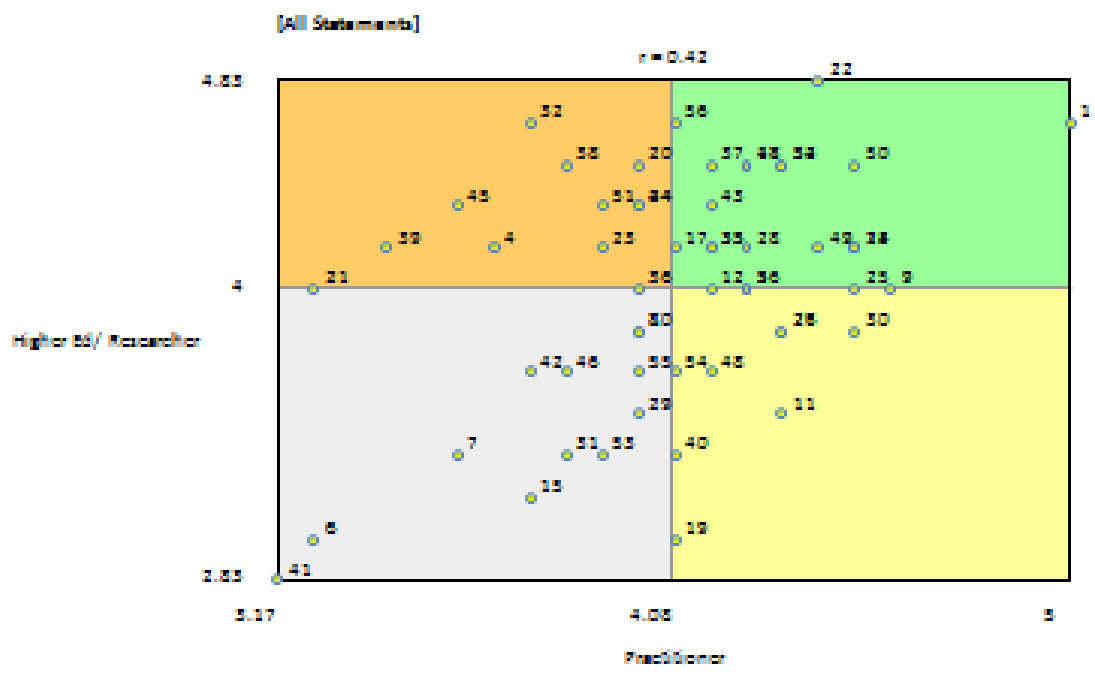

Bivariate graphs of statement va lues for two rating variableswithin a cluster, divided into quadrants above and below the mean of each variable, showing a "gozone" quadrant of statements that are above average on both variables

\section{Go Zone- Teambuilding/ Facilitating}

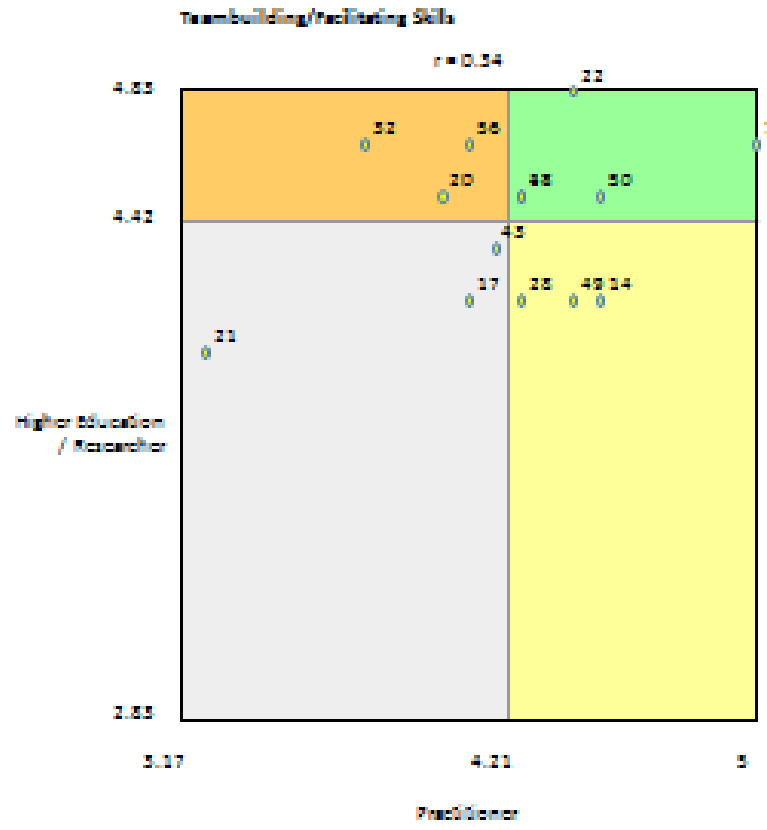

1. Communicating effectivelywith colleagues and other stakeholders.

18. Establishing relationships with individuals and organizations from the broader community.

22. Establishing positive relationship with colleagues and administrators that foster school-wide participation in physical activity promotion and implementation.

47. Leading school faculty/staff and students.

50. Providing access to opportunities for physical activity and encouraging othersto participate 


\section{Go Zone-Funding}

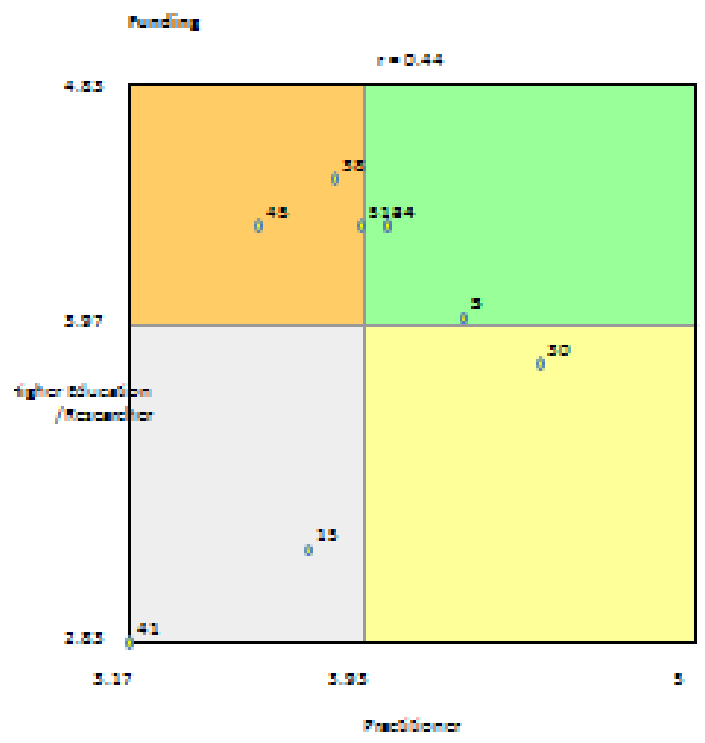

3. Advocating for the physical activity needs of children both at school and in the broader community.

5. Educating school faculty/staff, students, parents and community to understand the importance and health benefits of physical education, structured and unstructured play.

24. Desiring to increase one's involvement beyond simply teaching physical education.

44. Sharing guidelines for developmentally appropriate practice with others (i.e., playground supervisors, classroom teachers, before and after school providers).

\section{Go Zone-Knowledge of Pedagogy}

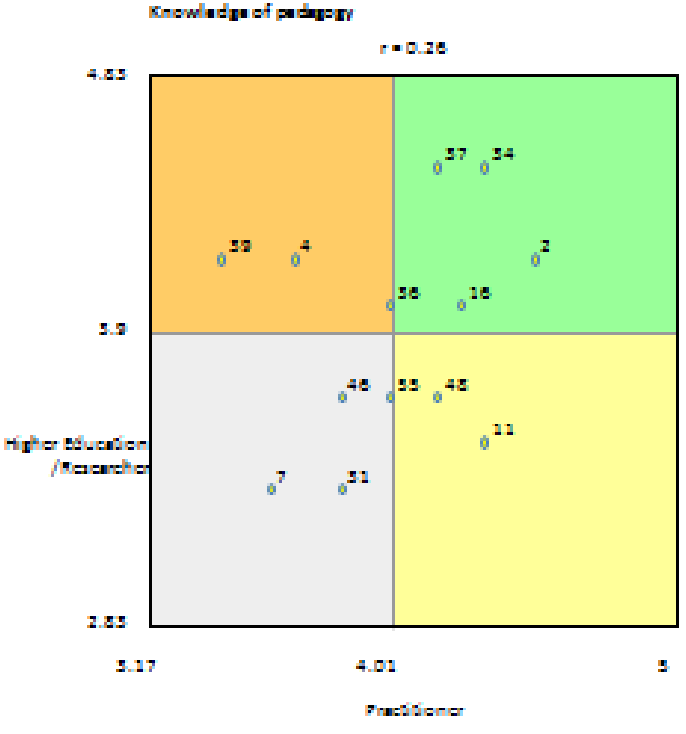

2. Identifying the components of a CSPAP and how each contributes to maximizing physical activity opportunities for schoolaged children.

16. Modeling effective physicalactivity programming for others to emulate.

34. Knowing guidelinesfor developmentally appropriate practice in physical activity programming.

37. Understanding effective pedagogy and selecting instructionalapproaches to lead various physical activities 


\section{Go Zone- Content Knowledge}

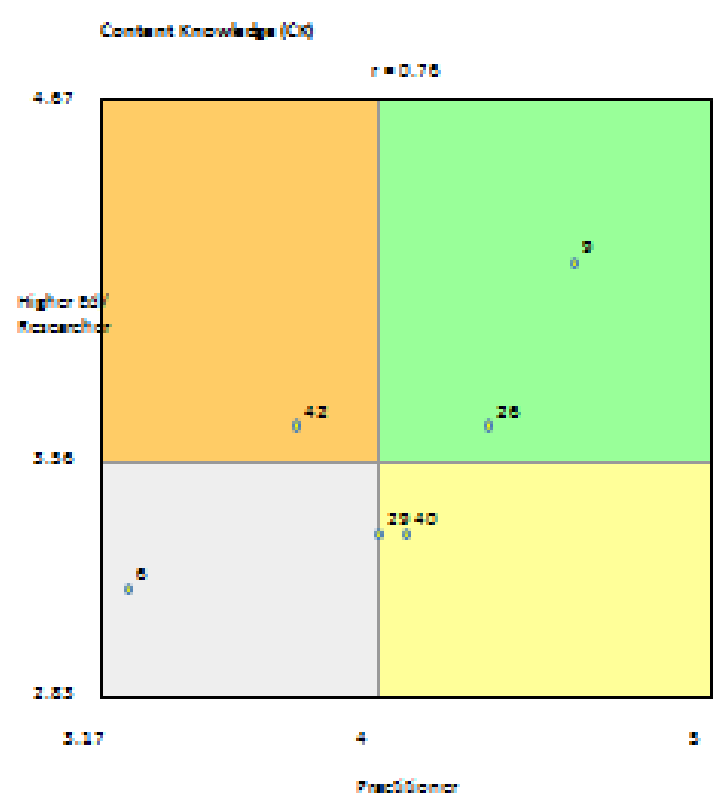

9. Remaining current with the literature in the field including recommendations for best practice and related resources.

26. Maintain ing extensive background knowledge in physical education including an awareness of contemporary research in the field

\section{Go Zone-Creating and Implementing}

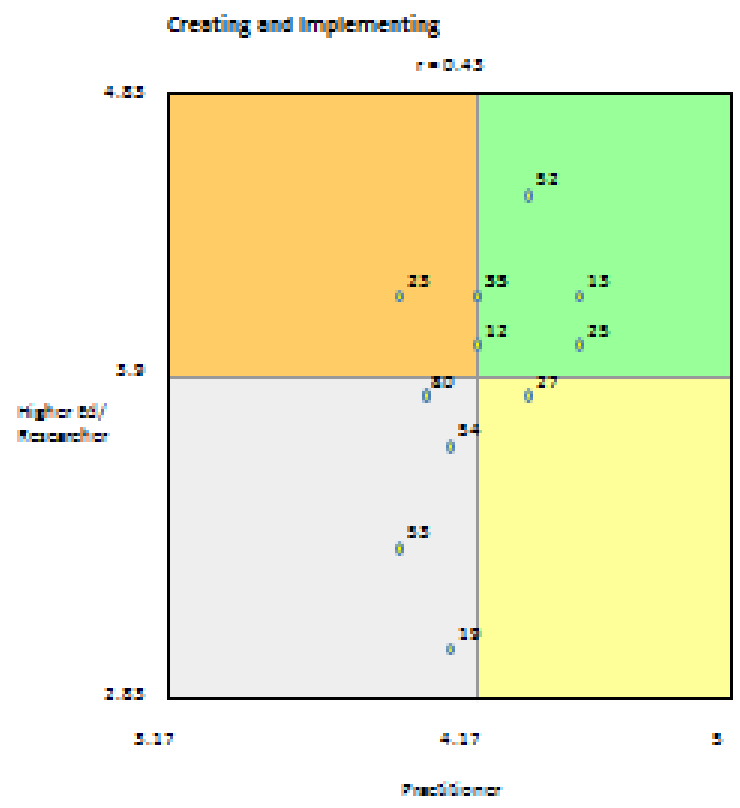

12. Finding physical activity opportunities that can be made avalable to students, faculty/staff, and community members.

13. Organizing, managing, and leading the various components of a program.

25. Developing, implementing and sustaining a district-wide quality physical education program across all grade levels.

33. Designing effective exercise and physical activity programs across varying developmental levels.

35. Modifying program features based on the characteristics of the students it is designed to impact.

52. Believing it is his or her responsibility to lead program efforts. 


\section{Interview 1:}

Date: $5 / 15 / 14$

Face Interview

Interview: J.H.

Interviewer: Kiel Illg

Interview Transcription

KI: Good Morning Mrs. H. First, thank you for taking the time to participate in this semi structured interview. The purpose of this interview will be structured around verifying the cluster groupings that the results of the survey yielded and second to discuss approaches for preparing professionals at pre-service and in-service levels to adapt and embed these competencies into their professions.

KI: So, first have you had an opportunity to review the executive summary?

JH: Yes.

KI: Ok. If you have any questions, we do have the executive summary in front of us and I can go over any questions during this process. We will be using the executive summary and cluster statements as we go along. Just to let you know the statements that were represented as the highlight statements were the statements that were represented in the Go zone in each individual cluster. So those statements were rated high both from the practitioner and higher education individuals.

JH: Ok.

KI: So you had a couple questions about the executive summary and the clusters, so we will start with that first. Let me know what your questions are in regards to the cluster maps as well as the executive summary that was sent to you?

$\mathrm{JH}$ : So there basically it looks like are they clustered then I was trying to match the numbers from where they were in the cluster and does the formation mean everything?

KI: Ok. So the point map here first displays the relationship of the statements in proximity of ideas to one another placed by a multidimensional scaling. The scaling analysis locates each statement as a separate point on a map, those statements that are closer to each other on the map are generally grouped together by the sorters more frequently.

JH: OK. So that's why I can see like statement \#1,18, 22, and 47 is somewhat near to each ok that makes sense.

KI: Ok, so then the clusters, so how the clusters come about is this. Orignally, we started off with 10 different cluster groups. So these clusters originally were broken up and separated. So let's say statement $\# 1,18,17,43,22$, and 56 they may have all been together at one point. Well, what we did with our data analysis was we went through starting with 10 clusters all the way down to our remaining 5 clusters. So, we looked at what clusters made sense. How if these were separated did they really fall into a separate 
group or could they be combined with other like statements to make a better cluster grouping. So myself and my committee member along with another researcher went through the process and analysis of trying to reduce our clusters and make sure the statements that were represented in the cluster were similar in nature. Now the names that came about for each cluster are the names that when participants sorted and labeled their piles were the most common names that participants used. So you may have said that it was teambuilding and another participant may have called it facilitating skills, so as we went through the clusters you'll see that some of these have changed those are based upon the participants and what the software analysis provided.

JH: Ok so you originally had 10 different categories and now you're down to these. Yep ok makes better sense.

KI: Now the cluster rating map that you see in front of you. It shows by the levels of importance rated by the participants. So as you can see we know that the content knowledge cluster is a one layer so it was rated from a 3.85-3.94. Now if you remember from our rating scale it was scaled from 1-not important, 2slightly important, 3-important, 4-very important, and 5-critical. So a 3.85-3.94 here really signifies that on this scale it is important; whereas when we look at our 5 layer cluster rating ranging from a 4.19-4.28 an example if you look is the teambuilding/facilitating cluster where you see five different layers, the map in this case is signifying the ratings of the practitioners and higher ed/researchers as this clusters being very important with the statements that are included.

JH: Ok I get it. Yes it is interesting on how it came out

KI: Ok now looking at the pattern match. This actually gives you a comparison of cluster ratings across the participant's criteria in this case the practitioners vs. higher education/ research participants. As you can see teambuilding/ facilitating skills each individual group rated it from an average of a 4.21 on the practitioner side whereas the higher ed/ researcher rated high also as a 4.42 rating. So both groups found it to be very important according to our rating scale. Whereas the content knowledge cluster which was interesting to see that the higher education/ research participants on an average rated it slightly lower at a 3.56 compared to the practitioner group that rated it higher above a 3.93 average.

JH: Right. When looking at this creating and implementing is interesting also.

KI: Right, because it falls at that same type of scale where the practitioners seemed that creating and implementing was rated on a higher average scale compared to that of the higher ed/ research participants.

$\mathrm{JH}$ : And I'm not surprised that funding for higher ed is where it is on the scale.

KI: Ok so then you saw the go zone statements. So this graph really represents our overall go zone map for the study, and these are where all 56 statements fall based upon the rating from each participant. So how I broke it down was you can so that some overlap with each on this map, so what I ended up doing was showing individual cluster go zone maps and where the statements fall within each cluster as a go zone map. So anything that falls within the green box is a go zone statement, a statement that was rated as very important to critical. The top left box represents statements that were still represented as very important but more so to the higher education/ research participants compared to the practitioner participants. If you are in the lower left hand quadrant that is where both the practitioner and higher ed/researcher rated that statement lower compared to the other statements, but if you look at the range of 
each in this case a 3.17 you still see based upon our rating scale it is important and the bottom right hand quadrant signifies the exact opposite of the top left hand quadrant where these statements are rated higher to the practitioner and lower to the higher ed/ researcher. So these maps give us our go zone statements. Now the following maps as you can see cluster 1, cluster 2, etc is the breakdown as I discussed before of each individual cluster and where the statements fell within the cluster according to the go zone map and concept software. Ok make sense do you have any questions?

JH: Yes makes sense thank you.

\section{KI: Looking at the first cluster grouping (Teambuilding/Facilitating Skills) would you say that the title adequately represents the competencies that were sorted together in that grouping? (Yes or No)}

JH: Yes. Now I did think that it did adequately represent. I know in my own forming mine was related to teambuilding, I don't think I used the term facilitating skills but definitely that model of establishing relationships and positive communication is very very important.

\section{KI: Ok, now holistically looking at this cluster what does this grouping mean to you in reference to your profession or CSPAP?}

JH: Right to me actually as the physical education teacher. That as the PE teacher you have to be able to effectively communicate with others. Whether it is the person above you that is actually organizing the physical activity plan or whether it is your colleagues that are on the same line with you. It could be your colleagues that are PE teachers that you have to work with every day or it is also for me that I communicate effectively with the classroom teachers as well. And its that idea again of the development of the whole child and shared decision making process that you see listed here in the cluster. Decisions should always be made together. Now I see the statement leading the school, faculty staff and students. When I looked at this that was the only one that I was kind of not sure if it belonged there, you can take that many different ways. You know for me when I was developing the statements I had leadership as a whole different cluster group, but if that is where most people sorted and where it fell in because it is also a go zone competency then I think that is being a leader within your building is one of the ways to make your physical education or physical activity program successful.

KI: Ok, thank you.

JH: You're welcome.

\section{KI: Looking at the second cluster grouping (Funding) would you say that the title adequately represents the competencies that were sorted together in that grouping? (Yes or No)}

JH: Yes. As it relates to me funding is very important because you can't do anything without it. In order to run a successful program you have to have that financial support whether it be for the equipment for the students; whether it be to introduce them to our NYS standard \#3 so that you can take field trips and get those community resources. Even the lesson I have going today on healthy eating. I needed funding to purchase the $\$ 200$ of food just for one grade level to be successful in my objective. No secret that I write many grants to support our program because the funding isn't there unfortunately these days. So I do write a lot of grants and that is very important that you do have people that are willing to do that and I 
have my own account down in the office for all the grants that have been awarded to us, so that I can do the things I would like to do within my physical education and physical activity programs. You also have to have that community support as well in order to help you secure additional funding and without funding you also can't keep your physical education teachers up to date on new things that are coming down the pipeline for physical education as well or just physical activity programming as well.

KI: Ok, thank you. Going on to cluster three. Looking at the third cluster grouping (Knowledge of Pedagogy) would you say that the title adequately represents the competencies that were sorted together in that grouping? (Yes or No)

JH: YES.

$\mathrm{KI}$ : Ok, then holistically looking at this cluster what does this grouping mean to you in reference to your profession or CSPAP?

$\mathrm{JH}$ : Well it is very important to me as professional, because that is what I have to communicate to the students every day and also understanding the CSPAP is very important because physical education is an integral part of that. We always tell our students that they need $60 \mathrm{~min}$ of physical activity a day and that you're not with me for 60 minutes, so we have other programs to help them meet that 60 minutes but I also developed a program where again it shows the working hand in hand with the classroom teachers and getting the classroom teachers to understand physical activity. I have a recess cart that I created here and I showed the students for three straight weeks in their classes all the different things they can do at recess. It is also me transferring my knowledge other stakeholders in the school so that we are all the same wavelength when it comes to children's health, physical education and physical activity within the school. You know developmentally appropriate are key words in statement \#34 is so important at the elementary level; to develop that progression in order to be successful at the elementary level you have to understand where the kindergartener is and where you want them to end in $5^{\text {th }}$ grade before they leave here. There are so many keywords in all of your go zone's here.

KI: Ok, sounds great. Looking at the fourth cluster grouping (Content Knowledge) would you say that the title adequately represents the competencies that were sorted together in that grouping? (Yes or No)

JH: Yes.

$\mathrm{KI}$ : Ok, then holistically looking at this cluster what does this grouping mean to you in reference to your profession or CSPAP?

$\mathrm{JH}$ : A lot of the same referring back to the other piece. Again, it is really breaking it down looking more specific into the units and things that are actually being taught. You know again you have that competency remaining current with the literature, I mean everything seems to relate back to the other ones. Because you can do some of that on your own, but some of that is great if it can come from the TOP DOWN-through staff development. Yea again the two go zone competencies seem to be very important, it's keeping up to date and being willing to change with the times as well. I mean all of us come out of college with a pretty good solid base of content knowledge but its maintaining that which is sometimes difficult; I mean it is sometimes difficult for some people, others can get caught up in all the other things they have to do, but then again that is the meat of our profession is the content knowledge. 


\section{KI: Ok great. Looking at the fifth cluster grouping (Creating and Implementing) would you say} that the title adequately represents the competencies that were sorted together in that grouping? (Yes or No)

JH: Yes. You have creating the opportunities for the kids and implementing them. Yes when you look at those competencies. And that's really a lot of what we really do especially here at the elementary level; you know I tell the kids I want to expose them to a variety of physical activity opportunities. We give kids so many opportunities whether its lifetime, sport related, gross motor, fine motor; we give them so many different experiences and you hope that they are going to grasp on to a few of those that they're going to carry through. Even our 38 mile walking field trip "Fit Story" that's exposure and that's making physical activity in your community fun and exciting. If you're not doing those type of things or leading these physical activity opportunities than the kids are not going to realize. You'd be amazed in this building when we take the kids to the A..... Bike Path and they are like wow there's a bike path? How long is this bike path? I mean they don't know, so you have to have that exposure to it. You know statement \#52 is a statement that I really liked because it is believing that it is his or hers responsibility to lead program efforts, and I do believe in my heart that that is one of the most important things that you can do. And it is believing not only to lead the program efforts but believing in what you do is important. I go back to so many of these overlap with one another again back to the teambuilding cluster my colleagues in this building the fourth grade teachers I work with on Fit Story. They believe that it is important that kids get physical activity and that's why we do these projects and programs together. I've been able to do that here to get everyone to believe what I do is important and I'm not just the gym teacher here. Were all on the same level; whether you're working in the cafeteria, whether your teaching, whether you're the physical education teacher or wellness teacher; it's a whole group effort. It is, it's creating and implementing those opportunities, and we do so much of that. I can think of my fifth graders I teach them Newton's Laws as an integration lesson with the classroom teachers, and then we go to a putt putt facility and we implement Newton's Laws through miniature golf. It's just a lot of collaboration and a lot of saying I can do this. A lot of designing and creating but it is fun.

KI: Awesome sounds like a fun time within your elementary school.

JH: Yes, Yes, Yes it is.

KI: Alright moving on to the second part of our questioning in regards to the interview. Now were going to be looking at some implications for professional preparation at the undergraduate, graduate or even inservice training for professionals. Alright so the first question asks What practical implications do the cluster or go zone statements have for the professional preparation of educators at the undergraduate or graduate level in physical education teacher education programs?

JH: So I just want to make sure that I have it straight in my mind. So looking at these how do we better prepare or how do we implement what we see here with the undergraduates?

\section{KI: Correct.}

JH: It's so hard because the undergraduates are so limited on time and I think that there is more emphasis on the content knowledge than on anything. That can easily come on your own time, but actually understanding the importance of some of these other roles that you'll have you know as a physical 
education teacher are so important. You know maybe not as much emphasis on the funding piece in the undergraduate, because that will come as well and eventually you develop that once you find your first job, but I just think that there needs to be a better job of getting them to understand the importance of those roles in order to help our profession be maintained and for people to understand the importance of what we do.

KI: Ok, you talked a little bit of the undergraduate level, how about the graduate level do you seen any of these clusters or statements following into the graduate level for physical education teacher education programs?

JH: Yes, they definitely could. The funding piece definitely could, you know when you are taking your graduate level courses you have a mix of students. I personally was already employed teaching here at S........so I could take what I was learning and implement it back, but for those that are going right from undergrad to graduate and actually haven't worked out in the field yet it might be a little tougher, but the Funding piece would be a great topic to cover. The creating and implementing cluster as well would be another topic at this level, because you have gotten your feet wet hopefully in a position and you're getting your content knowledge pretty secure and now you can't start taking those risks and trying some new things within your program and teaching. I know back in the day $\mathrm{CC}$ would bring all of their undergraduates here, now they have not done that in a while, but they would come here for an evening seminar to learn and see some of those things that they may have not been able to do with kids in class. That program really worked on and fell into what some the clusters including Cluster 1, Cluster 3 and Cluster 4 are really emphasizing.

\section{KI: Ok, thank you. Second question what implications would these results have on the continuing professional development for all personnel including administrators, classroom teachers, coaches, teacher assistants etc?}

JH: Well I think that it is interesting to see how they were actually clustered in the end and to see where the participants felt the statements were important. Personally in a school setting I would concentrate on the practitioner side and professional development would be great to see lead by physical education teachers to help the classroom teachers, teaching assistants and other professionals see you know what we really do, what our standards are, why we do some of the activities that we do and how we can help each other. It's usually not a two way street, its usually us asked to integrate the classroom teachers subject or content area not back and forth. However, if they saw what we were really trying to do I think it would definitely benefit them, there are so many places where we overlap and in order to have some buy in they have to understand and if they don't understand then they are not going to buy in.

Again, it goes back to you as a physical education teacher have to integrate yourself into the building; if classroom teachers are asked to send monthly newsletters you need to send monthly newsletters as well. There is so much that has to overlap and you have to immerse yourself completely in the building and be that leader. Back when we started our morning ACES program I did a $1 / 2$ day staff development for teaching assistants and teachers so that they understood what the program was about and they knew exactly what was expected of the kids. The kids and adults were using resistance bands, like every kid had their own resistance band in their desk and the classroom teachers were going to be the one's actually working with the students and helping them with this. So they first needed to be trained to use the bands the appropriate ways and know the different movements in order to get their buy in. 
Even for funding working together to secure funding. You know the content knowledge is mostly the responsibility of the physical education teacher but again getting some of that buy in and integration going both ways would be nice.

KI: Ok great, thank you. Are you aware of any physical education teacher education programs that are doing well in preparing educators to be physical activity leaders?

JH: It's hard to say. My only student teachers have been from CC, BC, I haven't had any from CU in a while. I feel I came out very well prepared but I'm 45 and so I don't know if my alma mater still has that program. I mean you have certain schools that have reputations better than others and it's not that anyone is doing a poor job. I just don't think their seeing the whole picture. That is a hard question to answer.

KI: Ok, I mean if you don't have answer for that portion it is ok.

JH: Yea, Yea, I mean even where my daughter is going to be going to college they have a fabulous reputation everybody I know from there are successful teachers. However, I don't know if I am one to judge anybody's program.

\section{KI: Ok. Can you give an example of any continuing professional development in your districts or higher education programs to continue developing physical activity leaders?}

JH: Yes in the past back when we had our PEP grants that's back when our physical education staff development took a complete change. Previous to that we never had physical education staff development. It was always that we would have to attend with the classroom teachers and their training but then the difference was that we had funding for it, through PEP we were able to fund that staff development and now we have been able to still meet as physical education teachers but I don't think it is necessarily always professional development. Like we had an Ubersense presentation this year and I thought it was great because I have never done or used it at our last professional development so it was great because it was a new program to me. But previous to that I wouldn't say it is staff development because we have been doing our curriculum mapping and we meet as a department but it's not continuing professional development. It would be nice to be able to bring some people in that can give us some new and fresh ideas, because it's also in this day of age you are not allowed to go to conferences. Back when we had the PEP funding we were able to send 3 or 4 people to the state conferences. I personally went to EDA and a few of us got to go to the national conference each year. But without that funding that was good six years, now we really don't get that opportunity to do that.

KI: OK, thank you. Are there any innovative programs that can you provide examples of that are doing this well? (ie. implementing CSPAP, Clusters, preparing PAL etc.) I know that you talked about some of those things here at your elementary school.

JH: Yes we do some of those components of CSPAP here. You know an interesting piece of background for us here is our wellness committee back when the feds first made you form a committee; CK and I were the co-chairs for the first couple years of it and that was when we also had the PEP grant as well; so everything was hunky-dory, but that committee could probably help facilitate a lot of this, but it hasn't met in a long time. I think that if we had someone or something like a structure in that case where we had parents in this case we had a parent representative from the elementary, a parent from the middle school, a parent from the high school we got great feedback, there was great input. Here at SDS we try to do 
different things; never satisfied with what we did the previous year, always trying to improve. I do think we do a good job with a lot of these things on the cluster list, but sometimes you feel like you are out on an island by yourself just doing it and no one really knows about it except the families of this building and the individuals involved within the building; besides what they read on our website, newsletters etc. Honestly, you feel like you're on an island, but it is what it is; we try to do the best that we can with what we have as well. In all honesty I'm so involved with things here in this building but I know a few teachers in other districts who are doing a lot of neat things as well that were presented at our western zone physical education conference and things like that. Other than that I'm pretty much concentrating on what I have going on here.

\section{KI: Ok thank you. Last question are there any other thoughts you would like to share in relevance to this study; comprehensive school physical activity programming or just your thoughts about the subject area?}

JH: Well I thought it was an interesting study. You know for me it reinforces just going through the process as a participant in this study to reinforce myself that you have to have a strong leader at the top for physical education and physical activity. And in NYS we know that person is synonymous with the Director of Health, Physical Education and Athletics, and that is a whole encompassing job that takes a lot of time dealing with just the athletics, and I feel physical education and physical activity gets put on the back burner. But it reinforced to me that you need that person; that team builder, that strong leader in order to help you with all the other items found in this study like funding you need that support. You can't remain current all the time if you don't have the support to attend conferences or order equipment. And again I go back to that wellness committee piece as well, if you have some sort of structure in place I think that would really help as well; but remember you have to have a certain type of leader leading that committee as well, I think that would be very important. Someone that can engage everybody and get buy in from the members. I also think it needs to be community based I think that is some of the keys as well everybody working together.

KI: Thank you for your time, I appreciate the information you have provided, just to make you aware I hope to share my findings at upcoming national and state conferences in order to help provide more support in advocating and politicking for comprehensive school physical activity programming. One last time I just wanted to make sure that I have consent to record this conversation.

\section{JH: YES.}

KI: Ok sorry I was supposed to ask in the beginning; also the file will be saved on a password protected file on my computer. I will also be sending you the transcribed interview for you to review. If you see any misrepresentations please highlight so I can adjust the transcription accordingly. Thank You once again for your time.

\section{Interview 2:}

Date: $5 / 16 / 14$

Phone Interview

Interview: G. R. 
Interviewer: Kiel Illg

Interview Transcription

KI: Good Afternoon, First, thank you for taking the time to participate in this semi structured interview. The purpose of this interview will be structured around verifying the cluster groupings that the results of the survey yielded and second to discuss approaches for preparing professionals at pre-service and inservice levels to adapt and embed these competencies into their professions. I just want to make sure that I have your consent as well to tape this interview.

GR: Yes you have my consent.

KI: Ok, what I am going to do as well just to give you a heads up I will be transcribing the recording and send back to you to make sure that I don't misrepresent anything that you say here today. Please feel free to review the transcription and let me know it is ok before I begin to analyze the qualitative data. Is that ok if I do that as well.

GR: Absolutely.

KI: Have you had an opportunity to review the executive summary and the cluster statements?

GR: Not very thoroughly, I glanced at the executive summary and kind of got the drift of what you were doing with that. The cluster statements no, but I am looking at it right now and reviewing.

KI: Ok, well as we are going through the interview at any time if you have any questions don't hesitate to stop me and ask those questions, just so you know how the concept mapping study kind of worked is that we used the computer software that you were able to go on through the site and brainstorm ideas anonymously in which we had 73 participants that participated. We had a total of 18 participants participate in the sorting and rating phase of the study from across the country that provided input from higher education professionals to practitioners so a little bit of the demographics of the study for your information. Like I said we had the 18 participants which were identified as our key stakeholders that had some experience with CSPAP either as practitioners or as a higher education/ research professional. Now with the interview how it will be structured the first series of questions will be a validation and verification of the go zone statements and the cluster groupings that you have in front of you within the executive summary and cluster statement list pdf. If you have the executive summary intron of you, you will see that we have five different clusters and within those clusters are all those various statements that were rated and sorted; so the cluster list not only provides the cluster name but also involves the statements that fell within that cluster.

GR: Ok

KI: OK. Now the cluster name so that you can get an understanding of it; those came from the pile names that were created by the participants, and what the computer software does is it started off at 10 different clusters and analyzes the statements by combining them all the way down until 5 in this study. The computer software also then takes those piles names that were most associated with those statements and names the cluster based upon the feedback given from participants if that makes.

GR: Ok, kind of sort of that makes sense. I think I have the drift of what happened. 
KI: Ok so the first part is we are going to look at those clusters and I am going to ask you some questions in regards to those clusters and statements. The second phase of the interview will be more about the implications for professional preparation at the undergraduate and graduate level as well as professional development and in-services for professionals within school districts.

GR: OK.

KI: Looking at the first cluster grouping (Teambuilding/Facilitating Skills) would you say that the title adequately represents the competencies that were sorted together in that grouping? (Yes or No)

GR: Now I would base that on... what am I looking to base that? So that I get this right from the get go.

KI: Yes, so the go zone statements that are highlighted under each of the clusters and the other statements that are listed under the cluster grouping as well. I'm just asking you

GR: Is this talking about slide 7 in the executive summary.

KI: Yes I'm looking at Teambuilding and Facilitating skills. See how \#1 communicating effectively with colleagues and other key stakeholders?

GR: Yes.

KI: OK so that statement that is highlighted is actually one of the go zone statements or one of the critical statements that practitioners and higher ed/ researchers rated as very important. The other statements that fall in there like \#14, \#20, \& \#21 that can be seen on the pdf file, those were other statements sorted together within the cluster but that the participants did not rate it combined as being a go zone statement.

GR: Ok I get it.

KI: Ok, so looking at that cluster (Teambuilding/Facilitating Skills) would you say that the name is an adequate representation of the statements that were sorted under that cluster? (Yes or No)

GR: YES

KI: OK. Now if you say no with any of these clusters just to give you a heads up so you can think about it as we are going through these clusters individually I will be asking you what some of your recommendations may be for the names of the cluster as well.

GR: Sure, sure, sure. And you're basically just so that we are on the same page you are saying that I think Teambuilding and Facilitating skills captures the meaning of really \#1, \#18, \#22, \#47, \#50 as the go zone statements.

KI: Correct. Are we good there?

GR: Yes.

$\mathrm{KI}$ : Ok in regards to the same cluster teambuilding and facilitating skills. Holistically looking at this cluster what does this grouping mean to you? (ie. Job, CSPAP) 
GR: Ok well I am very cognizant of the fact that this is not a one man job. It is therefore going take either an individual or a small team of people who are able to get the rest of the participants at least on board and part of the process, and engaged in activities and part of the actual outcomes; because otherwise it will remain fully dependent on the individual and that certainly above all will not create sustainability and culture change.

KI: Ok thank you, just to let you know I am doing some handwritten notes gather some of your big thoughts and ideas, so if there is a pause I apologize.

GR: That's fine.

KI: Ok, would you like to expand on that cluster topic anymore?

GR: I would just like to add the communicating effectively is very critical because that is in part the way we are going to educate people as well as to what this is and how important it is. So you will have to be able to communicate to one to educate them and secondly to get their buy in and figure out on how to find a place for them within the process.

KI: Ok. Alright thank you.

GR: No problem.

KI: The second question. Looking at the second cluster grouping (Funding) would you say that the title adequately represents the competencies that were sorted together in that grouping? (Yes or No)

GR: No. Now I'm looking at statement \#3,5,24,44.

KI: Yes those are the go zone statements for the cluster; you can also look at the other statements as well too.

GR: Which are?

KI: Statement 15, 30, 38, 41, 45, \& 51. Were really looking at those highlighted statements as our go zone statements but those other statements fall into the cluster grouping as well. They just weren't rated as high.

GR: Well I think yea. When I think of funding I think of statement \#15 raising funds needed to support programming is clearly funding, writing grants to support ongoing programming is clearly funding, identifying available programming is clearly funding, but to advocate and educate and share guidelines that is not necessarily funding dependent at all. So I seem to think that they have it backwards.

KI: You're right it seems like we have two different parts within this cluster as you mentioned the advocating, educating and funding pieces represented by the statements. Ok, so then what recommendations would you have for naming this cluster?

GR: I think statements \#3, 5, 24, and possibly 44 are the four that are green might go under teambuilding and more so facilitating. Now some you might argue would go under pedagogy and content knowledge, because \#5 the first word is educating so that might go under content knowledge which I think educating and advocating are not necessarily the same thing. I think however that advocating and desiring could go 
under the facilitating and teambuilding; sharing guidelines means its content knowledge or pedagogy and then statement \#51 which is providing professional development training for school faculty and staff to improve sustainability is clearly pedagogy or content knowledge, but that's just my two cents.

KI: Ok.

GR: Did you get all of that.

KI: Yes ma'am.

GR: Ok.

KI: Ok thank you. Now holistically looking at this cluster what does this grouping mean to you? (ie. Job, CSPAP).

GR: The one's all under funding or the four that you put under the PowerPoint.

KI: The ones that are under funding.

GR: On the power point.

KI: Correct.

GR: I think they are mis represented, I don't think they go under funding.

KI: Ok.

GR: I think they go under either facilitating/teambuilding or content knowledge.

KI: Ok.

GR: Did the computer sort these or did you?

KI: The sorting and the arrangement of where the statements fell were based upon the participants sorting data. So..

GR: Wow, Ok. I mean I have read them thoroughly now, but even if I look at the verb sharing guidelines I don't know if it has anything to do with funding. Desiring to increase one's involvement has nothing to do with funding, educating and advocating; I mean yes money always helps but raising funds is under funding. Writing grants is under funding. I mean you would have to be an advocate, no that's what I think.

KI: Ok.

GR: I think statement \#5, 24, and 44 should come out of there.

KI: Alright, thank you. Looking at the third cluster grouping (Knowledge of Pedagogy) would you say that the title adequately represents the competencies that were sorted together in that grouping? (Yes or No) 
GR: It's ok, yea. Yea that is pretty solid. Let me look at the one's that you left out on the cluster list. Yea that is pretty good.

KI: Ok. Then holistically looking at this cluster what does this grouping mean to you (ie. Job, CSPAP)?

GR: I think it is understanding how to deliver professional development and having the basis of the science behind you. So the knowledge of pedagogy and the content knowledge probably can be separate but they are also interrelated. I don't know what you do, I can't remember but when I hire teachers I'm looking for both.

\section{KI: Right.}

GR: People often argue if you can only have a teacher that has good pedagogy or content knowledge which would you pick. I would probably say I wouldn't, but that's my feeling on that one. I don't know if maybe they should both be combined, I noticed that you didn't...there was something else where the content knowledge was very small.

KI; Right.

GR: That cluster rating map. I think that maybe that can all be merged with the knowledge of pedagogy. Particularly that statement \#9 in the content cluster- remaining current with the literature in the field including recommendations for best practice and related resources that is so critical because things change, and if your still delivering the good pedagogy with the wrong information well then you'll become less respected and the people will stop listening to you.

\section{KI: Ok, thank you. So now looking at the fourth cluster grouping (Content Knowledge) which you kind of just commented on would you say that the title adequately represents the competencies that were sorted together in that grouping? (Yes or No)}

GR: The content knowledge?

KI: Yes.

GR: Ok, hold on. Yes that is fine. I would have liked statement \#42 to have been one of the go zone statements.

KI: And that is knowing the advantages of well-rounded approaches of physical activity programming compared to those delivered from a more narrow perspective?

GR: Yea. I mean right now there are specific trends in this case everyone likes to use the term fitness, and there is always the sports guys out there still, and I think that 42 encompasses statement \#6 and \#40 from this cluster as well; so maybe just add 42 to that as a go zone statement.

KI: Ok, you kind of touched on it before but looking at content knowledge how does that grouping related to CSPAP or your job as a Director of Physical Education and Health within your district.

GR: Well it sometimes becomes problematic because we get bogged down with the day to day grind of what we do, but the truth of the matter is we really need to keep up with the science and the literature. We need to be able to make sure that we remain credible; we don't want the general public to be \#1 ahead 
of us, but more than that almost we need to make sure that fads and trends that are seen on the internet or drive by news shows because you will often get those comments from people. Since this is more of a culture change supported by science I think we need to keep up with the science. Examples would be like now that the is that aerobic physical activity supports the brain through academic learning, well at some point the scientists are going to be able to tell us how much or for how long, because we really don't know yet. Well when we know we need to make sure we know and that we incorporate that and adjust our program accordingly.

KI: OK, thank you.

GR: You're welcome.

KI: Now looking at the fifth cluster grouping (Creating and Implementing) would you say that the title adequately represents the competencies that were sorted together in that grouping? (Yes or No)

GR: Hold on. Yes I do, but I would say that 27. Evaluating program outcomes is a significant thing because we could have been "successful at doing all the things that we planned to do, but they're not successful." We could have created and implemented but if it's not successful we need to tweak or change or delete. So maybe it should be Creating, Implement and evaluating as the title.

KI: Ok, holistically looking at this cluster what does this grouping mean to you (ie. Job, CSPAP)?

GR: Well actually it is kind of where the rubber makes the road. Because when you look at the others, the others are you got the money, you have the team, you know what you're doing, but when you get to creating and implementing that is when you know if you have done it well. So that is very important, that is the heart of it.

KI: Ok thank you now moving on to the second phase of the interview questions looking at implications for professional preparation. What practical implications do the cluster or go zone statements have for the professional preparation of educators at the undergraduate or graduate level in physical education teacher education programs?

GR: Well that is an issue that we... I don't mean to hesitate on this because it is a big passion of mine. The teacher prep programs and the schools always need to be working together, and I think in the $21^{\text {st }}$ century or in 2014, this decade however you would like to call it; I think physical educators need to at least be aware of the school culture and what's happening right now; but I think if all these things I'm going to assume at the university level that they better be getting knowledge of pedagogy and even if it is not specific to the components of CSPAP a good teacher is a good teacher. Content knowledge they should be working on that anyways, and to a certain point creating and implementing should be part of their regular program, the teacher prep schools should be talking about, it is like developing a unit what are your resources, why are you doing it, what are your outcomes you're looking for. I think the teambuilding part and facilitating is something that individual teachers struggle with a lot. Particularly let's say an elementary teacher who works by themselves a lot anyways they don't have a group of teachers they are working with so they could be isolated. So if they choose to wear this mantle of running or doing all of this they may not have a lot of practice of teambuilding and facilitating. Funding is another aspect that can be touched on at the university level, I don't think that we teach teachers how to 
write grants but it can be talked about briefly as in the different types of resources. You might have someone come in from a local school to talk for an hour about funding and that you don't have to write a check of your own on everything and that small amounts of funding add up to big amounts. So I think of all of those things teambuilding/ facilitating and funding are the least addressed thing is teacher prep programs. I mean that statement carries through a lot through teacher prep programs the time spent on the pedagogy and content knowledge is important but we often don't prepare teachers for the reality of working in the schools that maybe doesn't have many equipment, doesn't allow certain things, and these other additional programs such as having a running club after school, jump rope club, etc. I guess just trying to talk about that, maybe having a paper that the students write or something, you know what I mean.

KI: I do, that was a great answer thank you very much.

GR: You're very welcome.

\section{KI: Ok, question \#2 What implications would these results have on the continuing professional development for all personnel including administrators, classroom teachers, coaches, teacher assistants etc?}

GR: Good luck to that. I mean I just looked up what you do. You work at a school?

KI: Yes ma'am, I'm the assistant athletic director and assistant dean of students here at a high school.

GR: Ok, well I don't know about you. But I would say generally speaking I do a lot of work nationally and to get an audience to get facetime (either real or on an Ipad) with administrators is tough. But they need perhaps more than anybody professional development and content knowledge about the research and importance of physical activity. So you are going to have to be creative in working the program about how this is going to happen. Personally, I have managed every month to get 10-15 minutes on our principal meeting's agenda, well they may not seem like a lot of time but is more time than most of my colleagues get. So I have to take that 10-15 minutes and make it very useful and directed. We are a very large school district we have 83,000 students and so principals have a lot of hats they were, and with all of the things they are worried about to have someone telling them that they need to have more physical activity during the day and all they need to do is open the gym's up during lunch; well their like whatever (how am I going to staff it, what equipment am I going to use etc.). So when are you going to tell them about it, so what we have done is that we have gone through the back door kind of much with the CSPAP program; we have a champion at each school in which I have managed to get at stipend for and we educate them. We use them as the conduit as best we can in conjunction with the 10 minutes that I have. I think in the real world people who are interested in comprehensive health, coordinated health, CSPAP whatever you want to call it those individuals need to find ways to get their face out there, because I think actions speak a lot better than words. One thing that has happened is our principals are telling their bosses they like when I come because I don't make them sit and listen and so that modeling thing that you had in one of these clusters. So don't tell them sitting all day is bad but they figured out when they are not sitting they feel better. So I'll do all sorts of things, which I'll get wherever I can so you have to be very alert to opportunities once you get into a school and I'm sure that you can attest to that. 
KI: Correct. Yes I'm with you $100 \%$ when we do our professional development and some other things that we try to do to incorporate physical activity within our district at all levels. We don't have 83,000 students but we do have 4 different buildings within our district that we try and encompass a comprehensive school model within the district.

GR: Right, it doesn't matter if you are a small elementary school in the middle of nowhere principals are busy, because if it is a small little school he is probably also driving the bus.

KI: Thank you very much for that answer. Now on to the third question; are you aware of any physical education teacher education programs that are doing well in preparing educators to be physical activity leaders?

GR: No I don't, but that doesn't mean that they aren't doing it. Rather, this isn't what you want to hear but I'm not actually even that impressed with some the preparation programs in terms of pedagogy. And I noticed it's on here, but are you doing this for SHAPE?

KI: No I am actually doing this study as my dissertation study to complete my $\mathrm{PhD}$.

GR: Ok, well I have gotten to the point but I wouldn't write it down but I can always tell which university these kids went to whether they are going to be a good candidate for me to think about hiring. Well an example is I interviewed a couple candidates the other day, they were sharp nice, gave the right pad answers to my questions, but when I got them to describe what 50 min lesson in their class would be and at the end I asked well what were the student outcomes they were looking for, they answered what do you mean?

KI: Yep, they weren't able to answer what their objectives were from the get go.

GR: No, and because it appears that there is a great deal of levels of physical activity you have to be very careful of that. And let me tell you of something else this is kind of related in the state of T.... where I live coordinated school health programs are mandated by law and that means that we have to provide a coordinated school health program that address health education, physical education, nutrition services and parent/ community involvement ok? I have not interviewed one person in the last three weeks that have even heard of that.

KI: And it is mandated by your state!!

GR: And it is mandated by our state. It is part of what they need to be able to at least speak to. I have the program in place, so I don't expect them to be well versed in my particular program and it will be the same thing which would be interesting if anybody when we went across the country and to see if anybody knew anything about CSPAP, coordinated health, PAL programs, any of these things Lets Move in Schools; any of these things I would be surprised if our graduates were familiar with them. But I actually don't know.

$\mathrm{KI}$ : Ok, moving on to the next question. Can you give an example of any continuing professional development in your districts or higher education programs to continue developing physical activity leaders? 
GR: Yes. 5-6 years ago I decided that the only way that I could make this happen was really before CSPAP was introduced this was my own design, but I stole almost every idea from somebody else. I decided that we needed a champion at each school/campus we have in our district 145 different campuses; and I decided that I needed somebody on campus to be the liaison. So I managed to get private funding for the first four years and the individual was recommended by the principal who does not have to be a physical educator but there are some physical educators that I don't want to be this champion; but it is generally the physical educator. I pay them a small stipend and they have three training and specific assignments. If they go to all the trainings and do all of the assignments they get the $\$ 500$; because I hate paying people for nothing. At the district level we designed a district wellness initiative; in which we push it out to the schools, and each school is asked to do it so that we have continuity and sustainability. We then ask them to do some personal campus based evaluation and planning. We used the Let's Move Evaluation tool and CDC school health index and then the committee (SWAT-School Wellness Action Team) come together and they look and we have had some movement. We have had some recent minutes increased for physical activity; we have had gymnasiums open before and after school we have had a reduction of ice cream sold during the course of the day those kinds of things. We just finished our fifth year and we evaluate every year that is why I think evaluation is so important and we have gotten some anecdotal information/ hard evidence that this is working. We also asked for their suggestions about how we can make it better and so now it is becoming a part of what we do. We call it just our local wellness program and I am a big proponent of wellness versus physical activity or fitness. I like to include nutrition and hydration those kinds of things. I helped write the original DPA program and now it's the PAL training well I was actually one of the original writers and we actually piloted the program with my teachers. The response was we are doing a lot of those things anyways but everyone can get better. However, I have not seen the current version but I'm assuming it is very similar in regards they talk about how to get teachers to be better focused people for their program. PE teachers as a group are not very articulate at times or are do not articulate well they seem to get right into my class sizes are too big, my compass is broken etc. Which I understand; but principals don't care about that they want to know how you're impacting student performance, reducing absenteeism and increasing rates of graduation.

KI: Yes I agree with you once again. Especially when looking at the secondary level compared to the elementary level when administrators are constantly looking at graduation rates, attendance data; with us going to common core curriculum and having a new annual professional performance review by state law administrators have to keep a close eye on those statistics.

GR: Exactly, exactly so if you want to try and get any type of attention we need to talk about the improvement of test scores when children are physically active, absenteeism rates decline because kids aren't suffering from asthma as much etc.

\section{KI: Great. Are there any innovative programs that can you provide examples of that are doing this well? (ie. implementing CSPAP, Clusters, preparing PAL etc.)}

GR: Well, I have seen quite a bit, I think the ideas and concepts of Brain Breaks and all of that stuff seem to be taking off. I just had the pleasure of hearing two superintendents speak recently here in North Texas from wealthier suburban schools about how they are recognizing that healthier children are better learners that we need to do something and I see some movement and thinking about staff health and that teachers attendance and productivity benefits children's academic performance. I also did here of one 
superintendent speak about a program, they have about 300 people in their administration building and he gives them 15 minutes every day time to just walk out on the track. They don't need to ask permission, nothing, they each have a little brick and when they go out walking they put it on their desk to signify they are out on the track for their 15 minutes, and I thought how clever that is. I mean I share my program a lot I haven't seen to many out there, people do use my program and piggy back on it but I think everyone is trying to move in the same direction, but I don't know when we will see systematic cultural changes in our schools, right now we see individual schools doing a good job.

\section{KI: Ok thank you, Are there any other thoughts you would like to share in relevance to this study?}

GR: Relevance of what you are doing?

KI: Correct.

GR: I think it is fabulous. I mean it is some of the work, do you know who Darla Castelli is?

KI: Yes I actually tried to get an interview with her in regards to this study.

GR: Hard to get a hold of. She is a colleague of mine I have worked with her and then the other guy is Aaron Beighle

KI: Yes from University of Kentucky, I met him at a state conference and was able to speak to him a bit about this subject area.

GR: Right well those two people and Russ were the three people I worked with when we developed the first Director of Physical Activity.

KI: Yes you're thinking of Russ Carson from LSU correct?

GR: But he moved. I heard the other day I want to say NM but my colleague is telling me Colorado. But yea you'll have problems getting ahold of Darla. Have you emailed her?

KI: Yes I've emailed and called and left a message. I know it is a busy time of year for a lot of the higher education faculty.

GR: Well if you try again mention my name, but she hasn't responded to me either. She right now is doing some research and evaluation of the presidential youth fitness program, so she is very busy.

\section{KI: Any other thoughts about the study that you would like to see come out of it?}

GR: Well I just think if you can take this approach on it the solution is really going to be the people coming out of undergraduate and graduate level programs and I don't know if you have given this any thought of the Kinesiology departments but the general education departments. Well so that everybody knows the benefits of physical activity and CSPAP. I mean I was thinking if you want to be an elementary teacher and I'm not sure what they do now but you should take a class of art, class of music and separate class for PE because you may have to teach those subjects on top of their regular course load. Ok so what if they had a little class on CSPAP, just a small class a couple of lectures on it just so they are familiar with the terminology and the benefits of physical activity for kids, and that's where you 
may be able to get a large school like your state universities to introduce this like University of Wisconsin, Michigan etc.

KI: Ok that is a good thought. I just wanted to once again thank you for your time. I appreciate the information you have provided, just to make you aware I hope to share my findings at upcoming national and state conferences in order to help provide more support in advocating and politicking for comprehensive school physical activity programming.

GR: Ok thank you and good luck.

\section{Interview 3:}

Phone Interview

$5 / 13 / 14-$

$\underline{\mathbf{R}}$-Researcher of the study

DE- Participant of the study from Higher Education

\section{Validation/Verification of Go Zone Maps and Cluster Groupings:}

R: Good afternoon DE, thank you for taking the time to take my call.

DE: So what is up with your Data here, I actually read the cluster statements that you sent today.

R: That was the first thing I was going to ask you, was if you had the executive summary and cluster group statements in front of you to use as a reference.

DE: Yes, I have that information in front of me.

R: Second, can I ask your permission and get your consent to record this conversation as an audio recording, in order to transcribe this interview and use for the study?

DE: Sure.

R: I will make sure that the file is secure and password protected on my hard drive of my computer.

R: DE I just want to give you a heads up of what the interview is going to look like as far as questioning. The first aspect of the interview is going to look at the validation and verification of the clusters as well as the go zone maps. So if you have any questions about any of the information in the executive summary or what was provided to you, please do not hesitate to stop me and ask questions.

DE: Ok

R: The cluster list and statements that you have in front of you, the first question I would like to ask you is Looking at the first cluster grouping (Teambuilding/Facilitating Skills) would you say that the 
title adequately represents the competencies that were sorted together in that grouping? (YES or NO)

DE: YES.

R: $\mathrm{OK}$

R: Second, Holistically looking at this cluster what does this grouping mean to you? (If you were to put it in your own words?)

DE: Well I guess just the importance of a team concept. It takes more than just one person to do this or two people the principal and the PE teacher. You need to have a team of dedicated people in the school and you need to have everyone communicating or on the same page.

However, a couple of these statements in the cluster I found to be important but didn't come out in the Go Zone, but I think however you look at it in terms of a group leading the charge in the school is important that is why I think statement \#20 about the wellness committee and \#28 engaging others is very important. However those two competencies didn't come out in the go zone, maybe if they would have been worded differently. In my own words this cluster would mean that it is very important to have a team of colleagues and stakeholders working together and building the Comprehensive School Physical Activity Plan (CSPAP) together to make it really work as well as it can.

R: Thank you, and to answer your question that was a great response. As the question stated in your own words feel free to express each group on how it means to you or how you view it and your thoughts would be perfect.

\section{R: Looking at the second cluster grouping (Funding) would you say that the title adequately represents the competencies that were sorted together in that grouping? (Yes or No)}

DE: NO.

\section{R: If not what recommendations do you have as a title?}

DE: Oh gosh I'm not sure. I have to think about this one for a minute... I'm not sure how funding became the title of this cluster. Funding in not necessary required for efficacy or educating or maybe you or however this was interpreted. I'm just not sure how some of these fit into funding.

R: Well the interpretation of the data analysis was done by a concept mapping software that the participants signed onto. The analysis takes the statements that the participants grouped together and the most common pile names that were used for those sorting statements is used to describe that cluster. So some of the cluster names actually are a representation of the participant's piles that they named during the sorting process of the study.

DE: Ok, well a few of these statements are about funding. Like writing grants, professional development training could be funding but is also education. For me this cluster was all over the place because I look at it in one respect as educating (As in the professional development) and identifying already available programs and related resources in PA promotion. But then there is advocacy, statement \#44 guidelines for developmentally appropriate practice with others... Looking at \#24 desiring to increase one's 
involvement beyond simply teaching physical education I don't know how that fits with a lot of these other ones. It really doesn't fit to me under funding. The one's that aren't highlighted as go zone competencies are related more to funding than the ones that are, in my opinion.

Maybe the title is more about Advocacy and Education.

R: Ok, thank you. Basically in your previous statement discussing the clusters you answered the question holistically what the cluster and group of statements mean to you. Would you say that in a nutshell that the cluster in your own words is about education and advocacy; would you agree with that statement?

DE: YES. And even the one \#24 desiring to increase one's involvement beyond simply teaching physical education that is still advocacy and education.

R: Right, ok thank you.

\section{R: Looking at the third cluster grouping (Knowledge of Pedagogy) would you say that the title adequately represents the competencies that were sorted together in that grouping? (Yes or No)}

DE: NO.

R: Ok, then what recommendations do you have as a title for this cluster?

DE: If I had known you would ask me this I would have thought about it before you asked me.

R: You can always have time to look over the statements and collect your thoughts. We can always come back to that question after you look over the statements again if you'd like to.

DE: Here's my problem with that cluster. Pedagogy is how to teach (ie. the techniques, strategies, methods whatever you do to teach. It's not what you teach it's how to teach. A bunch of these competencies are content, they are what you would teach, not so much how to teach it. Like \#16 Modeling effective physical activity programming for others to emulate that could be pedagogy, but statement \#34 Knowing guidelines for developmentally appropriate practice in physical activity programming and \#2 identifying the components of a CSPAP and how each contributes to maximizing physical activity opportunities for school-aged children are content knowledge to me not pedagogy.

I think that this cluster \#3 goes into cluster \#4 Content knowledge. I would say that a lot of these statements would fit under content knowledge, but you already have a cluster there. Here's the thing I don't understand why these were clustered together. An example is if you look at \#6 under cluster 4Content Knowledge -Explaining exercise physiology principle and concepts, I wonder why this got clustered under this group when there is a very similar one clustered in the group before that. So that is the part that is a little confusing to me.

However the Go zone competencies in cluster \#4 statement \#9 Remaining current with the literature in the field including recommendation for best practice and related resources and \#26 Maintaining extensive background knowledge in physical education including an awareness of contemporary research in the field, I agree that those are all good content knowledge statements. I don't know how you designate this different from cluster \#3. 
R: Ok, thank you for that incite. So Dr. E. if you had the option and those clusters were linked together at one point on the map you would cluster all of those statements together into one broad cluster group.

DE: I would. Particularly based on even if you name the cluster pedagogical content knowledge. It just seems to me that those two clusters are not different enough to be two different clusters.

R: Ok DE. Since you talked about Cluster number 4 already and gave your opinion that three and four should be represented together. How about we move on to cluster \#5 and discuss your thoughts on this cluster.

\section{R: Looking at the fifth cluster grouping (Creating and Implementing) would you say that the title} adequately represents the competencies that were sorted together in that grouping? (Yes or No)

DE: Yes.

R: Ok, thank you then holistically looking at this cluster what does this grouping mean to you?

DE: To me in some ways developing might be a better word than creating. Because developing the CSPAP you may not be creating something new but you're developing your own program. So you are looking for those things in your school. Each one of those components of a CSPAP that you may already be doing that you can enhance or look for new resources to help develop that component. I would say that this represents developing a cspap that is contextually appropriate for your school and developing a plan to implement it. To me that kind of represents the different competencies that are highlighted within that cluster.

R: Thank you very much for your response. Ok we are going to move into the second phase of the interview. You can still keep those competencies and the executive summary in front of you as a reference but we are going to move into looking at the implications of these results on professional preparation.

\section{Implications for Professional Preparation:}

R: The first question is What practical implications do the cluster or go zone statements have for the professional preparation of educators at the undergraduate or graduate level in physical education teacher education programs? (Repeated for the interviewer)

DE: Well I think that most PETE programs have the clusters related to pedagogical and content knowledge covered. What I think that is often times not addressed is the importance of teambuilding and working as a team outside of your pe teachers. I think we teach students how to work together with another pe teacher, but not necessary how to collaborate with others in the school and community. I think that is a big piece that is missing in some programs. Related to that with the second cluster how students get involved in this beyond just simply teaching their classes and students. How do they become the physical activity expert in the school? What makes them a leader, what makes some students leaders and others not, and how can we help facilitate leadership for students to learn the roles of the leader and help provide others with information or motivation. Also, related to the last cluster making sure that they understand the components of a CSPAP and how to develop those components. If we don't teach our 
own students how to do that, we can't expect them to be a part of an effective team, whether they are the leader or the pe teacher representing the physical education department. Obviously we spend a lot of time on quality physical education but do the students know how to think outside of the box for promoting staff wellness, community involvement, and family involvement. Do we show them activities they can show classroom teachers what they can do in the classroom. So those would be some practical implications for PETE program resulted to CSPAP and getting them ready and prepared to facilitate as a leader or member of the team based upon the clusters and some of the items.

R: Ok great that was a very insightful answer and description in relevance to the clusters. Thank you. Now since we just talked about PETE programs were going to look at implications on professional development more. What implications would these results have on the continuing professional development for all personnel including administrators, classroom teachers, coaches, teacher assistants etc.?

DE: I think in terms of practical implications of other people, in my experience with working with all of these different people within the school the classroom teacher; principal, superintendent that there has to be some type of buy in from someone who can make decisions about changes and policies. That is what is sometimes difficult for a motivated physical education teacher to help facilitate a cspap by themselves; they just can't do it they need all the other supports. In terms of that the second cluster that talks about advocacy and education, we have to advocate and educate those other people first.

A perfect example is that someone from the state department decided that we were going to do Let's Move within the state so they gave out CD's and a booklet and informational tools. The state department went out to each school building to talk to the principals and superintendents and of course they educated them about the importance of PA and what their roles should be. They are not the PE teacher but what is their role. A lot of them embraced that and then they took it back and did workshops with the teachers and offered those kind of professional development opportunities for the school staff and teachers, but they took a top down approach.

I think the top down approach is really important. Another good example is at the same time the state superintendent was on board. She spoke about PA and the need for healthy behaviors for children to help them be better learners, and because she talked about it at the state, county superintendents talked about it and it trickled down to each of the school buildings across the state. Once again the top down approach which some don't agree with but I've watched it work. The other thing also is when this happened they were able to get the classroom teachers involved, the classroom teachers have so many things going on; they have to be responsible for reading, math and sometimes they don't see the advantage of promoting PA, but once they are educated and are given resources to do so, not all of them but some say hey I can do this, I want to do this. My kids act a lot better, their behaviors are better. I'm not sure if I answered that question exactly, but I think the education and advocacy cluster is the most important part in educating others on the importance of PA and benefits of it, especially for professional development of different school personnel. Because school personnel always want to know what is in it for them as well. I think it is really important. So to me that cluster is the most important on how we educate and do in-service.

Of course if there is a push or desire within a school system or school to do CSPAP for whatever reason than certainly in service training to help get the people involved is important. Such an example is in M... County we required every school to meet with us with their school wellness team. Well, because it is a 
national requirement and federal requirement everyone has one. It doesn't mean that they have met in the last three years, but when you say you want to meet with them they all got together and met with us. The advantage of that was they all got involved in choosing their equipment and choosing their programs, but they never had that opportunity before and so we saw preschool teachers saying "oh I want new tricycles for kids for recess." So once you start educating them about the components CSPAP they see where they fit in. The bottom line is they have to see where they fit and once they see where they fit like the preschool teacher saying we do physical activity during other opportunities during the school day, we do that so we need resources such as the tricycles and balls etc. That also brings out cluster 1 as well, everybody has to get involved and feel like they have a place in it and what they bring to the table so that the plan can really work.

DE: How many interviews are you going to be doing?

R: I have four interviews as of right now that I will have to transcribe and go through the same process. Not too bad.

DE: Oh, Ok yes not too bad, ok I'll be shorter.

R: DE you kind of referenced talking points that are in my upcoming questions. Are you aware of any physical education teacher education programs that are doing well in preparing educators to be physical activity leaders?

DE: Well, it's not that I know about all these PE programs going on in the nation. I know that at WVU the faculty and staff have a course related to CSPAP that the teachers take. I think that the teachers are made aware of it, so I assume that it helps prepare them to be a leader of CSPAP. Based upon research and literature that I know University of Kentucky has produced they probably prepare their teachers with CSPAP in mind. They have a faculty and staff that do a lot of work within CSPAP and advocating for it, but to say I know that these places do it I don't. I just know based upon recent literature.

\section{R: Can you give an example of any continuing professional development in your districts or higher education programs to continue developing physical activity leaders? You kind of talked about the course at WVU, is there anything within the counties that you work with that you have seen that can help develop PAL's?}

DE: To develop the leaders themselves for CSPAP not necessarily I can't really think of anything other than when you do in services with PE teachers and your teaching / sharing with them resources for the components of CSPAP you are helping them to become a leader. But to say that we actually train people to be leaders other than the physical activity leader (PAL) training that is being conducted now by SHAPE of America (Society of Health and Physical Educators) in conjunction with the Let's Move Active Schools programs. LMAS but in terms of training the leader, they do have a LMAS training that they do that is in conjunction with the PAL training that we will be on a conference call tomorrow to learn more about it. As far as I know though the PAL's training is specifically, you would know this better than I would in your research but it is more specific toward the leader. We did do let's move active schools in the eleven schools that we were working with, and we did not say that the pe teacher had to be the school leader. We said to the school principals that it was their responsibility to designate a school leader. Every school but one designated the PE teacher as the PAL for the school. However, one 
elementary school designated a classroom teacher who taught the before school program and was much more motivated and dedicated to physical activity than the physical education teacher, and she was the classroom teacher. When discussing with the principal they ultimately thought that this classroom teacher would do a better job with the faculty as a whole than the pe teacher, because remember we asked them to meet with their wellness teams, and to determine the certain aspects such as professional development, programming, and equipment purchases. Out of those 11 however I would say that half of the schools the PE teacher and the principal made most of the decisions, but they still had to have that meeting with the wellness committee, so that the wellness team was at least aware when they were writing their comprehensive plan.

\section{R: Ok, thank you on to the final question. Are there any innovative programs that can you provide examples of that are doing this well? (i.e. implementing CSPAP, Clusters, preparing PAL etc.)}

DE: Well we intimately work with G..... and M....Choices and those are the programs that we are familiar with. Now I am sure that there are other really good programs out there that are doing that, but I don't know what they are. In G... we only worked with 2 middle schools so we didn't' see the whole county school system. However that grant is about to end but we saw great things happen with that program, they took what they were doing in PE and had after school programs related to their units, they got staff involved in after school programs. They were able to get families to participate in terms of the biking unit they did a trail run on Saturday. And in that case the leader was the program director for the most part, who was not the pe teacher but someone hired by the grant to be in charge of the program. So she was a paid director who wore many hats and helped facilitate many of the programs to happen, she made a lot of the programming happen. Which goes back to the first cluster, if you really want to facilitate all these things working together the leader has to be able to have time to do that kind of thing. Whereas in the Mc..... choices we had to facilitate so that the people from the university team was able to facilitate. The school leader facilitates to a certain degree. We give them ideas for instance when they say we want to Zumba but we don't know any instructors, we would then find them instructors or references to help facilitate. So those two programs are the programs that I am aware of and invested in because they are going on right now, but I am sure that there are more out there.

\section{R: Ok. Thank You for your time I just wanted to ask if there are any other thoughts that you would like to share in relevance to this study.}

DE: Any other thoughts hmmmm... Well I think that I know that you are specifically looking at the school leaders not necessarily the pe teacher and I think that that is cool. I think if the results of your study and in your discussion you can help make that case that the school leader doesn't have to necessarily be the PE teacher. I think that's a good thing. Because I think people think the PE teacher has to do it all and sometimes schools have terrible PE teachers, so they think they can't do this and they can. It's just like the school that didn't have the pe teacher be the leader. The other teacher was much more motivated to make it more of a school wide program. I think it is really cool that you looked at it from that standpoint rather than just the pe teacher needs to be the leader. 
R: I appreciate that. That was my thought behind the study as well. It goes back to what you were kind of saying. The people that are making the decisions in schools and incorporating the school wellness committee, looking at the research and my experience working in schools is the PE teacher really at the point that there able to develop and implement a CSPAP in a school or district or is it someone higher up within the school that can make these decisions happen.

DE: That's interesting that I talked about the top down approach. I have seen it make a difference in our state. The other thing too and I know that you'll probably talk about this but the whole clusters related to knowledge both content and pedagogical, I wonder if some of the people that rated and sorted were thinking from a PE standpoint rather than a leader position. Because in my personal opinion I don't think leaders have to......and its interesting the go zone statement competencies are one's that anybody who is leader has to know so that's good. But some of those you have to know the FITT Principle and exercise physiology, whatever I was like no. You don't have to know that to be a good leader. So, I shared that with you earlier but that was a thought that jumped out at me while I was rating and sorting. But I wondered if some of the people that did, it would be easy to think of it that yea a good pe teacher should know that.

R: And that might be a limitation to the study as well.

DE: Absolutely, that was exactly what I was thinking. Maybe you should think about that and possibly discuss that. I even thought at one point, but I had to remind myself that its' not about the pe teacher but about a leader. So you just wonder how many people were thinking about what would be a competency of the pe teacher. You might think of that as a limitation.

R: Ok thank you, I will have to see what the other participants who I am interviewing think about the same information and the possibility of that being a limitation to the study. Thank You for your time, I appreciate the information you have provided, just to make you aware I hope to share my findings at upcoming national and state conferences in order to help provide more support in advocating and politicking for comprehensive school physical activity programming. 


\section{Appendix E: Updated Curriculum Vitae}

KIEL M. ILLG, M.S.

193 Palmdale Drive Apt. 2

Williamsville, NY 14221
Email: kielmillg@gmail.com

Cell Phone: (716) 868-1479

\section{ACADEMIC PREPARATION}

Doctorate of Philosophy in Kinesiology, College of Physical Activity and Sport Sciences, West Virginia University, Morgantown, West Virginia. Major Field: Physical Education Teacher Education. Minor field: Educational Leadership Studies. Research interests: comprehensive school physical activity programming, childhood obesity, physical activity interventions in children and adolescents, effective teaching. Dissertation topic: Competencies of a School Leader Implementing A Comprehensive School Physical Activity Program: A Concept Map Design Chair: Dr. Sean Bulger. Expected date of graduation August, 2014.

Master of Science, Differentiated Instruction, School of Education \& Human Services, The Canisius College, Buffalo, New York. Professional specialization: Gifted and Talented Education. Practicum topic: How to Implement Differentiated Instruction into the Classroom. January 2009.

Bachelor of Science, Physical and Health Education, School of Education \& Human Services, The Canisius College, Buffalo, New York. Graduation Honors: Cum Laude. May 2007.

High School Diploma, Regents, Saint Francis High School, Athol Springs, New York. Graduation Honors: National Honors Society, Man of the Year Award. May 2002.

\section{ACADEMIC HONORS, AWARDS AND CERTIFICATIONS}

\section{Academic Honors \& Awards:}

West Virginia University Graduate Student of the Year

- College of Physical Activity and Sport Sciences-PETE

Canisius College Cannon Design Leadership Award

Canisius College Dean's List

Metro Atlantic Athletic Conference All-Academic Team

(2012)

(2006, 2007)

$(2005,2006,2007)$

$(2005,2006,2007)$

\section{$\underline{\text { Athletic Honors \& Awards: }}$}

Saint Francis High School Sports Hall of Fame

National LOWE's Senior "CLASS" Award Nominee 
NCAA Northeast Regional Leadership Conference

Metro Atlantic Athletic Conference Lacrosse All-Tournament Team

NCAA National Leadership Conference

\section{Certifications:}

New York State School Building Leader Certification

New York State Professional Certification in Physical Education (K-12)

New York State Professional Certification in Health Education

New York State Coaching Certification

West Virginia State Certification in Physical and Health Education (K-12)

American Red Cross First Aid/CPR/AED Certification

\section{EMPLOYMENT HISTORY}

\section{Amherst Central School District, Amherst, New York}

Amherst Central High School

(2013-Present)

Assistant Dean of Students \& Assistant Athletic Director

- $\quad$ Serve on the District Safety Committee

- $\quad$ Serve on the Building Leadership Committee

- $\quad$ Serve on the Instructional Support Data Team

- $\quad$ Serve on the Student Services Data Team

Amherst Central Middle School

Health Education Teacher- Grades (6-8)

- $\quad$ Long-term substitute teacher August-January

- $\quad$ Eighth grade class advisor

Windermere Boulevard School, Amherst, New York

Physical Education Teacher- Grades (K-5)

- WBS PTA Award Recipient

West Virginia University, Morgantown, West Virginia

Graduate Teaching Assistant Physical Education Teacher Education

Saint Benedict School, Amherst, New York

Physical Education Teacher- Grades (K-8)

Health Education Teacher- Grades (6-8)

Morgantown High School, Morgantown, West Virginia

Principal Internship-Grades (9-12)

Martin Road Elementary School, Lackawanna, New York

Student Teacher-Grades (3-6)

(2008-2010)

West Seneca East Senior High School, West Seneca, New York

(2010-2012)

Student Teacher- Grades (9-12) 


\section{ADDITIONAL EXPERIENCE}

Varsity Football Coach, Amherst High School

- $\quad$ Assistant Football Coach- Wide Receivers and Defensive Backs

- Varsity Offensive Coordinator and First Assistant.

(2012-Present)

(2007-2010)

Varsity Lacrosse Coach, Amherst High School

(2013-Present)

-Varsity Defensive Coordinator

Varsity Lacrosse Coach, University High School

(2011-2012)

- Offensive Coordinator, and Special Teams

-2011 WV State Champions

Varsity Basketball Coach, Amherst High School

(2008- 2010)

-Junior Varsity Head Coach and Varsity First Assistant.

Junior Varsity Lacrosse Coach, Amherst High School

(2009- 2010)

-Defensive Coordinator.

Varsity Lacrosse Coach, Saint Francis High School

(2008-2009)

-Head Varsity Lacrosse Coach.

Varsity Wrestling Coach, Saint Francis High School

(2007- 2008)

-Junior Varsity Head Coach and Varsity First Assistant.

Varsity Football Coach, Saint Francis High School

- Junior Varsity Offensive Coordinator.

-Varsity Football Defensive Back Coach.

\section{PUBLICATIONS}

Jones, E.M., Bulger, S.M., Illg, K.M., Wyant, J.D., (2012). Modified Delphi Investigation of Instructional Technology in PETE. The Global Journal of Health and Physical Education Pedagogy, 4(1), 295-310.

\section{PRESENTATIONS}

Illg, K.M. (2014, March). Comprehensive School Physical Activity Program: A Guide to Implement and Sustain. This lecture session is being presented at the annual meeting of the Western Zone of the New York State Association for Health, Physical Education, Recreation and Dance (NYSAHPERD), Buffalo, NY. 
Miller, W.M., Illg, K.M. (2012, October). Life After the Party-transitioning from college student to professional. This lecture session was presented at the annual meeting of the West Virginia Association for Health, Physical Education, Recreation and Dance (WVAHPERD), Bridgeport, WV.

Bulger, S.M., Illg, K.M., Hawkins, A., Meeteer, W., Sager, J., Wiegand, R. (2012, March). Physical Activity Levels During an After-School Sport Education Season. This poster session was selected to be presented at the annual National Convention for the American Alliance of Health, Physical Education, Recreation, and Dance (AAHPERD), Boston, MA.

Jones, E.M., Bulger, S.M., Wyant, J.D., Illg, K.M. (2012, March). Modified Delphi Investigation of Instructional Technology in PETE. This paper was selected be presented at the annual National Convention for the American Alliance of Health, Physical Education, Recreation, and Dance (AAHPERD), Boston, MA.

Illg, K.M. (2011, October). Lacrosse Fever Catch It If You Can- The Fastest Game on Two Feet. The activity session was presented at the annual meeting of the West Virginia Association for Health, Physical Education, Recreation and Dance (WVAHPERD), Flatwoods, WV.

Illg, K.M., Satzer, K. (2011, October). Move Your Body- The Let's Move Fitness Initiative. The activity session was presented at the annual meeting of the West Virginia Association for Health, Physical Education, Recreation and Dance (WVAHPERD), Flatwoods, WV.

Illg, K.M., Miller, W.M.,Wyant, J.D. (2011, October). Life After the Party-transitioning from college student to professional. This lecture session was presented at the annual meeting of the West Virginia Association for Health, Physical Education, Recreation and Dance (WVAHPERD), Flatwoods, WV.

\section{GRANTS AND CONTRACTS}

West Virginia University, Internal Grant Program, Graduate Student Research Grant, \$1000.00 (2013).

West Virginia University, Internal Grant Program, Graduate Student Travel Grant. \$600.00 (2012).

\section{COLLEGE TEACHING EXPERIENCE}

\section{CURRENT COURSES TAUGHT}

Teacher Education Courses: The following courses were taught within the university physical education teacher education program.

I. Courses Taught:

Course Title

PE 101 Badminton

PE 158 Indoor Soccer

PE 164 Weight Training

PE 167 Intro to Physical Education

PE 293 J Beginning Lacrosse

PE 293 O Intermediate Lacrosse

PET 233 Pedagogy Theory/Application

PET 340 Teaching Soccer

PET 344 Teaching Field/ Floor Hockey
Semester/Year

Fall 2010/2011

Fall 2010, Spring 2011

Fall 2010

Spring 2011

Spring 2011/2012, Fall 2011

Spring 2011

Fall 2011, Spring 2012

Spring 2011

Fall 2011, Spring 2012 
PET 350

PET 483

ACE 493
Teaching Primary Physical Education

Issues in Physical Education

Techniques of Coaching Lacrosse
Fall 2010

Summer 2011

Spring 2012

II. Supervisory Responsibilities

Student Teaching Supervision

Fall $2010 \quad 2$ Student Teachers

Fall $2011 \quad 2$ Student Teachers

Spring 2012 1 Student Teacher

\section{PROFESSIONAL DEVELOPMENT}

\section{Training}

Erie 1 Boces: The Principals of School Safety: Critical Information for Critical People (2013)

-Training involved implementing a comprehensive safety strategy, reshaping the school environment to reduce unwanted behaviors, identify threats, and accurately assessing threats once discovered.

Erie 1 Boces: Violent and Disruptive Incident Reporting (VADIR) and Dignity for All Students Act (DASA) Workshop

-Training covered a review of legislation, definitions, VADIR thresholds and categories, identification of material incidents, forms/record keeping, intersection of VADIR and Material Incidents, examples and differences on when to use each reporting system

Erie 1 Boces: NYS Common Core Learning Standards Workshop

-PEHPC 102: Directors of Health and Physical Education to understand the leadership role they play in managing staff.

-PEHPC 104: Paradigm Shifts in HPE Administration: Understanding and Writing Effective SLO's, Observations, and APPR's using the Danielson Model.

Amherst Central School District: Culturally Responsive Training

-Interacted and engaged in a professional development in-service to improve the experiences and educational outcomes of our African American students within the Amherst Central School District.

Amherst Central School District: Thoughtful Classroom Teacher Framework Training (2012)

-Engaged in an instructional in-service on The Thoughtful Classroom Teacher Effectiveness

Framework presented by Silver Strong \& Associates; as well as developed student learning objectives and assessment tools for health education students.

\section{Service}

Amherst Central School District: Physical \& Health Education Staff Development

-Directed physical education \& health professional development in aligning district physical education plan with building physical $\&$ health education teachers, aligned curriculum to new national standards in physical education and collaborated with staff members in developing and implementing curriculum maps. 
-Volunteered as a student of the College of Physical Activity and Sport Sciences, directed a physical activity session with children on Exer-gaming and physical activity during the launch at the Capitol building.

West Virginia University PETE Majors Club Advisor

-Served as the advisor of the West Virginia University Physical Education Teacher Education Majors Club. Guided students of the major with opportunities for professional development, public service opportunities, and academic guidance.

West Virginia University Men's Club Lacrosse- Faculty Advisor

- Served as faculty representative for the West Virginia Men's Club lacrosse team on campus.

Canisius College Student Athlete Advisory Committee Vice President

(2006-2007)

- As a student athlete representative I worked with student affairs, faculty, and the athletic department on academic, service, and fundraising opportunities for athletes within the community.

Canisius College Athletic Advisory Board Committee-Student Representative

- As the college's student athlete representative I served on the athletic advisory board committee with Canisius College Faculty, Athletic Director and representatives from the school's Presidents' office.

\section{Affiliations}

American Alliance of Health Physical Education Recreation and Dance (AAHPERD)

National Association for Sport and Physical Education (NASPE)

New York State Association for Health Physical Education Recreation and Dance

New York State Council of Administrators (NYS COA)

\section{Portfolio and references furnished upon request}


